\title{
Risk of Newly-diagnosed Depression, Treatment and its Economic Outcomes among Elderly Medicare Beneficiaries with Incident Breast, Colorectal or Prostate Cancer
}

\author{
Monira Mansour Alwhaibi
}

Follow this and additional works at: https://researchrepository.wvu.edu/etd

\section{Recommended Citation}

Alwhaibi, Monira Mansour, "Risk of Newly-diagnosed Depression, Treatment and its Economic Outcomes among Elderly Medicare Beneficiaries with Incident Breast, Colorectal or Prostate Cancer" (2016).

Graduate Theses, Dissertations, and Problem Reports. 5092.

https://researchrepository.wvu.edu/etd/5092

This Dissertation is protected by copyright and/or related rights. It has been brought to you by the The Research Repository @WVU with permission from the rights-holder(s). You are free to use this Dissertation in any way that is permitted by the copyright and related rights legislation that applies to your use. For other uses you must obtain permission from the rights-holder(s) directly, unless additional rights are indicated by a Creative Commons license in the record and/ or on the work itself. This Dissertation has been accepted for inclusion in WVU Graduate Theses, Dissertations, and Problem Reports collection by an authorized administrator of The Research Repository @ WVU.

For more information, please contact researchrepository@mail.wvu.edu. 
Risk of Newly-diagnosed Depression, Treatment and its Economic Outcomes among Elderly Medicare Beneficiaries with Incident Breast, Colorectal or Prostate Cancer

\author{
Monira Mansour Alwhaibi \\ Dissertation submitted \\ to the School of Pharmacy \\ at West Virginia University
}

in partial fulfillment of the requirements for the degree of

Doctor of Philosophy in

Health Outcomes Research

\author{
Usha Sambamoorthi, Ph.D., Chair \\ Suresh Madhavan, Ph.D. \\ Thomas Bias, Ph.D. \\ Kimberly Kelly, Ph.D. \\ James T Walkup, Ph.D. \\ Department of Pharmaceutical Systems and Policy \\ Morgantown, West Virginia \\ 2016
}

Keywords: Cancer, Depression, Treatment, Expenditures, Medicare

Copyright 2016 Monira Mansour Alwhaibi 


\section{AbSTRACT \\ Risk of Newly-diagnosed Depression, Treatment and its Economic Outcomes among Elderly Medicare Beneficiaries with Incident Breast, Colorectal or Prostate Cancer Monira Mansour Alwhaibi}

Depression is a highly prevalent chronic condition among the elderly cancer survivors. It is estimated that 5-25\% of elderly cancer survivors suffer from depression. Depression co-existing with cancer is associated with many negative health consequences such as high mortality, poor health related quality of life and high healthcare utilization and expenditures. However, depression is treatable with pharmacotherapy, psychotherapy or combination of both. There are no studies that examine the variations in the risk of depression by cancer types and there are few studies that examined the rates of depression treatment among elderly with cancer. In addition, there is lack of evidence on the impact of depression treatment on the economic outcomes of cancer survivors. To fill the knowledge gap, the three related aims of this dissertation were to: (1) examine the variations in the risk of depression by cancer types among elderly with incident breast, colorectal, and prostate cancer; (2) identify the rates of depression treatment and the factors associated with depression treatment among elderly with newly-diagnosed depression and incident breast, colorectal and prostate cancer; (3) analyze the impact of depression treatment on the healthcare expenditures among elderly with newly-diagnosed depression and incident breast, colorectal and prostate cancer. The study used a retrospective cohort study design, using multiple years (2002-2011) of the cancer registry data from the Surveillance, Epidemiology and End Results (SEER) program linked with the Medicare claims data, the American community survey census-tract files and the Area Health Resource Files. In the first aim, among elderly with incident breast, colorectal and prostate cancer $(\mathrm{N}=53,821)$, women with colorectal cancer had $28.0 \%$ higher risk of newly-diagnosed depression as compared to women with breast cancer; men with colorectal cancer had $104.0 \%$ higher risk of newly-diagnosed depression as compared to men with prostate cancer. Elderly diagnosed with cancer at an advanced stage had a $61.0 \%$ higher risk of newly-diagnosed depression as compared to those diagnosed with cancer at an early stage. Elderly with higher number of primary care providers visits had a higher newlydiagnosed depression as compared to those with lower number of primary care providers visits. In the second aim, among elderly with newly-diagnosed depression and incident breast, colorectal and prostate cancer $(\mathrm{N}=1,673), 45.7 \%$ received antidepressants only; $8.8 \%$ received psychotherapy only; $18.4 \%$ received combined therapy; and $27.1 \%$ received no treatment for depression. Elderly cancer survivors who received ongoing cancer treatment were less likely to receive psychotherapy only, or combination therapy. Elderly living in counties with a higher percentage of psychologists were more likely to receive psychotherapy only, or combination therapy. In the third aim, among elderly with newly-diagnosed depression and incident breast, colorectal and prostate cancer $(\mathrm{N}=1,502)$, the average 1-year total healthcare expenditures after depression diagnosis were higher among those who received depression treatment as compared to no depression treatment. The associations between depression treatment and the higher healthcare expenditures were observed across all types of healthcare expenditures (inpatient, outpatient, prescription drugs, and other expenditures). To summarize, this dissertation found that there are variations in the risk of newly-diagnosed depression by cancer type. Among cancer survivors with newly-diagnosed depression, one-quarter of cancer survivors did not receive any 
form of depression treatment; cancer-related factors were associated with depression treatment; and depression treatment was associated with increase in short-term healthcare expenditures.

\section{DEDICATION}

I dedicate this dissertation to my mom, my dad, my husband (Suliman Aloraini), and my kids (Raha, Abdualziz, and Aseel) without their love and support this would not have been possible 
I am very grateful to several individuals who helped me in completing my dissertation. First, I would like to thank Dr.Usha Sambamoorthi for being an excellent mentor. Dr.Sambamoorthi have provided me an extensive training, guidance, and support for an area of research that was completely new to me. Without her support, this dissertation would not have been completed. Thank you Dr.Sambamoorthi for being an amazing mentor.

I also would like to thank my committee members Dr. Suresh Madhavan, Dr. Thomas Bias, Dr. Kimberly Kelly, Dr. James Walkup for their critical inputs and continuous support. I also want to thank the grant that supported my dissertation, grant 1-R24 HS018622-03 from the Agency for Healthcare Research and Quality (AHRQ). I want also to thank the WVU family: Dr. Ginger Scott, Dr. Nilanjana Dwibedi and Angie Frame, and all the graduate students for their love and support. I also want to aknowldge Saudi Arabian Cultural Mission for supporting the tuition of my education, providing monthly salary and other benefits that makes it possible to study in the United States. Thank you is not enough for the Saudi Government, without their support I would not have been a graduate student at West Virginia University and I would not have completed my dissertation.

Finally, I want to thank my mom, my dad for believing in me and encouraging me to travel abroad and continue my education. Thanks for my brothers and sisters for their support and love. Special thanks for my husband, Suliman Aloraini, and my kids (Raha, Abdualziz, and Aseel), for their support and unweaving love during the four years journey of completing my dissertation. 


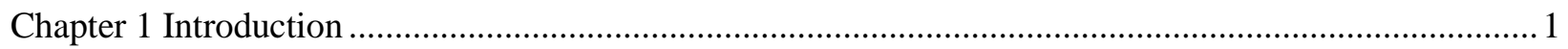

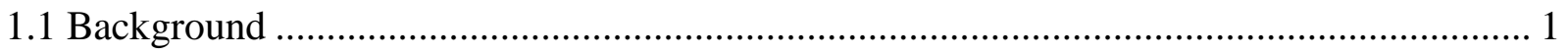

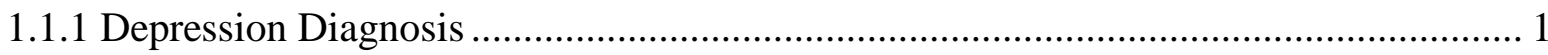

1.1.2 Prevalence of Depression among Cancer Survivors .............................................. 2

1.1.3 Incidence of Depression among Cancer Survivors .................................................. 3

1.1.4 Risk Factors for Depression among Cancer Survivors............................................ 3

1.1.5 Negative Health Consequences of Depression among Elderly Cancer Survivors ........ 5

1.1.6 Depression and Cancer Treatment........................................................................ 7

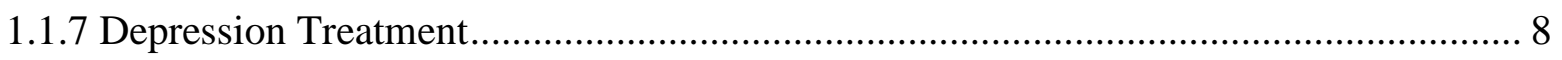

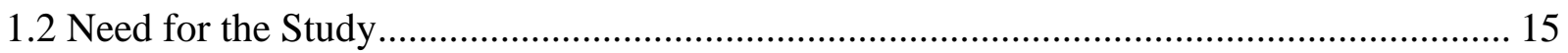

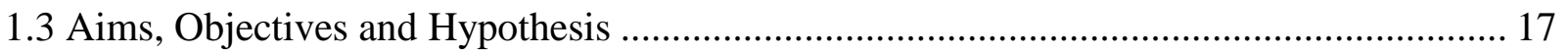

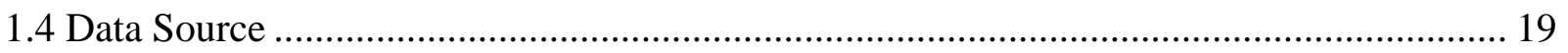

1.4.1 Surveillance, Epidemiology and End Results (SEER) ......................................... 19

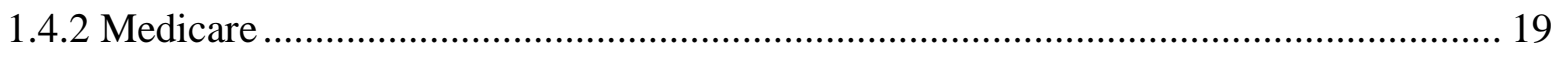

1.4.3 American Community Survey (ACS) Estimates from Census................................. 20

1.4.4 The Area Health Resource File (AHRF) .............................................................. 20

1.5 Rationale for Cancer Selection................................................................................ 21

1.6 Rationale for Selection of Elderly Individuals ....................................................... 22

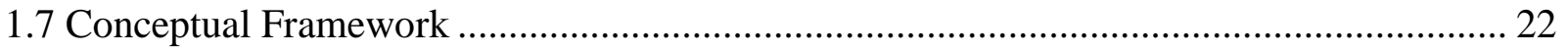

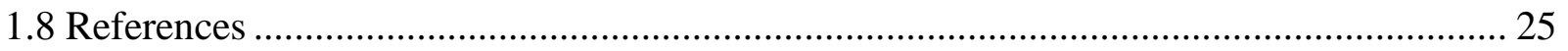

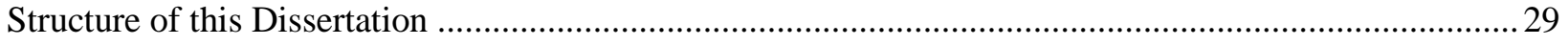

Chapter 2 Cancer Types and the Risk of Newly-Diagnosed Depression among Elderly Medicare Beneficiaries with Incident Breast, Colorectal and Prostate Cancer....................................................... 30

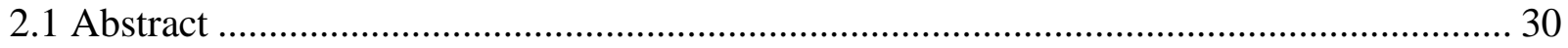

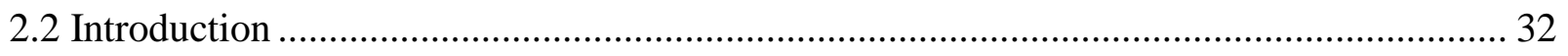

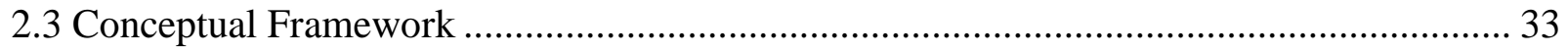

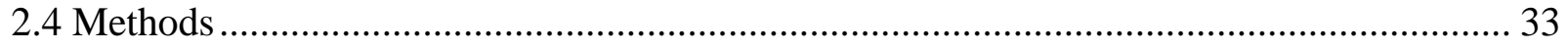

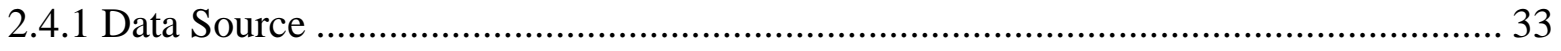

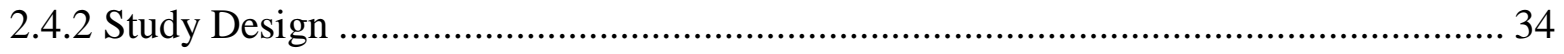

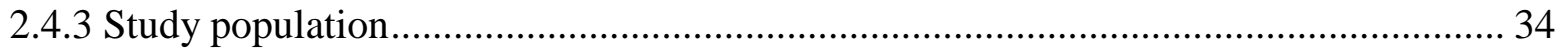

2.4.4 Dependent Variable: Newly-diagnosed Depression (Yes/No) ................................. 35

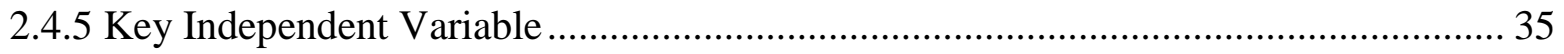

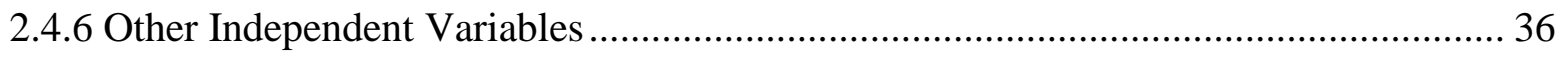

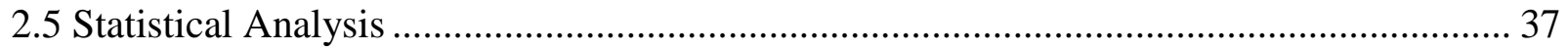




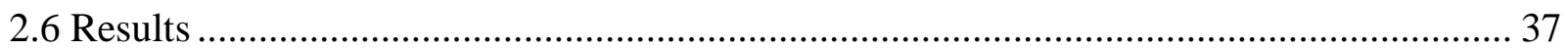

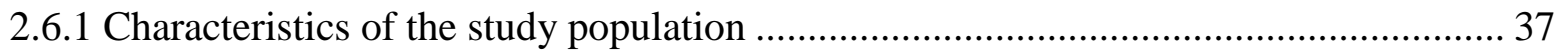

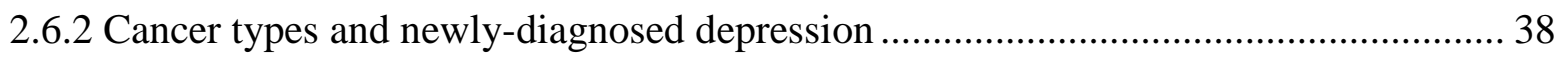

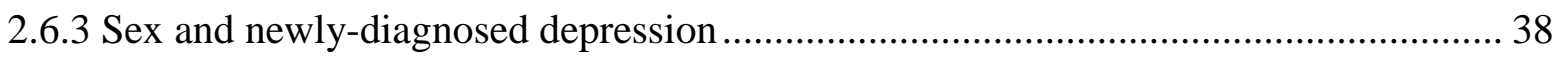

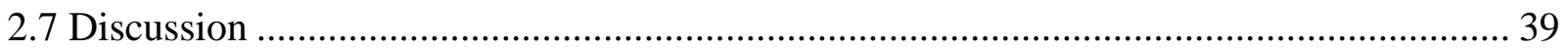

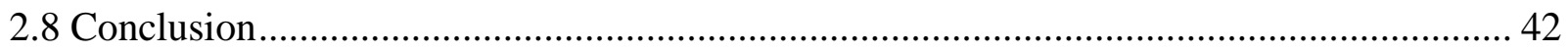

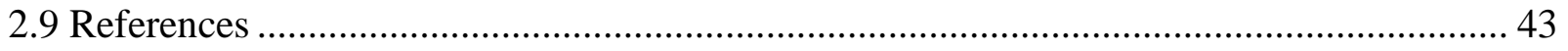

Chapter 3 Depression Treatment among Elderly Medicare Beneficiaries with Incident Cancer and Newly-

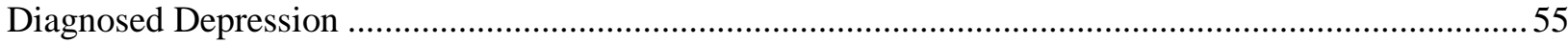

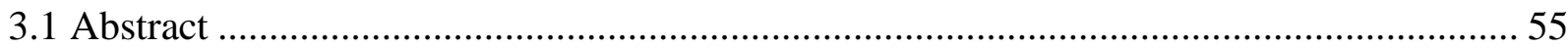

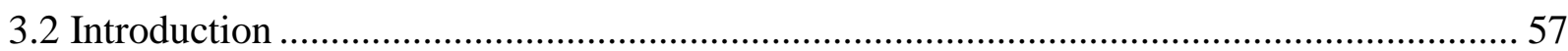

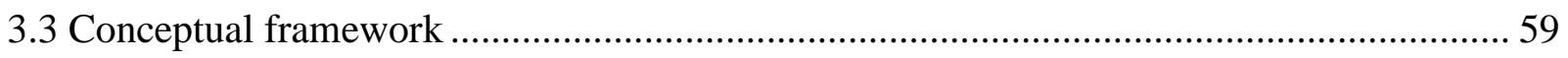

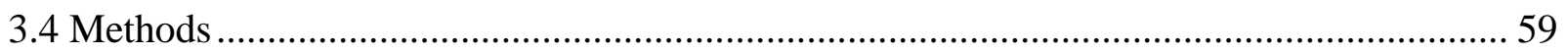

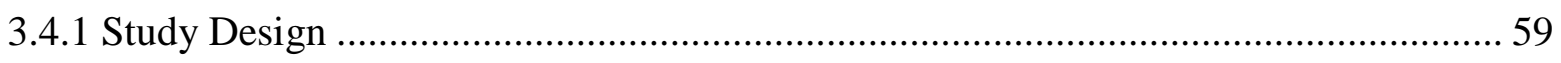

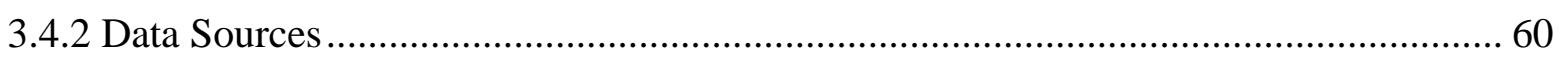

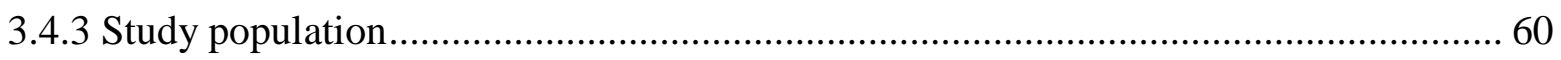

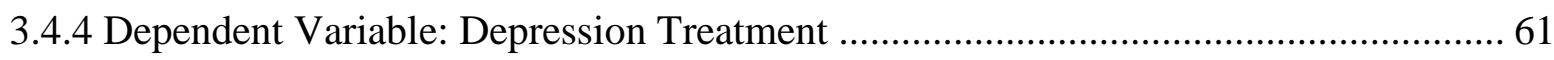

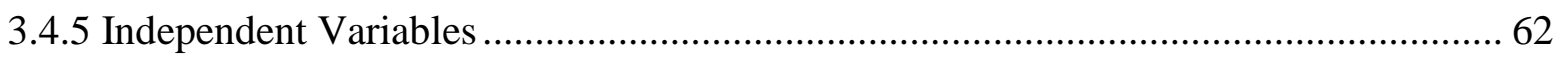

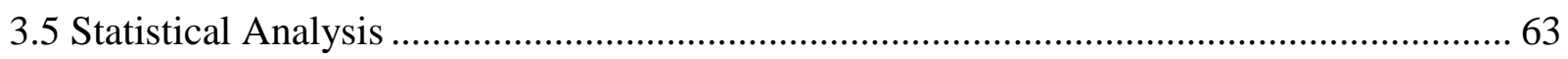

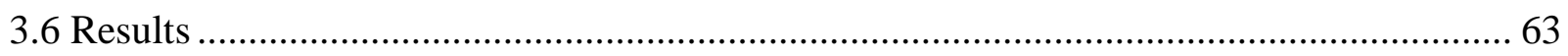

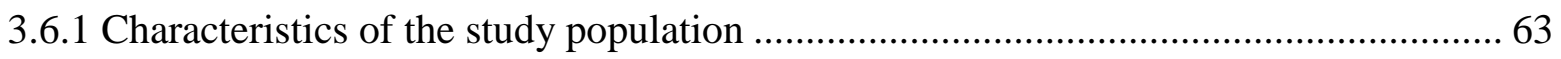

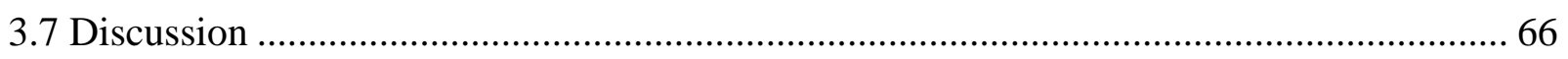

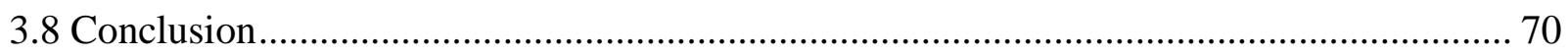

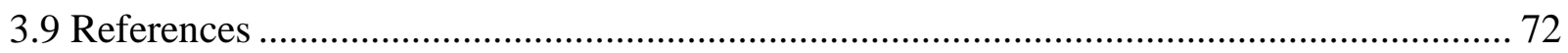

Chapter 4 Depression Treatment and Short-term Healthcare Expenditures among Elderly Medicare Beneficiaries with Newly-diagnosed Depression and Incident Breast, Colorectal or Prostate Cancer .......87

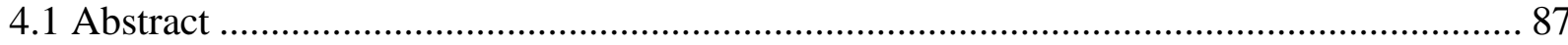

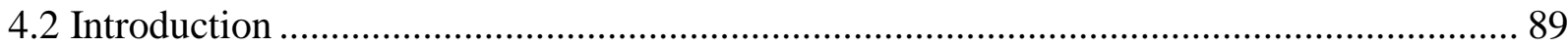

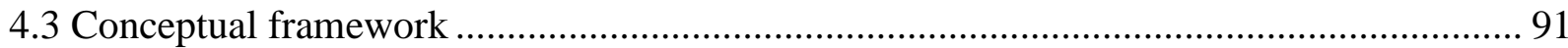

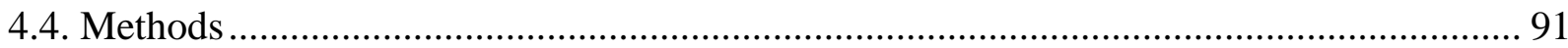

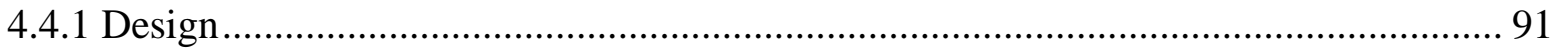

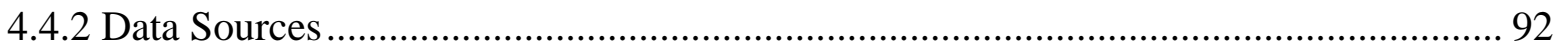

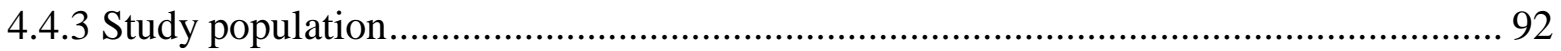

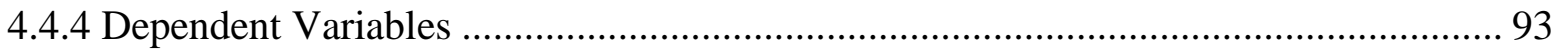

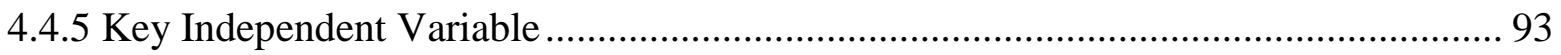




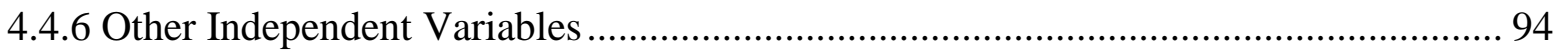

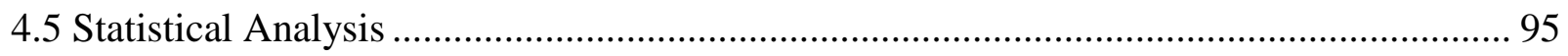

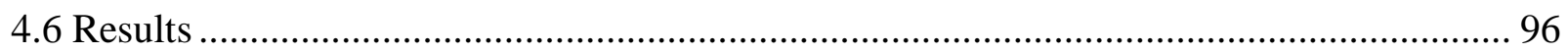

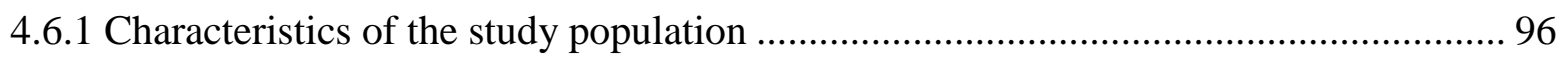

4.6.2 IPTW-adjusted Yearly Healthcare Expenditures by Depression Treatment Categories

4.6.3 IPTW-Adjusted Generalized Mixed Linear Models of Monthly Expenditures ........... 97

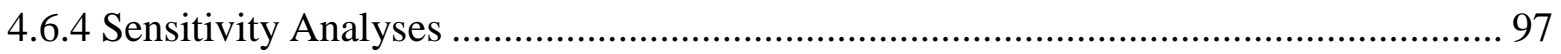

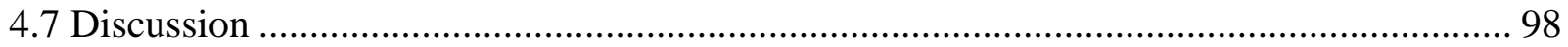

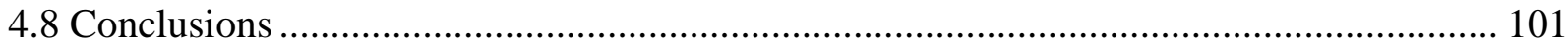

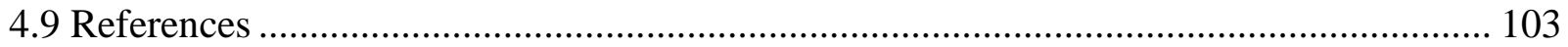

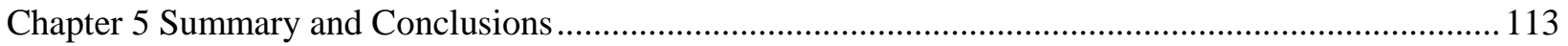

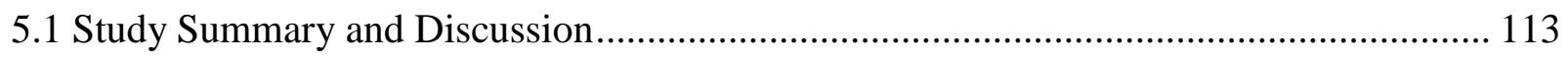

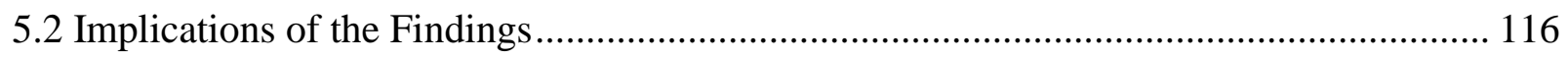

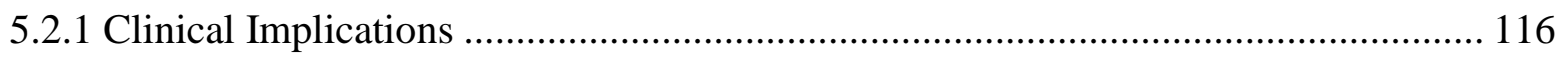

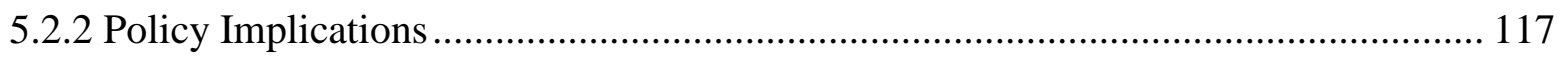

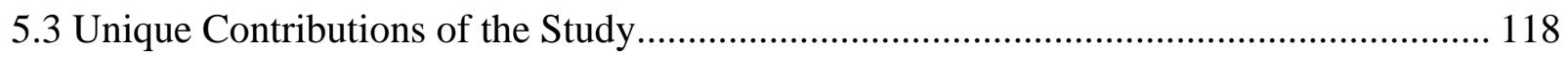

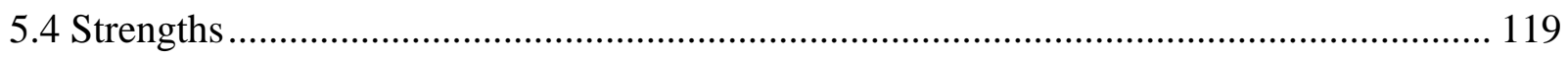

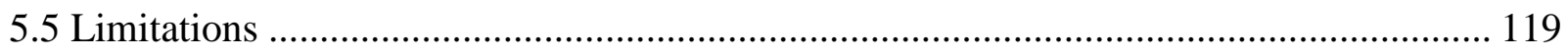

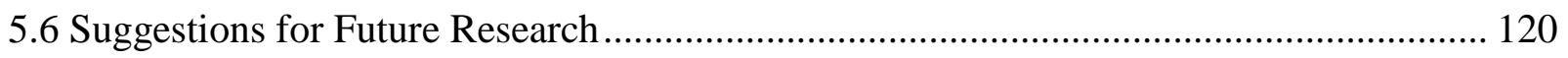


Table 2.1 Selected Characteristics of the Study Population by Cancer Types Elderly Fee-forservice Medicare beneficiaries with Incident Breast, colorectal, and Prostate Cancer SEERMedicare database 2007-2012 .

Table 2.2 Number and Percentage of Newly-Diagnosed Depression by Cancer Types and Treatment Characteristics Elderly Fee-for-service Medicare beneficiaries with Incident Breast, colorectal, and Prostate Cancer SEER-Medicare Database, 2007-2012.

Table 2.3 Adjusted Risk Ratios and 95\% Confidence Intervals (CI) of Cancer Types from Complementary Log-Log Regression on Newly-Diagnosed Depression Elderly Fee-for-service Medicare beneficiaries with Incident Breast, colorectal, and Prostate Cancer SEER-Medicare database, 2007-2012

Table 2.4 Sex Differences in Newly-Diagnosed Depression Adjusted Risk Ratios and 95\% Confidence Intervals of Cancer Types from Complementary Log-Log Regression on NewlyDiagnosed Depression Elderly Fee-for-service Medicare beneficiaries with Incident Breast, colorectal, and Prostate Cancer SEER-Medicare Database, 2007-2012.

Table 3.1 Description of the Study Population Elderly Fee-for-service Medicare beneficiaries with Breast, Colorectal or Prostate Cancer and Newly-diagnosed Depression, SEER-Medicare

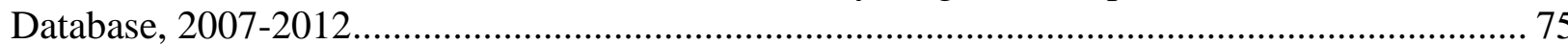

Table 3.2 Description of the Study Population by Depression Treatment Categories.................. 77 Elderly Fee-for-service Medicare beneficiaries with Breast, Colorectal or Prostate Cancer and Newly-diagnosed Depression, SEER-Medicare Database, 2007-2012

Table 3.3 Unadjusted Odds Ratios and 95\% Confidence Intervals of Depression Treatment Categories from Multinomial Logistic Regression on Depression Treatment Categories Elderly Fee-for-service Medicare beneficiaries with Breast, Colorectal or Prostate Cancer and Newlydiagnosed Depression, SEER-Medicare database, 2007-2012

Table 3.4 Adjusted Odds Ratios and 95\% Confidence Intervals of Depression Treatment Categories from Multinomial Logistic Regression on Depression Treatment Categories Elderly Fee-for-service Medicare beneficiaries with Breast, Colorectal or Prostate Cancer and Newlydiagnosed Depression SEER-Medicare database, 2007-2012 ………………………............... 82 Table 4.1 Description of the Study Population by Depression Treatment Categories Elderly Feefor-service Medicare beneficiaries with newly-diagnosed Depression and Incident Breast, colorectal, or Prostate Cancer, SEER-Medicare Database, 2007-2012 105

Table 4.2 Description of Time Varying Independent Variables for the Study Population by Depression Treatment Categories Elderly Fee-for-service Medicare beneficiaries with Newlydiagnosed Depression and Incident Breast, colorectal, or Prostate Cancer, SEER-Medicare Database, 2007-2012.

Table 4.3 IPTW adjusted Mean Expenditures by Depression Treatment Categories Elderly Feefor-service Medicare beneficiaries with Newly-diagnosed Depression and Incident Breast, colorectal, or Prostate Cancer, SEER-Medicare database, 2007-2012.

Table 4.4 Parameter Estimates of Depression Treatment Categories From GLMM and Mixed Effects linear Model On Monthly Healthcare Expenditures, Elderly Fee-for-service Medicare Beneficiaries with Newly-diagnosed Depression and Incident Breast, Colorectal or Prostate Cancer, SEER-Medicare Database, 2007-2012 .

Table 4.5 Parameter Estimates of Depression Treatment Categories from Generalized Linear Models on One-year Healthcare Expenditures Elderly Fee-for-service Medicare beneficiaries 
with newly-diagnosed Depression and Incident Breast, colorectal, or Prostate Cancer SEER-

Medicare Database, 2007-2012

\section{LIST OF FIGURES}

Figure 1.1 Conceptual Framework: Adapted Andersen Behavioral Model.............................. 24

\section{LIST OF APPENDIX}

Appendix 2.1 Adjusted Risk Ratios (ARR) and 95\% Confidence Intervals (CI) from Complementary Log-Log Regression on Newly-Diagnosed Depression Elderly Fee-for-service Medicare beneficiaries with Incident Breast, colorectal, and Prostate Cancer SEER-Medicare Database, 2007-2012

Appendix 2.2 Study Cohort Development Flow Diagram for Study Population of Elderly Medicare Beneficiaries Diagnosed with Incident Breast, Colorectal and Prostate cancer

Appendix 3.1 Study Cohort Development Flow Diagram for Study Population of Elderly Medicare Beneficiaries Diagnosed with Incident Breast, Colorectal or Prostate cancer and Newly-diagnosed Depression

Appendix 3.2 Adjusted Odds Ratios and 95\% Confidence Intervals of Depression Treatment Categories by Cancer Types from Multinomial Logistic Regression on Depression Treatment Categories Elderly Fee-for-service Medicare beneficiaries with Breast, Colorectal or Prostate Cancer, SEER-Medicare data from 2007-2012

Appendix 4.1 Study Cohort Development Flow Diagram for Study Population of Elderly Medicare Beneficiaries Diagnosed with Incident Breast, Colorectal or Prostate cancer and Newly-diagnosed Depression 


\section{LIST OF ABBREVIATIONS}

ADRD

AHR

AHRF

AJCC

AOR

CBT

CI

CMHC

CMS

COPD

DME

DSM-V

GLMM

HADS

HDRS

HHA

HMOs

HR

HRQoL

ICD-9-CM

IPTW

MAOIs

MEDPAR

MEPS

NDC

OR

PCP

RCTs

PEDSF

PST

SEER

SNRI

SSRIs

TCAs

US
Alzheimer's Disease and Other Related Disorders

Adjusted Hazard Ratio

Area Health Resource File

American Joint Committee on Cancer

Adjusted Odds Ratio

Cognitive Behavioral Therapy

Confidence Interval

Community Mental Health Clinics

Center for Medicare and Medicaid

Chronic Obstructive Pulmonary Disease

Durable Medical Equipment

Diagnostic and Statistical Manual of Mental Disorders, Fifth Edition

Generalized Linear Mixed Model

Hospital Anxiety and Depression Scale

Hamilton Depression Rating Scale

Home Health Agencies

Health Maintenance Organizations

Hazard Ratio

Health Related Quality of Life

International Classifications of Diseases $-9^{\text {th }}$ edition, Clinical Modification

Inverse Probability of Treatment Weighting

Monoamine Oxidase Inhibitors

Medicare Provider Analysis and Review

Medical Expenditures Panel Survey

National Drug Codes

Odds Ratio

Primary Care Physician

Randomized Control Trials

Patient Entitlement and Diagnosis Summary File

Problem Solving Therapy

Surveillance Epidemiology and End Results

Selective Norepinephrine Reuptake Inhibitors

Selective Serotonin Reuptake Inhibitors

Tricyclic Antidepressants

United States 


\section{Chapter 1}

Introduction

\subsection{Background}

It is projected that there will be 19 million cancer survivors in the United States (US) by 2024. "A cancer survivor is a person who has been diagnosed with cancer, from the time of diagnosis throughout his or her life." (1). Cancer is the disease of the elderly; 63\% of cancer survivors are age 65 years and older (2). Cancer survivors often find the diagnosis of cancer to be a very stressful life event; they may face a fear of death, changes in physical health, life plans, work, and social roles and may face some financial concerns (3). As a result, some cancer survivors may have difficulties adjusting to the diagnosis of cancer and may develop psychological side effects. Evidence from the literature suggests the psychological effects of a cancer diagnosis may range from sadness to depressive symptoms to clinical depression, hereinafter referred to as "depression" (4).

\subsubsection{Depression Diagnosis}

According to the Diagnostic and Statistical Manual of Mental Disorders, Fifth Edition (DSM-V), a depression diagnosis is confirmed if individuals present with at least five symptoms which persist over a period of at least two weeks (5). These symptoms include: 1) depressed mood; 2) loss of interest or pleasure in usual activities (anhedonia); 3) weight loss or change in appetite; 4) change in sleep (insomnia or hypersomnia); 5) change in activity; 6) fatigue/loss of energy; 7) feelings of guilt/worthlessness; 8) difficulty concentrating or thinking; 9) thoughts of death or suicide. Depression is present when these symptoms cause clinically significant distress and impairment in social, occupational or other important areas of functioning (5).

There are different tools to diagnose depression; the gold standard for depression diagnosis is the Structured Clinical Interview, a clinical interview administered by mental health 
providers that is based on the symptom criteria for a major depressive disorder in the DSM-IV (5). However, because the structured clinical interview can be time-consuming and expensive to administer, epidemiological studies often use depression rating scales with cut-off points to diagnose depression. Depression rating scales can be administered by trained interviewers or can be completed by patients (a patient self-report scale). Examples of the scales administered by trained interviewers include the Hamilton Depression Rating Scale (HDRS) and the Montgomery-Åsberg Depression Rating Scale. Examples of patient self-report scales include the Beck Depression Inventory, the Center for Epidemiologic Studies Depression Scale, the Hospital Anxiety and Depression Scale (HADS), the Geriatric Depression Scale, the Patient Health Questionnaire, and the Zung Self-rating Depression Scale. These scales are usually used in Randomized Control Trials (RCTs) as screening tools to identify depression before conducting a structured clinical interview or as assessment tools for response to depression treatment.

\subsubsection{Prevalence of Depression among Cancer Survivors}

Using these self-reported scales or physician diagnoses, it has been found that prevalence rates of depression are higher among cancer survivors as compared to their matched non-cancer controls (6-8). It is estimated that $10-25 \%$ of breast cancer survivors $(7,9,10), 8-18 \%$ of colorectal survivors $(11,12)$, and 5-10\% of prostate cancer survivors suffer from depression $(13,14)$. The variability in the prevalence rates of depression within any cancer types is due to heterogeneous samples, different settings, time periods, and the use of different instruments used to diagnose depression. Some studies used the structured clinical interview (9) or the International Classifications of Diseases $-9^{\text {th }}$ edition, Clinical Modification Codes (ICD-9-CM) diagnostic codes recorded in healthcare claims (11-14). Other studies used self-reported symptoms scales with cut-off points to diagnose clinical depression, specifically the Hospital Anxiety and Depression Scale and the Beck Depression Inventory $(9,10)$. 


\subsubsection{Incidence of Depression among Cancer Survivors}

While the prevalence of depression among cancer patients is examined extensively in the literature, studies on the incidence of depression after cancer diagnosis are sparse. Studies that examined the incidence rate of depression have compared the rate of depression among cancer survivors to matched non-cancer cohorts (6-8). An observational study using the Surveillance Epidemiology and End Results (SEER)-Medicare database for the years 1998-2002 examined the age-race adjusted incidence rate of depression among 51,590 elderly Medicare beneficiaries (age $\geq 66$ ) with breast cancer (7). This study found a 12-month depression incidence rate was 24 per 1000 person-years after cancer diagnosis. Another study using SEER-Medicare data for the years 1998-2002 examined the unadjusted incidence rate of depression among 5,087 elderly Medicare beneficiaries (age $\geq 66$ ) with ovarian cancer (6). This study found a 12-month depression incidence rate of 65 per 1000 person-years after cancer diagnosis. These studies followed individuals over varying periods and, therefore, estimated the incidence rate of depression per 1000 person-years.

\subsubsection{Risk Factors for Depression among Cancer Survivors}

\section{Cancer-Related Factors}

The stage at cancer diagnosis can increase the risk of developing depression, hereinafter referred to as "newly-diagnosed" depression. A longitudinal study of 500 elderly cancer patients (age $\geq 65$ ) receiving chemotherapy found that advanced stage at cancer diagnosis was significantly associated with depression $(\beta=0.83, \mathrm{SE}=0.28, \mathrm{P}=0.003)(15)$. An observational study using the SEER-Medicare database for the years 1998-2002 among 51,590 elderly Medicare beneficiaries (age $\geq 66$ ) with breast cancer found that the risk of depression was higher among women with advanced stage at breast cancer diagnosis as compared to those with earlystage at breast cancer diagnosis (7). 
Cancer treatment type can affect the risk of developing depression. A study among women with early-stage breast cancer found that women who received chemotherapy were more likely to have a probable case of depression (Odds Ratio (OR) $=2.07 ; 95 \%$ CI: $1.18-3.62)$ as compared to those who did not receive chemotherapy (16). A prospective study among 64 women with stage I-III breast cancer found a significant association between chemotherapy treatment and depression (17). Another prospective study among 32 women with stage I-III breast cancer also found a significant association between chemotherapy treatment and depression (18). A study among 61 men with prostate cancer found that androgen deprivation therapy was associated with depression as compared to those who received surgery (19). Another study among men with prostate cancer found that radiotherapy was associated with depression as compared to prostatectomy (20). These findings suggest that the risk of developing depression may depend on the type of treatment received.

\section{Socio-demographic Correlates}

Socio-demographic factors can also influence the risk of depression among cancer survivors. A retrospective cohort study using SEER-Medicare data for elderly Medicare beneficiaries with localized prostate cancer found that a higher percentage of men who were white ( $4.8 \%$ vs. $3.5 \%$ ), unmarried (6.6\% vs. $3.9 \%$ ), had low income (5.4\% vs. $3.6 \%$ ), and lived in non-metropolitan area (5.5\% vs. $4.4 \%)$ had diagnosed depression as compared to African Americans, married, those who had high income or lived in metropolitan areas (14). Among cancer survivors, older age groups had higher rates of diagnosed depression, as compared to younger age groups $(16-18,21)$. 
Pre-existing and co-existing chronic conditions

The number and types of pre-existing chronic conditions may also be associated with depression among cancer survivors. A retrospective cohort study using SEER-Medicare data for men diagnosed with localized prostate cancer found that men with a higher comorbidity index had a significantly higher percentage of depression diagnosis as compared to those with a lower comorbidity index (9.1\% vs. 3.4\%) (14). Anxiety usually co-exists with depression in cancer patients. A cross-sectional study of 8,265 adult cancer patients has found that $12.4 \%$ of patients had co-existing anxiety and depression (16).

\subsubsection{Negative Health Consequences of Depression among Elderly Cancer Survivors Mortality}

Among cancer survivors, the presence of depression is associated with higher all-cause mortality (13), cancer-specific mortality (11), and suicide (22). A retrospective cohort study using SEER-Medicare data for 50,147 elderly Medicare beneficiaries (age $\geq 66$ ) with prostate cancer examined the association between depression and all-cause mortality (13). The investigators of this study found that among men with prostate cancer, depression was associated with $88 \%$ greater all-cause mortality (Hazard Ratio (HR), 1.88; $95 \%$ CI: 1.24-2.83) as compared to those without depression. A retrospective cohort study using the SEER-Medicare data for 2,199 elderly Medicare beneficiaries (age $\geq 66$ ) with colorectal cancer examined the association between depression before cancer diagnosis and cancer-specific mortality (11). This study found that those with a depression diagnosis had $25 \%$ greater cancer-specific mortality (Adjusted Hazard Ratio $(\mathrm{AHR})=1.25 ; 95 \%$ CI: 1.08-1.46) as compared to those without a depression diagnosis. Depression is also associated with a high risk of suicide among cancer 
survivors. In a retrospective cohort of 667 elderly men (age $\geq 65$ ) with prostate cancer, it was found that depression was correlated with the risk of suicide (22).

\section{Health-related Quality of Life (HRQoL)}

Depression among cancer survivors has been found to be associated with poor HRQoL (23). A cross-sectional study among 240 women with breast cancer (mean age 58) found that those who had depression scored significantly lower on all HRQoL subscales that measured cognitive, emotional, role, physical, and social functioning, and overall HRQoL compared to those without depression (23).

\section{Healthcare Utilization and Expenditures}

The cost of cancer in the United States is projected to increase from $\$ 124$ billion to $\$ 173$ billion by 2020, a 39\% increase from 2010 (24). This increase is due to improving survival, new cancer treatments, and the growth and aging of the population. The financial burden can also vary by the type of cancer. For example, the estimated cost of cancer was highest for breast cancer ( $\$ 16.5$ billion), colorectal cancer ( $\$ 14$ billion), followed by prostate cancer ( $\$ 12$ billion) (25).

Depression among cancer survivors can further increase the financial burden. It is reported that elderly individuals with cancer and depression had higher healthcare utilization and expenditures as compared to their counterparts without depression (13,26). A study using SEERMedicare data for the years 1995-2003 examined the association between depression and healthcare utilization and expenditures among 4,285 elderly (age $\geq 66$ ) with prostate cancer and depression (13). This study found that elderly with both cancer and depression were more likely to have emergency room visits (Adjusted odds ratio $(A O R)=3.5,95 \%$ CI: 3.2-4.3.7), inpatient visits (AOR=2.8, CI: 2.6-2.9), and outpatient visits (AOR=1.8, CI: 1.7-1.8) as compared to those 
without depression. In addition, this study found that during all phases of cancer (treatment, follow-up, and terminal phase) prostate cancer patients with depression had higher total healthcare expenditures as compared to those without depression. For example, during the treatment phase, depression among elderly with prostate cancer was associated with higher total health expenditures ( $\$ 27,500$ vs. $\$ 20,000$ ) as compared to those without depression. Another study using claims data for the years 2006-2007 examined the association between depression and health care expenditures among 11,014 non-elderly military healthcare beneficiaries (ages 18-64) with different types of cancer and newly-diagnosed depression (26). This study found that those diagnosed with depression had a significantly higher healthcare utilization for inpatient visits (mean: 3.2 vs. 0.6), outpatient visits (mean: 33.7 vs. 18.7), and medication use (mean: 45.3 vs. 24.5). This study also found that depression among cancer survivors was associated with a $110 \%$ increase in total health expenditures $(\$ 16,212$ vs. $\$ 7,728$, p-value $<0.05)$ as compared to those without depression.

\subsubsection{Depression and Cancer Treatment}

Depression may affect the choice of cancer treatment, which may, in turn, affect cancer outcomes. A retrospective cohort study using SEER-Medicare data for elderly Medicare beneficiaries with colorectal cancer found that those with depression were less likely to receive chemotherapy (AOR=0.67; 95\% CI: 0.48-0.92) as compared to those without depression (11). A cross-sectional study among 117 women with breast cancer (ages 28-72) found that those with depression had a significantly lower acceptance for receiving adjuvant chemotherapy as compared to those without depression $(51.3 \%$ vs. $92.2 \%, \mathrm{P}<0.0001)(27)$. An observational study using SEER-Medicare data among 24,698 elderly women with breast cancer found that women with depression were more likely to receive non-definitive cancer treatment as compared to those without a depression diagnosis (AOR=1.19; 95\% CI: 1.06-1.33) (28). A population-based 
observational study using SEER-Medicare data on men with localized prostate cancer found that those with pre-existing depression were less likely to undergo definitive treatment (surgery or radiation) as compared to those without a depression diagnosis (14).

\subsubsection{Depression Treatment}

\section{Modalities of Depression Treatment}

While depression has many negative consequences, it is a treatable chronic illness (3). Relief from depression can be achieved with either pharmacotherapy, psychotherapy or a combination of pharmacotherapy and psychotherapy (American Psychiatric Association, 2010). Pharmacotherapy typically consists of antidepressants such as Selective Serotonin Reuptake Inhibitors (SSRIs), Selective Norepinephrine Reuptake Inhibitors (SNRIs), Tricyclic Antidepressants (TCAs), Monoamine Oxidase Inhibitors (MAOIs) and others (mirtazapine, bupropion) (5). The selection of antidepressant medication depends on concurrent chronic conditions, the safety and the side-effects profile of the antidepressant, pharmacological properties (drug interaction) and patient preference.

Depression can also be treated with psychotherapy. Psychotherapy can take different forms and be provided in group or individual settings. These therapies consist of cognitivebehavioral therapy (CBT), interpersonal therapy, psychodynamic therapy, and problem-solving therapy (PST) (5). Factors that can affect the choice of using psychotherapy can include the severity of depression, availability and affordability of psychotherapy, and patient preferences.

\section{Efficacy of Antidepressants in Treating Depression among Elderly}

A case needs to be made for the efficacy of depression treatment among the elderly (age $\geq 65$ years) because cancer is often considered the disease of the elderly (2). The median age at diagnosis is 61 for breast cancer, 69 for colorectal cancer, and 66 for prostate cancer (29). 
However, there is uncertainty about the efficacy of antidepressants in adults 65 years and older (30,31). A meta-analysis of 6 double-blind RCTs involving 1,840 patients aged 65 years and older examined the efficacy of antidepressants in treating depression (30). The investigators of this meta-analysis concluded that there were no statistically significant differences between the treatment groups and the placebo groups (Relative Risk $(\mathrm{RR})=1.13 ; 95 \% \mathrm{CI}: 0.93-1.37, \mathrm{p}=$ 0.265). The efficacy of antidepressants in treating depression among adults aged 60 years and older was also examined in a meta-regression of 34 double-blind RCTs (31). Findings from this meta-regression revealed that at 12-week follow-up, older age was associated with lower response to antidepressants.

\section{Efficacy of Antidepressants in Treating Depression among Adult Cancer Survivors}

There have been few RCTs that examined the efficacy of antidepressants in treating depression among cancer survivors. The efficacy of antidepressants in all of these clinical trials was defined as a reduction in depressive symptoms scores. A 4-week RCT compared mianserin, a TCA, to a placebo in 73 women with depression and different types of cancer (32). This study found a significant reduction in depression score from baseline on the HDRS rating scale in the mianserin group as compared to the placebo at week 4 of depression treatment. A 6-week RCT among 55 women with both early stage breast cancer and depression compared mianserin to a placebo (33). This study found a significant reduction in depression score from baseline on the HDRS rating scale in the mianserin group as compared to the placebo at four and six-week follow-up periods. A 6-week RCT among 40 women with depression and different types of cancer assigned them to either fluoxetine or desipramine or placebo (34). The investigators found a significant reduction in depression score from baseline on the HDRS rating scale in both the fluoxetine and the desipramine groups as compared to the placebo. 
In contrast, a 5-week RCT among 115 cancer patients with depression and different types of cancer compared fluoxetine, an SSRI, to a placebo (35). This trial found no significant reduction in depression scores from baseline on the HADS rating scale between the fluoxetine group and the placebo. A 6-week RCT among 35 women with breast cancer compared paroxetine, an SSRI, or desipramine, a TCA, to a placebo (36). The investigators did not find a significant reduction in depression score from baseline on the HDRS rating scale between the treatment groups and the placebo. Laoutidis \& Mathiak conducted a meta-analysis of six RCTs that examined the efficacy of antidepressants in patients with cancer (37). Based on this metaanalysis, the investigators found that patients who used antidepressants were $50 \%$ more likely to achieve a therapeutic response compared to the placebo $(\mathrm{RR}=1.56,95 \% \mathrm{CI}: 1.07-2.28)$. However, these investigators concluded that due to the small number of patients and lack of clarity in the risk of bias, the findings cannot be used to recommend antidepressant therapy for treating depression among cancer patients.

In summary, RCTs have shown mixed results on the efficacy of antidepressants among cancer patients even with the same type of antidepressants. In, addition, there are no studies on the efficacy of antidepressants in elderly cancer survivors. Even when antidepressant usage was examined among elderly individuals in general (age $\geq 65$ ), antidepressants were not found to be efficacious in treating depression among the elderly. As cancer is often diagnosed in the elderly population (2) and the efficacy of antidepressants among elderly individuals is questionable, one can conclude that the efficacy of antidepressants among cancer survivors is yet to be established. 
Efficacy of Psychotherapy in Treating Depression among Elderly Individuals

RCTs have shown all types of psychotherapy to be efficacious in the short-term among individuals aged 50 and older (38). A RCT among 44 elderly (age $\geq 60$ ) individuals with depression compared CBT versus usual care (39). This study found a significantly lower percentage of individuals with depressive symptoms in the CBT group as compared to usual care at the 18 weeks follow-up period ( $26 \%$ vs. $58 \%, \mathrm{p}=0.05$ ). A meta-analysis of $27 \mathrm{RCTs}$ involving 2,245 patients 55 years and older compared psychotherapy treatment to control groups (waitinglist, usual care, attention, supportive therapy, and placebo) (38). This meta-analysis included different types of psychotherapy with varying observation periods (4 to 26 weeks) and varying numbers of psychotherapy sessions (4 to 12 sessions). The results from this meta-analysis revealed that psychotherapy was effective in reducing depression scores as compared to control groups (Standardized mean differences (SMD): 0.73; 95\% CI: 0.51-0.95, p <0.00001). In this meta-analysis, a subgroup analysis of individuals who were aged 60 and above revealed similar results. Another meta-analysis of 44 RCTs involving 4,409 patients aged 50 and older compared psychotherapy to control groups (waiting-list, usual care, attention, supportive therapy, pharmacotherapy, and placebo) (40). In this meta-analysis, psychotherapy was found to be effective compared to the control groups (Hedge's g: 0.64; 95\% CI: 0.47-0.80). The abovementioned RCTs and meta-analysis of RCTs indicate that psychotherapy is effective in treating depression in elderly individuals.

\section{Efficacy of Psychotherapy in Treating Depression among Adult Cancer Survivors}

Few RCTs have examined the efficacy of psychotherapy in cancer patients. The most commonly examined forms of psychotherapy among cancer patients include CBT and supportive therapy provided in an individual or group setting. A RCT of 45 women with an advanced stage 
of breast cancer and depressive symptoms compared 8-week sessions of individual CBT with three booster sessions to a waiting-list control (41). The study findings showed a significant reduction in depression score from baseline on the HDRS rating scale in the CBT group as compared to a waiting-list control. Another RCT compared group CBT to a waiting-list control group among 62 women with breast cancer (42). This trial found that patients receiving group CBT achieved a significantly greater reduction in the depression score from baseline as compared to the control group. In a RCT of 88 women with breast cancer, women were randomized to 6-week sessions of group CBT or usual psychosocial care (43). The investigators found that women in the CBT group had lower rates of depression compared to the control group at six weeks follow-up (6.5\% vs. 10.4\%, p<0.05). A RCT involving 458 women with metastatic breast cancer compared weekly group supportive therapy to no therapy. The study found lower rates of depression in group supportive therapy as compared to the control group at a six months follow-up period ( $18 \%$ vs. $40 \%, \mathrm{p}=0.002)$ (44). A meta-analysis of six RCTs, which involved 1,362 participants with mixed types of cancer, compared psychotherapies (PST, CBT) to control groups (wait-list, usual care). This meta-analysis found that psychotherapy interventions were more efficacious than the control groups (45).

To summarize, although studies among elderly, in general, did not specifically focus on individuals aged 65 and older, all types of psychotherapy have been found to be efficacious in the short-term among individuals aged 50 and older. In addition, studies among adult cancer survivors revealed that psychotherapy is efficacious in the short-term. However, none of these RCTs evaluated the efficacy of psychotherapy among elderly cancer patients. 
Efficacy of Combined Antidepressants and Psychotherapy in Treating Depression among Elderly

There is a limited number of RCTs on the combination of psychotherapy and antidepressants compared with mono-therapies for the treatment of depression in the elderly. A 12-week RCT of 102 elderly with depression compared combination therapy (desipramine + CBT) with antidepressant only (desipramine) and CBT only (46). The findings of this trial show a greater reduction in depressive symptoms for the "combination therapy" group as compared to antidepressants only. However, there were no differences between combination therapy and CBT only. A double-blind RCT among 80 ambulatory older adults (age $\geq 50$ ) examined the efficacy of combined IPT and nortriptyline versus a placebo and IPT group for treating bereavement-related major depressive episodes (47). This study found that the remission rate for nortriptyline plus IPT was higher than for the placebo plus IPT (69\% vs. 29\%).

Efficacy of Combined Antidepressants and Psychotherapy in Treating Depression among Cancer Survivors

There is limited research on the efficacy of combination therapy, with antidepressants and psychotherapy, in treating depression among cancer patients. To our knowledge, only one RCT examined the efficacy of combination therapy among cancer survivors in usual care settings. A RCT of 72 adult cancer patients (non-elderly) with depression has compared a narrative therapy (NT) plus escitalopram group to a escitalopram plus usual care group (48). This study found no significant difference in depressive symptoms between the two groups.

The above-mentioned RCTs provide some evidence for the efficacy of combination therapy as compared to mono-therapy in treating depression among the elderly. However, none of these studies examined the efficacy of combination therapy in treating depression among elderly cancer patients, therefore combination therapy's efficacy is not yet established. 


\section{Clinical Practice Guidelines for Treating Depression in Cancer Survivors}

Despite mixed evidence regarding the efficacy of antidepressants and psychotherapy for treating depression in cancer patients, practice guidelines have been developed for treating depression in cancer patients (49,50). A guideline was established by the Supportive Care Guidelines Group from Canada based on a systematic review of the published literature through June 2005 (50). This guideline recommends antidepressants to cancer patients with moderate to severe major depression. However, this guideline does not prioritize antidepressants over psychosocial interventions, nor one antidepressant over another. Another Canadian guideline was developed in 2010 through a collaboration between the Canadian Partnership against Cancer and the Canadian Association of Psychosocial Oncology (CAPO) (49). This guideline was adopted by the American Society of Clinical Oncology (ASCO) in 2014 (51). In this guideline, there is no recommendation about any antidepressants being better than the other and it recommends that the selection of antidepressants should be based on side-effect profile, drug interaction, patient age, and patient preference.

The American Psychiatric Association (APA) guideline recommends treatment of depression in all adults and includes specific recommendations for the elderly (5). According to the APA, depression treatment needs to be considered in three phases: an acute phase to attain remission of symptoms, a continuation phase to prevent a relapse, and a maintenance phase to prevent a recurrence. This guideline recommended a period of 4-8 weeks to assess the effectiveness of treatment in the acute phase of treatment. If patients respond to treatment in the acute phase, then the guideline recommends that they should continue the treatment for 4 to 9 months (continuation phase). A maintenance phase is required to prevent a relapse for patients at high risk of recurrence such as a family history of depression or residual symptoms. 
Depression Treatment in Real-World Clinical Practice Settings

Depression treatment among cancer survivors has been examined with a few studies. A cross-sectional study using the Medicare Current Beneficiary Survey (MCBS) from 2000-2005 examined the rate of antidepressant use among 865 elderly (age $\geq 65$ ) with both cancer and depression. The investigators found that among elderly with both cancer and depression, 57\% received antidepressants only, 19\% received psychotherapy with or without antidepressants, and $24 \%$ did not receive any depression treatment (52). Another cross-sectional study using the Medical Expenditures Panel Survey (MEPS) from multiple years, 2006-2008, examined depression treatment among 528 adults (both elderly and non-elderly) with both cancer and depression (53). This study estimated that $17 \%$ of elderly cancer patients with depression did not receive any depression treatment (defined as antidepressants with or without psychotherapy). These studies indicate that no treatment for depression can range from $17 \%$ to as high as $24 \%$ of elderly with both cancer and depression.

\subsection{Need for the Study}

Based on our review of the existing literature on depression among cancer patients, studies on the incidence of depression after cancer diagnosis are sparse. To date, there have been only two studies that examined the incidence of depression among cancer survivors $(6,7)$. These studies suggested that the incidence of depression within 12 months after the cancer diagnosis is 24 per 1000 person-years for women with breast cancer and 65 per 1000 person-years for women with ovarian cancer. While these studies contributed to the knowledge-base for incidence of depression among women with breast and ovarian cancer, none of them examined the risk of developing depression in colorectal and prostate cancer patients, thus, a knowledge-gap exists. Further, there are no studies that compare the risk of depression among gender-specific cancers 
(women breast cancer vs. women colorectal cancer and men prostate cancer vs. male colorectal cancer).

There is also a paucity of research on depression treatment in elderly cancer patients with newly-diagnosed depression after a cancer diagnosis. Only two studies in the United States have examined depression treatment in elderly cancer patients with a depression diagnosis $(52,53)$. These studies indicate that no treatment for depression for elderly with both cancer and clinical depression can range from $17 \%$ to as high as $24 \%$. However, these studies were limited to examining any depression treatment (53) and did not examine treatment with psychotherapy only (52). In addition, both studies examined depression treatment among elderly with any cancer and did not distinguish between types of cancer and non of these controlled for cancer related factors such as stage at cancer diagnosis and cancer treatment. It is unknown how depression is treated for distinct types of cancer. In addition, the subgroup differences in depression treatment among elderly with breast, colorectal or prostate cancer is unknown, therefore, a knowledge-gap exists.

Further, there is evidence that depression among cancer patients is associated with increased financial burden. Studies have shown that depression among cancer patients was associated with a $37.5 \%$ to $110 \%$ increase in total health care expenditures as compared to the expenditures of those without depression $(13,26)$. Depression treatment can be a pathway to reduce healthcare utilization and expenditures as it has been shown to reduce depressive symptoms and to improve the quality of life for cancer survivors $(54,55)$. There are no studies that examined the association between depression treatment and healthcare expenditures among cancer survivors with newly-diagnosed depression in a usual care setting, thus, a knowledge-gap exists. Therefore, the current dissertation will address these gaps in knowledge among elderly cancer survivors with incident breast, colorectal or prostate cancer. The rationale for the 
selection of these cancer types is discussed in the Methods section. The study has the following specific aims, objectives, and hypotheses.

\subsection{Aims, Objectives and Hypothesis}

$\underline{\operatorname{Aim} 1}$

Investigate the risk of newly-diagnosed depression among elderly Medicare beneficiaries with incident breast, colorectal or prostate cancer.

\section{Objective 1.1}

Estimate the rates of newly-diagnosed depression by cancer types (breast vs. female colorectal and prostate vs. male colorectal cancer) among elderly Medicare beneficiaries who have incident breast, prostate or colorectal cancer.

\section{Objective 1.2}

Examine the risk of newly-diagnosed depression by cancer types (breast vs. female colorectal and prostate vs. male colorectal cancer), after controlling for other risk factors, among elderly Medicare beneficiaries who have incident breast, prostate or colorectal cancer.

\section{Hypothesis 1.2}

Among cancer patients, women with colorectal cancer will be more likely to be diagnosed with incident depression as compared to women with breast cancer; men with colorectal cancer will be more likely to be diagnosed with incident depression as compared to men with prostate cancer. 
$\underline{\operatorname{Aim} 2}$

Examine the rates and factors associated with depression treatment among elderly Medicare beneficiaries with newly-diagnosed depression and incident breast, colorectal or prostate cancer.

\section{Objective 2.1}

Estimate the rates of depression treatment among elderly Medicare beneficiaries with newlydiagnosed depression and incident breast, colorectal or prostate cancer.

\section{Objective 2.2}

Examine the predisposing, enabling, need, and external environment factors associated with depression treatment among elderly Medicare beneficiaries with newly-diagnosed depression and incident breast, colorectal or prostate cancer.

\section{Hypothesis 2.2}

Cancer-related factors will be associated with a lower likelihood to receive depression treatment.

\section{$\underline{\operatorname{Aim} 3}$}

Examine the association between depression treatment and total healthcare expenditures among elderly Medicare beneficiaries with newly-diagnosed depression and incident breast, colorectal or prostate cancer.

\section{Objective 3.1}

Estimate total and types of healthcare expenditures by depression treatment categories among elderly with newly-diagnosed depression and incident breast, colorectal and prostate cancer. 


\section{Objective 3.2}

Evaluate the relationship between depression treatment categories and total and types of healthcare expenditures among elderly with newly-diagnosed depression and incident breast, colorectal and prostate cancer, after controlling for predisposing, enabling, need, and external environment factors.

\section{Hypothesis 3.2}

The short-term total healthcare expenditures will be higher among elderly who received depression treatment compared to those who received no treatment.

\subsection{Data Source}

\subsubsection{Surveillance, Epidemiology and End Results (SEER)}

The SEER Program is an epidemiologic surveillance system consisting of populationbased tumor registries residing in 18 SEER areas (Atlanta, Connecticut, Detroit, Hawaii, Iowa, New Mexico, San Francisco-Oakland, Seattle-Puget Sound, Utah, Los Angeles and San JoseMonterey, Rural Georgia, Alaska Native, Greater California, Kentucky, Louisiana, New Jersey, and Greater Georgia) (56). SEER cancer registries collect data on all incident cases of cancer that occur in persons residing in SEER areas. These data are available in the Patient Entitlement and Diagnosis Summary File (PEDSF) file which has information on a patient's demographic characteristics, cancer type, tumor characteristics, and chemotherapy and radiation therapy provided within four months of cancer diagnosis.

\subsubsection{Medicare}

As Medicare is the primary health insurer for the elderly, SEER data have been linked to Medicare claims. SEER has been linked to Medicare using an algorithm based on the patient first name, last name, date of birth and social security number. A total of $93 \%$ of persons age 65 and 
older in the SEER files has been matched to the Medicare enrollment file (57). Most of Medicare beneficiaries receive Medicare Part A and B coverage. Part A of the Medicare program covers the following types of services: inpatient hospitalization, Skilled Nursing Facility (SNF), home health services following hospital stay (HHA) and hospice care. Part B of the Medicare program covers the following types of services: physician services, outpatient services, diagnostic tests, Durable Medical Equipment (DME), emergency room visits, home health care not following a hospital stay, laboratory services, and other medical services. Medicare program also covers prescription drugs, Medicare Part D. Medicare data does not include all the claims for the beneficiaries enrolled under the Health Maintenance Organizations (HMOs) as the organizations are not required to submit all their services claims to Center for Medicare and Medicaid (CMS). Medicare claims files consist of inpatient claims (Medicare Provider Analysis and Review (MEDPAR), outpatient claims (National Claims History $(\mathrm{NCH})$ and Outpatient Claims Files (OUTSAF)), Durable Medical Equipment (DME), Home Health Agency (HHA) as well as a prescription drug file (PDESAF). In the current study, this study utilized data from the PEDSF file linked with MEDPAR, OUTSAF, and NCH, HHA and PDESAF files for the years 2007 to 2012.

\subsubsection{American Community Survey (ACS) Estimates from Census}

This study used the ACS 2008 to 2012 census tract and census zip code files. These files were linked to PEDSF files by geographic codes, which included state and county. These files were used to derive the census tract median household income and education level.

\subsubsection{The Area Health Resource File (AHRF)}

The AHRF is a publicly available data file provided by Department of Health and Human Services; it includes county, state and national files (58). The AHRF provides more than 6,000 variables for each of the nation's counties. The AHRF contains information on health facilities, 
health professions, and socioeconomic and environmental characteristics. The AHRF was used to provide county-level urban/rural continuum codes, percentage of psychologists, and on the presence of community mental health clinics. The AHRF files were linked to PEDSF files by geographic codes, which included state and county.

\subsection{Rationale for Cancer Selection}

This dissertation included breast, colorectal or prostate cancers because they are projected to be the most common types of cancer by 2024; breast cancer among women (41\%), prostate cancer among men (45\%), and colorectal cancer among men and women (8\%) (29). In addition, depression is highly prevalent in these cancer types $(9,11-13)$. In this dissertation, depression incidence and depression treatment were compared within gender-specific cancers (women breast vs. women colorectal cancer and men prostate vs. men colorectal cancer).

Depression incidence and depression treatment may not be similar among these types of cancer due to differences in survival prognosis and stage at the time of cancer diagnosis. With regard to cancer survival, survival prognosis may affect the risk of developing depression and depression treatment, and it is well documented that survival rates vary by types of cancer. The estimated 5-year relative survival rate is $89 \%$ for women with breast cancer, $99 \%$ for patients diagnosed with prostate cancer and $65 \%$ for patients with colorectal cancer (29). With regard to the stage at cancer diagnosis, the differences in the stage of cancer at the time of cancer diagnosis can affect the risk of depression. Danese and colleagues found that the risk of depression among women with breast cancer was higher among women diagnosed at an advanced stage of cancer compared to those diagnosed at an early stage of breast cancer (Stage IV: 17\% vs. Stage I: 3\%) (7). Colorectal cancer is usually diagnosed at a late stage as compared to breast and prostate cancer (29). It is plausible that due to competing demands and prioritization, all attention may be 
focused on the treatment of cancers that have lower survival rates and are diagnosed at late stage rather than on the recognition and management of other co-existing conditions such as depression.

\subsection{Rationale for Selection of Elderly Individuals}

This dissertation focused on elderly individuals with breast, colorectal or prostate cancer. Elderly individuals were selected because cancer is the disease of the elderly; $72 \%$ of breast cancer, $82 \%$ of colorectal cancer, and $90 \%$ of prostate cancer patients were 60 years and older (29). In addition, as $97 \%$ of the US population aged 65 years and older are covered by Medicare, which is the US government mandated insurance program, this study used inpatient, outpatient, prescription drugs claims that were linked to cancer related information from PEDSF file.

\subsection{Conceptual Framework}

The first aim of the current dissertation adapted the determinants-of-health model by Marmot and Wilkinson (1999) (59). This model posits that many dimensions affect an individual's health or disease/illness (e.g., newly-diagnosed depression). These dimensions are 1) Individual physical makeup variables included age in years at cancer diagnosis, and race/ethnicity; 2) Social Support was marital status; 3) Access to care was measured by Primary Care Physicians (PCP) visit, census-tract median household income, and percentage with less than high school education level; 4) Health behavior consisted of tobacco use; 5) Psychological factors included anxiety; 6) Biological risk factors were the stage of cancer at diagnosis and chronic physical conditions during; 7) Treatment factors included cancer treatment; 8) Community Resources consisted of the presence or absence of county-level community mental health clinics (CMHC) and whether the county of residence was designated as health 
professional shortage area (HPSA) for mental health; 8) Geographical location consisted of the SEER region, and county metro status. To control for changes in patterns of diagnosis over time, year of cancer diagnosis was also included.

The second and third aim of the current dissertation used the expanded behavioral model on healthcare utilization, the Andersen Behavioral Model, to help in our selection of variables that may affect health care utilization (Figure 1) (60). For the second aim, according to this model, depression treatment (i.e. health services utilization) is a function of: 1) an individual's predisposition to utilize the services - predisposing factors (age, race/ethnicity); 2) factors which enable individuals to use healthcare services - enabling factors (marital status, PCP visits, cancer type, cancer stage, cancer treatment) 3) an individual's level of need - need factors (chronic conditions) and 4) the external environment.

For the third aim, according to this model, healthcare expenditures varies as a function of 1) predisposing factors - age and race; 2) enabling factors: cancer type, cancer stage, cancer treatment, marital status and PCP visits; 3) need factors - depression treatment, the number of chronic physical and mental health conditions; and 4) the external environment: SEER region and year of cancer diagnosis. 
Figure 1.1: Conceptual Framework: Adapted Andersen Behavioral Model

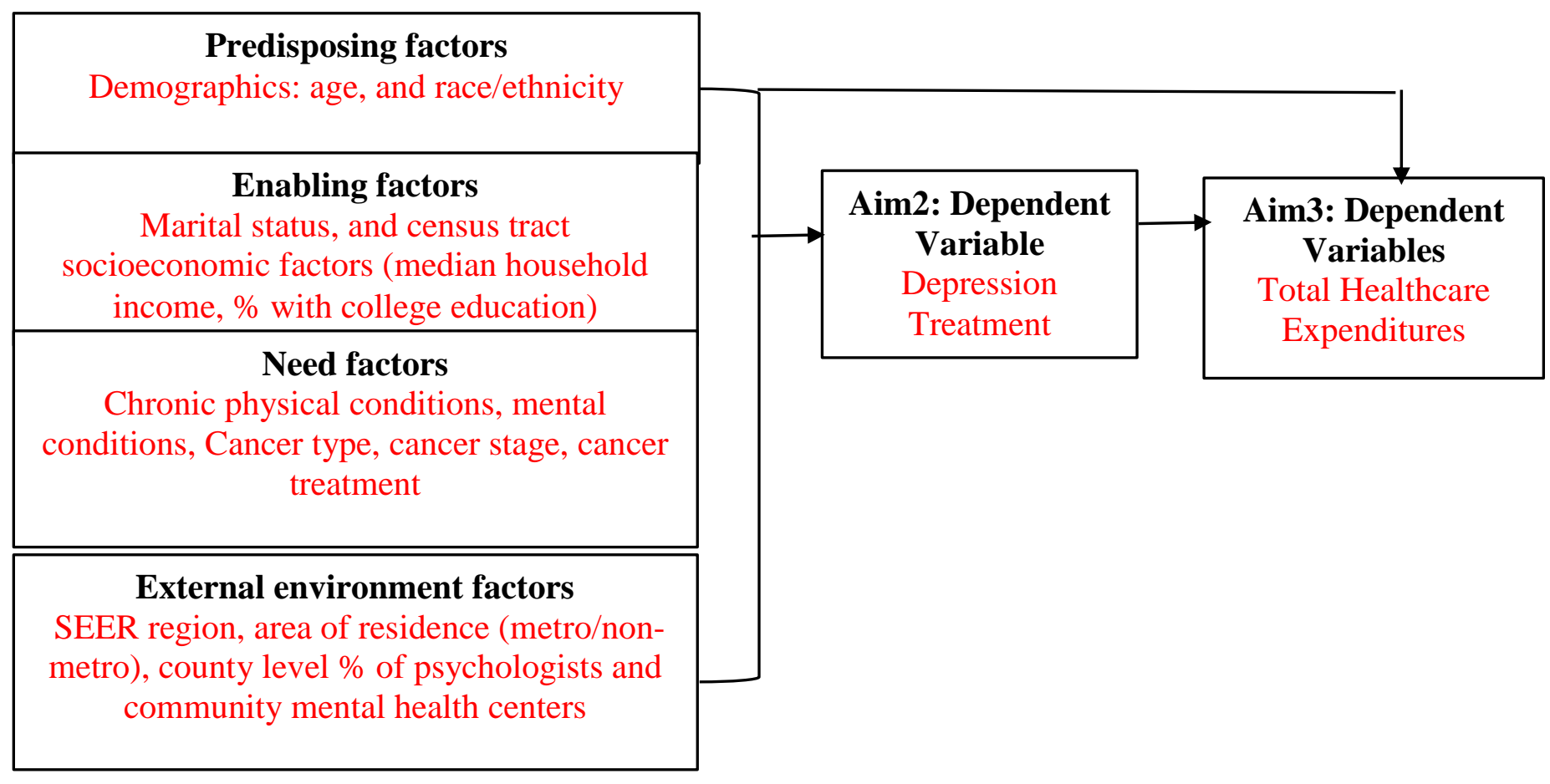




\subsection{References}

(1) Centers for Disease Control and Prevention. Basic Information About Cancer Survivorship. August 25, 2014; Available at: CDC, http://www.cdc.gov/cancer/survivorship/basic_info/index.htm. Accessed 12/06, 2014.

(2) Parry C, Kent EE, Mariotto AB, Alfano CM, Rowland JH. Cancer survivors: a booming population. Cancer Epidemiol Biomarkers Prev 2011 Oct;20(10):1996-2005.

(3) National Cancer Institute. Depression (PDQ). 2014; Available at: http://www.cancer.gov/about-cancer/coping/feelings/depression-pdq\#section/_1.

(4) National Cancer Institute. Adjustment to Cancer: Anxiety and Distress (PDQ®). 2015; Available at: http://www.cancer.gov/cancertopics/pdq/supportivecare/adjustment/Patient/page1.

(5) American Psychiatric Association. Practice guideline for the treatment of patients with major depressive disorder. : American Psychiatric Association; 2010.

(6) Chia VM, O'Malley CD, Danese MD, Lindquist KJ, Gleeson ML, Kelsh MA, et al. Prevalence and incidence of comorbidities in elderly women with ovarian cancer. Gynecol Oncol 2013;129(2):346-352.

(7) Danese MD, O'Malley C, Lindquist K, Gleeson M, Griffiths RI. An observational study of the prevalence and incidence of comorbid conditions in older women with breast cancer. Ann Oncol 2012 07;23(7):1756-1765.

(8) Dalton SO, Laursen TM, Ross L, Mortensen PB, Johansen C. Risk for hospitalization with depression after a cancer diagnosis: a nationwide, population-based study of cancer patients in Denmark from 1973 to 2003. J Clin Oncol 2009 Mar 20;27(9):1440-1445.

(9) Fann JR, Thomas-Rich AM, Katon WJ, Cowley D, Pepping M, McGregor BA, et al. Major depression after breast cancer: a review of epidemiology and treatment. Gen Hosp Psychiatry 2008 Mar-Apr;30(2):112-126.

(10) Linden W, Vodermaier A, MacKenzie R, Greig D. Anxiety and depression after cancer diagnosis: Prevalence rates by cancer type, gender, and age. J Affect Disord 2012;141(2):343351.

(11) Pallavi Balwant Rane. Burden of Colorectal Cancer among the elderly Medicare beneficiaries in West Virginia A comparative analysis with national data. United States -- West Virginia: West Virginia University; 2014.

(12) Kurtz ME, Kurtz JC, Stommel M, Given CW, Given B. Predictors of depressive symptomatology of geriatric patients with colorectal cancer: a longitudinal view. Support Care Cancer 2002 Sep;10(6):494-501.

(13) Jayadevappa R, Malkowicz SB, Chhatre S, Johnson JC, Gallo JJ. The burden of depression in prostate cancer. Psycho-Oncology 2012;21(12):1338-1345.

(14) Prasad SM, Eggener SE, Lipsitz SR, Irwin MR, Ganz PA, Hu JC. Effect of depression on diagnosis, treatment, and mortality of men with clinically localized prostate cancer. J Clin Oncol 2014 Aug 10;32(23):2471-2478.

(15) Weiss Wiesel T,R., Nelson CJ, Tew WP, Hardt M, Mohile SG, Owusu C, et al. The relationship between age, anxiety, and depression in older adults with cancer. Psychooncology 2014 08/06.

(16) Hopwood P, Sumo G, Mills J, Haviland J, Bliss JM. The course of anxiety and depression over 5 years of follow-up and risk factors in women with early breast cancer: results from the UK Standardisation of Radiotherapy Trials (START). The Breast 2010;19(2):84-91. 
(17) Torres MA, Pace TW, Liu T, Felger JC, Mister D, Doho GH, et al. Predictors of depression in breast cancer patients treated with radiation: role of prior chemotherapy and nuclear factor kappa B. Cancer 2013;119(11):1951-1959.

(18) Reece JC, Chan YF, Herbert J, Gralow J, Fann JR. Course of depression, mental health service utilization and treatment preferences in women receiving chemotherapy for breast cancer. Gen Hosp Psychiatry 2013 Jul-Aug;35(4):376-381.

(19) Lee M, Jim HS, Fishman M, Zachariah B, Heysek R, Biagioli M, et al. Depressive symptomatology in men receiving androgen deprivation therapy for prostate cancer: a controlled comparison. Psychooncology 2014 06/13.

(20) Korfage I, Essink-Bot M, Janssens A, Schröder F, De Koning H. Anxiety and depression after prostate cancer diagnosis and treatment: 5-year follow-up. Br J Cancer 2006;94(8):10931098.

(21) Nelson CJ, Weinberger MI, Balk E, Holland J, Breitbart W, Roth AJ. The chronology of distress, anxiety, and depression in older prostate cancer patients. Oncologist 2009

Sep;14(9):891-899.

(22) Llorente MD, Burke M, Gregory GR, Bosworth HB, Grambow SC, Horner RD, et al.

Prostate cancer: a significant risk factor for late-life suicide. The American Journal of Geriatric Psychiatry 2005;13(3):195-201.

(23) Reyes-Gibby C, Anderson K, O., Morrow P, Kanh, Shete S, Hassan S. Depressive Symptoms and Health-Related Quality of Life in Breast Cancer Survivors. J WOMENS HEALTH (15409996) 2012 03;21(3):311-318.

(24) Mariotto AB, Yabroff KR, Shao Y, Feuer EJ, Brown ML. Projections of the cost of cancer care in the United States: 2010-2020. J Natl Cancer Inst 2011 Jan 19;103(2):117-128.

(25) Yabroff KR, Lund J, Kepka D, Mariotto A. Economic burden of cancer in the United States: estimates, projections, and future research. Cancer Epidemiol Biomarkers Prev 2011 Oct;20(10):2006-2014.

(26) Jeffery DD, Linton A. The impact of depression as a cancer comorbidity: rates, health care utilization, and associated costs. Community Oncology 2012;9(7):216-221.

(27) Colleoni M, Mandala M, Peruzzotti G, Robertson C, Bredart A, Goldhirsch A. Depression and degree of acceptance of adjuvant cytotoxic drugs. Lancet 2000 Oct 14;356(9238):13261327.

(28) Goodwin JS, Zhang DD, Ostir GV. Effect of Depression on Diagnosis, Treatment, and Survival of Older Women with Breast Cancer. J Am Geriatr Soc 2004 01;52(1):106-111. (29) DeSantis CE, Lin CC, Mariotto AB, Siegel RL, Stein KD, Kramer JL, et al. Cancer treatment and survivorship statistics, 2014. CA: A Cancer Journal for Clinicians 2014;64(4):252271.

(30) Tedeschini E, Levkovitz Y, Iovieno N, Ameral VE, Nelson JC, Papakostas GI. Efficacy of antidepressants for late-life depression: a meta-analysis and meta-regression of placebocontrolled randomized trials. J Clin Psychiatry 2011 Dec;72(12):1660-1668.

(31) Calati R, Salvina Signorelli M, Balestri M, Marsano A, De Ronchi D, Aguglia E, et al. Antidepressants in elderly: Metaregression of double-blind, randomized clinical trials. J Affect Disord 2013;147(1):1-8.

(32) Costa D, Mogos I, Toma T. Efficacy and safety of mianserin in the treatment of depression of women with cancer. Acta Psychiatr Scand Suppl 1985;320:85-92.

(33) van Heeringen K, Zivkov M. Pharmacological treatment of depression in cancer patients. A placebo-controlled study of mianserin. Br J Psychiatry 1996 10;169(4):440-443. 
(34) Holland JC, Romano SJ, Heiligenstein JH, Tepner RG, Wilson MG. A controlled trial of fluoxetine and desipramine in depressed women with advanced cancer. Psychooncology 1998 07/19;7(4):291-300.

(35) Razavi D, Allilaire JF, Smith M, Salimpour A, Verra M, Desclaux B, et al. The effect of fluoxetine on anxiety and depression symptoms in cancer patients. Acta Psychiatr Scand 1996 Sep;94(3):205-210.

(36) Musselman DL, Somerset WI, Guo Y, Manatunga AK, Porter M, Penna S, et al. A doubleblind, multicenter, parallel-group study of paroxetine, desipramine, or placebo in breast cancer patients (stages I, II, III, and IV) with major depression. J Clin Psychiatry 2006 Feb;67(2):288296.

(37) Laoutidis ZG, Mathiak K. Antidepressants in the treatment of depression/depressive symptoms in cancer patients: a systematic review and meta-analysis. BMC Psychiatry 2013 May 16;13:140-244X-13-140.

(38) Huang AX, Delucchi K, Dunn LB, Nelson JC. A Systematic Review and Meta-analysis of Psychotherapy for Late-Life Depression. The American Journal of Geriatric Psychiatry 2014. (39) Laidlaw K, Davidson K, Toner H, Jackson G, Clark S, Law J, et al. A randomised controlled trial of cognitive behaviour therapy vs treatment as usual in the treatment of mild to moderate late life depression. Int J Geriatr Psychiatry 2008;23(8):843-850.

(40) Cuijpers P, Karyotaki E, Pot AM, Park M, Reynolds CF. Managing depression in older age: Psychological interventions. Maturitas 2014;79(2):160-169.

(41) SAVARD J, SIMARD S, GIGUÈRE I, IVERS H, MORIN CM, MAUNSELL E, et al. Randomized clinical trial on cognitive therapy for depression in women with metastatic breast cancer: psychological and immunological effects. Palliative \& supportive care 2006;4(03):219237.

(42) Qiu J, Chen W, Gao X, Xu Y, Tong H, Yang M, et al. A randomized controlled trial of group cognitive behavioral therapy for Chinese breast cancer patients with major depression. J Psychosom Obstet Gynaecol 2013 Jun;34(2):60-67.

(43) Simpson JSA, Carlson LE, Trew ME. Effect of group therapy for breast cancer on healthcare utilization. Cancer Pract 2001;9(1):19-26.

(44) Kissane DW, Grabsch B, Clarke DM, Smith GC, Love AW, Bloch S, et al. Supportiveexpressive group therapy for women with metastatic breast cancer: survival and psychosocial outcome from a randomized controlled trial. Psychooncology 2007 Apr;16(4):277-286.

(45) Hart SL, Hoyt MA, Diefenbach M, Anderson DR, Kilbourn KM, Craft LL, et al. Metaanalysis of efficacy of interventions for elevated depressive symptoms in adults diagnosed with cancer. J Natl Cancer Inst 2012 Jul 3;104(13):990-1004.

(46) Thompson LW, Coon DW, Gallagher-Thompson D, Sommer BR, Koin D. Comparison of desipramine and cognitive/behavioral therapy in the treatment of elderly outpatients with mildto-moderate depression. The American journal of geriatric psychiatry 2001;9(3):225-240. (47) Reynolds III CF, Miller MD, Pasternak RE, Frank E, Perel JM, Cornes C, et al. Treatment of bereavement-related major depressive episodes in later life: a controlled study of acute and continuation treatment with nortriptyline and interpersonal psychotherapy. 2014. (48) Rodriguez Vega B, Palao A, Torres G, Hospital A, Benito G, Perez E, et al. Combined therapy versus usual care for the treatment of depression in oncologic patients: a randomized controlled trial. Psychooncology 2011 Sep;20(9):943-952.

(49) Howell D, Keller-Olaman S, Oliver T, Hack T, Broadfield L, Biggs K, et al. A panCanadian practice guideline: screening, assessment and care of psychosocial distress (depression, 
anxiety) in adults with cancer. Toronto: Canadian Partnership Against Cancer (Cancer Journey Action Group) and the Canadian Association of Psychosocial Oncology 2010.

(50) Rodin G, Lloyd N, Katz M, Green E, Mackay JA, Wong RK, et al. The treatment of depression in cancer patients: a systematic review. Support Care Cancer 2007 Feb;15(2):123136.

(51) Andersen BL, DeRubeis RJ, Berman BS, Gruman J, Champion VL, Massie MJ, et al. Screening, assessment, and care of anxiety and depressive symptoms in adults with cancer: an American Society of Clinical Oncology guideline adaptation. J Clin Oncol 2014 May 20;32(15):1605-1619.

(52) Findley PA, Shen C, Sambamoorthi U. Depression Treatment Patterns among Elderly with Cancer. Depress Res Treat 2012;2012:676784.

(53) Rane PB, Sambamoorthi U, Madhavan S. Depression treatment in individuals with cancer: a comparative analysis with cardio-metabolic conditions. Health Psychology Research

2013;1(1):e2.

(54) Giese-Davis J, Collie K, Rancourt KM, Neri E, Kraemer HC, Spiegel D. Decrease in depression symptoms is associated with longer survival in patients with metastatic breast cancer: a secondary analysis. J Clin Oncol 2011 Feb 1;29(4):413-420.

(55) Navari RM, Brenner MC, Wilson MN. Treatment of depressive symptoms in patients with early stage breast cancer undergoing adjuvant therapy. Breast Cancer Res Treat 2008 Nov;112(1):197-201.

(56) National Cancer Institute. Surveillance, Epidemiology and End Results (SEER) Registry Groupings for Analyses. 2015; Available at: http://seer.cancer.gov/registries/terms.html. (57) National Cancer Institute. SEER-Medicare: How the SEER \&amp; Medicare Data are Linked. 2015; Available at:

http://healthcaredelivery.cancer.gov/seermedicare/overview/linked.html. Accessed 04/03, 2016. (58) Department of Health and Human Services. Area Health and Resources Files (AHRF). 2015; Available at: http://ahrf.hrsa.gov/overview.htm.

(59) Marmot M, Wilkinson R. Social determinants of health. : Oxford University Press; 2005.

(60) Andersen RM. Revisiting the behavioral model and access to medical care: does it matter? J Health Soc Behav 1995:1-10. 


\section{STRUCTURE OF THIS DISSERTATION}

The current dissertation was organized as follows: Chapter One reviews the current literature on depression diagnosis among elderly with cancer and provides a justification for the aims of the current dissertation. Furthermore, Chapter One describes the data sources, provides the rationale for the selection of cancer types and the conceptual frameworks that guide the selection of variables in the current dissertation. The methods to conduct the studies of the current dissertation are described in each chapter. Chapter Two focuses on the risk of newly-diagnosed depression among elderly with incident cancer; Chapter Three focuses on the rates and factors associated with depression treatment among elderly with newly-diagnosed depression and incident cancer; Chapter Four focuses on the association between depression treatment and shortterm healthcare expenditures among elderly with newly-diagnosed depression and incident cancer. Finally, Chapter Five includes a summary of findings, implications, strengths and limitations and a conclusion from all the findings from the studies of the current dissertation. 


\section{Chapter 2 \\ Cancer Types and the Risk of Newly-Diagnosed Depression among Elderly Medicare Beneficiaries with Incident Breast, Colorectal and Prostate Cancer}

\subsection{Abstract}

\section{Purpose}

Elderly individuals (age > 65 years) with cancer are at high risk for newly-diagnosed depression after cancer diagnosis. It is not known whether the risk of newly-diagnosed depression varies by cancer type. Therefore, this study examined the variations in the risk of newly-diagnosed depression by cancer types among elderly individuals with cancer.

\section{Patients and Methods}

This study utilized a retrospective cohort study design and used data from the linked Surveillance, Epidemiology and End Results (SEER)-Medicare files. Elderly individuals (age > 65 years) with incident breast, colorectal, and prostate cancer diagnosed between 2007 and 2011 $(\mathrm{N}=53,821)$ were followed for 12 months after cancer diagnosis. The risk of newly-diagnosed depression after cancer diagnosis was identified using the International Classification of Diseases, $9^{\text {th }}$ Edition, Clinical Modification (ICD-9-CM) Codes. Complementary log-log regression was used to examine the association between cancer types and the risk of newlydiagnosed depression after adjusting for other risk factors for depression.

\section{Results}

This study found a significantly higher percentage of newly-diagnosed depression among women with colorectal cancer as compared to women with breast cancer (5.8\% vs. $3.9 \%)$, and among men with colorectal cancer as compared to men with prostate cancer (3.4\% vs. $1.6 \%)$. In the adjusted analysis, women with colorectal cancer had $28.0 \%$ higher risk of newly-diagnosed depression as compared to women with breast cancer (Adjusted Risk Ratio $(A R R)=1.28$ 
[95\%CI, 1.12-1.46]) and men with colorectal cancer had 106.0\% higher risk of newly-diagnosed depression as compared to men with prostate cancer (ARR $=2.06$ [95\% CI, 1.65-2.58]).

\section{Conclusion}

The study findings identified cancer types with a high risk of newly-diagnosed depression after cancer diagnosis who might benefit from routine depression screening and monitoring to help in early detection and treatment of depression.

Keywords: Cancer, oncology, incident, depression, risk, Medicare. 


\subsection{Introduction}

Depression is a highly prevalent mental health condition among elderly cancer survivors. It is estimated that 5-25\% of cancer survivors suffer from depression (1-5). Further, the risk of newly-diagnosed depression is higher among cancer survivors when compared to age-sex matched non-cancer cohorts, as two retrospective studies have shown (6,7). One study using the Surveillance Epidemiology and End Results (SEER)-Medicare data found that women with breast cancer had 58\% higher risk of newly-diagnosed depression within a year after cancer diagnosis as compared to their matched non-cancer counterparts (Adjusted Risk Ratio $(A R R)=1.58 ; 95 \% C I, 0.84-3.0)(6)$. A second study, among adults with different cancer types found that men with colorectal cancer had $67 \%$ higher risk of newly-diagnosed depression as compared to their age-sex matched non-cancer cohort (Risk Ratio $(\mathrm{RR})=1.16$; 95\% CI, 0.901.51) (7).

The risk of newly-diagnosed depression maybe higher among some cancer types as compared to others due to differences in survival prognosis and stage at cancer diagnosis $(6,8)$. The estimated 5-year relative survival rate is $65 \%$ for individuals with colorectal cancer as compared to $89 \%$ for women with breast cancer and $99 \%$ for men with prostate cancer (8). Danese and colleagues found that elderly women with breast cancer diagnosed at an advanced stage (stage IV) had a higher risk of newly-diagnosed depression as compared to those diagnosed at an early stage (Stage $\mathrm{I})(\mathrm{RR}=5.03,95 \% \mathrm{CI}=3.45-7.35)(6)$. Colorectal cancer is more likely to be diagnosed at an advanced stage and to have a poor survival prognosis as compared to breast and prostate cancers $(6,8)$. Therefore, colorectal cancer patients may have a higher risk of newly-diagnosed depression as compared to those with breast or prostate cancer. 
Although the risk of newly-diagnosed depression may vary by cancer type, there is a paucity of research on the variations in the risk of newly-diagnosed depression by cancer type. Identifying cancer survivors, who are at high risk of newly-diagnosed depression, is important because depression can negatively affect the health-related quality of life (HRQoL) and survival after cancer diagnosis $(1,3,9)$. Therefore, the objective of this study was to examine the variations in the risk of newly-diagnosed depression by cancer types among elderly Medicare beneficiaries with incident breast, colorectal and prostate cancer. These cancers were selected because they are projected to be the most common cancer types by 2024 and in which depression is highly prevalent (8). This study evaluated the risk of newly-diagnosed depression by cancer types with the following comparisons: women with breast cancer compared to women with colorectal and men with prostate cancer compared to men with colorectal cancer.

\subsection{Conceptual Framework}

This study adapted the determinants-of-health model by Marmot and Wilkinson (1999) (10). This model posits that many dimensions affect an individual's health or disease/illness (e.g., newly-diagnosed depression). These dimensions are an individual's physical make-up, social support, access to care, health behaviors, psychological factors, biological risk factors, treatment factors, community resources, and geographical region.

\subsection{Methods}

\subsubsection{Data Sources}

The current study linked data from several sources including the SEER-Medicare linked database, ACS estimates from census, and the AHRF files. The detailed description of the data sources are provided in Chapter 1. 


\subsubsection{Study Design}

This study utilized a retrospective cohort study design with a baseline and follow-up period. It considered the date of cancer diagnosis as the index date. This study defined the 12 months before the index date as the baseline period and the 12 months after index date as the follow-up period.

\subsubsection{Study population}

\section{Identification of Cancer Survivors}

The study population composed of elderly cancer patients, age 66 years and older who were diagnosed with primary only incident breast, colorectal, and prostate cancer between 2007 and 2011. An age of 66 years and above was imposed to allow 12-month baseline period before cancer diagnosis. The cancer types (breast, colorectal and prostate cancer) were identified using the primary site variable and the International Classification of Diseases for Oncology, 3rd Edition (ICD-O-3) histology codes.

\section{Depression-free Individuals at Cancer Diagnosis}

This study identified a depression-free cohort among individuals with incident cancer. To ensure that the incident cancer cases were depression free, a validated criteria from the National Committee for Quality Assurance (NCQA) was used (13). According to the NCQA, an individual is considered to be depression-free at index date, if he or she did not receive antidepressants 90 days before the index date (i.e. date of cancer diagnosis) or did not have any depression diagnosis 120 days before the index date.

\section{Other inclusion/exclusion criteria}

This study required that all individuals have continuous enrollment in Medicare part A, B and no enrollment in managed care plans during the baseline and follow-up periods. To identify antidepressants 90 days before the index date, this study also required that individuals have 
continuous enrollment in Medicare part D three months before cancer diagnosis. This study excluded individuals with an unknown stage at diagnosis or those diagnosed through autopsy or death certificate, and those who died during the follow-up period of 12 months. Appendix 2.1 demonstrates the analytical population selection process.

\subsubsection{Dependent Variable: Newly-diagnosed Depression (Yes/No)}

The dependent variable was newly-diagnosed depression after cancer diagnosis (newlydiagnosed depression) in breast, colorectal and prostate cancer survivors. To identify depression diagnosis, a validated algorithm developed by the Centers for Medicare and Medicaid Services (CMS) Chronic Conditions Data Warehouse (CCW) was used (14). Individuals with at least one inpatient visit or one outpatient visit with depression diagnosis during the 12 month follow-up period were classified as having a newly-diagnosed depression. This study identified depression diagnosis using the International Classifications of Diseases $-9^{\text {th }}$ edition, Clinical Modification Codes (ICD-9-CM). The ICD-9-CM codes were: 296.2 , 296.3, 298.0, 300.4, 309.1, and 311.0. These codes are widely used to identify depression diagnoses among Medicare beneficiaries $(1,15,16)$.

\subsubsection{Key Independent Variable}

This study selected the independent variables based on the Determinants of Health Model. The key independent variable was cancer types which is considered a biological risk factor. Cancer types were: women with breast cancer, women with colorectal cancer, men with colorectal cancer and men with prostate cancer. 


\subsubsection{Other Independent Variables}

Individual physical makeup variables included age in years at cancer diagnosis (66-69, 70-74, 75-79, >=80), and race (White, African American, Hispanic, and others). Social Support included marital status (married, divorced/separated/widow and never married). Access to care was measured by Primary Care Physicians (PCP) visit quartiles during 12 months before cancer diagnosis, census-tract median household income quartiles, and percentage with less than high school education level quartiles. Health behavior consisted of tobacco use in the baseline period. Psychological factors included the presence of anxiety during the baseline period. Biological risk factors were: the stage of cancer at diagnosis (based the American Joint Committee on Cancer (AJCC) grouped staging) and chronic physical conditions during the baseline period. The chronic conditions categories included: cardiovascular disease (heart disease (cardiac arrythmia, coronary heart disease, congestive heart faliure), diabetes, hyperlipidemia, hypertension, stroke), respiratory disease (asthma, chronic obstructive pulmonary disease), and musculoskeletal disease (arthritis, and osteoporosis) (17). These conditions were selected based on the Multiple Chronic Conditions working group framework for research, planning, programs and policy purposes (17). These conditions were identified based on a validated algorithm developed by the CMS Chronic Conditions Data Warehouse (14); individuals had at least one inpatient visit or two outpatient visits during the baseline period. Treatment factors included cancer treatment during the six months after cancer diagnosis which included chemotherapy, radiation therapy, hormone therapy, and surgery. Cancer treatment was identified from claims data using the ICD-9-CM, Health Healthcare Common Procedure Coding System (HCPCS) and the Common Procedural Terminology (CPT) codes. Community Resources consisted of the presence or absence of county-level community mental health clinics (CMHC) and whether the county of residence was designated as health professional shortage area (HPSA) for mental health. Geographical location 
consisted of the SEER region (Northeast, South, North-central, West), and county metro status (metro/non-metro) which was defined using 2013 urban/rural continuum codes from the United States Department of Agriculture's Economic Research Service. To control for changes in patterns of diagnosis over time, year of cancer diagnosis was also included as one of the independent variables.

\subsection{Statistical Analysis}

This study used chi-square tests to test the significance of unadjusted differences in baseline characteristics and newly-diagnosed depression. A complementary log-log regressions analysis were used to examine the adjusted associations between cancer types and the risk of newly-diagnosed depression with four different models. In model I, only cancer types was included without controlling for other factors. Model II controlled for individual physical makeup (e.g., age, race) and social support. Model III additionally controlled for access to care, health behaviors, biological risk factors, and psychological factors. Model 4 additionally controlled for treatment factors, county-level community resources, geographical region, and the year at cancer diagnosis. All statistical analyses were carried out in SAS 9.4 (SAS Institute Inc., Cary, NC).

\subsection{RESULTS}

\subsubsection{Characteristics of the study population}

The study population consisted of 53,821 elderly fee-for-service Medicare beneficiaries with incident breast, colorectal, and prostate cancer who were depression-free at the time of cancer diagnosis. In the study populations, $36.4 \%$ were women with breast cancer; $12.5 \%$ were women with colorectal cancer; $9.5 \%$ were men with colorectal cancer, and $41.6 \%$ were men with prostate cancer (data not shown in tabular form). The majority of the study population were White $(80.7 \%)$, married (52.5\%). Eighty-one percent of the counties were metro areas, $51.0 \%$ of 
the counties had a shortage of mental health professionals and $48.9 \%$ did not have community mental health centers.

\subsubsection{Cancer types and newly-diagnosed depression}

Overall, 3.3\% of elderly Medicare with breast, colorectal and prostate cancer had newlydiagnosed depression during the follow-up year. A chi-square analysis showed that newlydiagnosed depression rates significantly differed by cancer types $(\mathrm{P}<0.001)$ (Table 2$)$. This study found a significantly higher percentage of newly-diagnosed depression among women with colorectal cancer as compared to women with breast cancer (5.8\% vs. 3.9\%), and among men with colorectal cancer as compared to men with prostate cancer (3.4\% vs. $1.6 \%)$.

Tables 3 displays the risk ratios (RR) and adjusted RR (ARR) of newly-diagnosed depression by cancer types from multivariable complementary log-log regression analyses. In model 1, which included only cancer types, women with colorectal cancer had a $53 \%$ higher risk of newly-diagnosed depression $(\mathrm{RR}=1.53$ [95\%CI, 1.36-1.73]) as compared to women with breast cancer; men with colorectal cancer had a $111 \%$ higher risk of newly-diagnosed depression( $\mathrm{ARR}=2.11$ [95\% CI, 1.76-2.53]) as compared to men with prostate cancer. This association between cancer types and the risk of newly-diagnosed depression persisted in Models II to IV. Even after controlling for all the risk factors and the year at cancer diagnosis in the final model, women with colorectal cancer had $28 \%$ higher risk of newly-diagnosed depression (ARR $=1.28,95 \% \mathrm{CI}, 1.12-1.46)$ as compared to women with breast cancer. Men with colorectal cancer had a $106 \%$ higher risk of newly-diagnosed depression $(\mathrm{ARR}=2.06,95 \% \mathrm{CI}, 1.65-2.58)$ as compared to men with prostate cancer.

\subsubsection{Sex and newly-diagnosed depression}

This study found a significantly higher percentage of newly-diagnosed depression among women with colorectal cancer as compared to men with colorectal cancer (5.8\% vs. 3.4\%). 
Tables 4 displays the RR and ARR of newly-diagnosed depression by sex. After controlling for all the risk factors and the year at cancer diagnosis, women with colorectal cancer had a 52\% higher risk of newly-diagnosed depression as compared to men with colorectal cancer (ARR= $1.52[95 \% \mathrm{CI}, 1.26-1.83])$.

Cancer stage and newly-diagnosed depression

This study found that cancer survivors diagnosed at stage II had 22\% higher risk of newly-diagnosed depression as compared to those diagnosed at stage I (ARR $=1.22$ [95\%CI, 1.06-1.40]). Cancer survivors diagnosed at stage III had $41 \%$ higher risk of newly-diagnosed depression as compared to those diagnosed at stage I (ARR $=1.41$ [95\%CI, 1.19-1.68]). This study also found that cancer survivors diagnosed at stage IV had $63 \%$ higher risk of newlydiagnosed depression as compared to those diagnosed at stage I (ARR $=1.63$ [95\%CI, 1.312.03]). The RR and ARR of newly-diagnosed depression by other variables are displayed in Appendix 1.1.

\subsection{Discussion}

This is the first study to date that has evaluated the relationship between cancer types and the risk of newly-diagnosed depression after cancer diagnosis among elderly individuals with incident breast, colorectal and prostate cancer. In our study, the rate of newly-diagnosed depression was highest (5.8\%) among women with colorectal cancer and lowest (1.6\%) among men with prostate cancer. The rate of newly-diagnosed depression among women with breast cancer was $3.9 \%$ in our study. This rate is higher than the one estimate (2.4\%) available from the published literature (6). The higher incidence of depression among women with breast cancer in our study may be due to differences in observation years as it has been reported that the percentage of diagnosed depression among elderly Medicare beneficiaries increased over time 
(18). While Danese and colleague used data from 1998 through 2002, the current study utilized data from 2007 through 2012 (6). No other studies have examined the incidence of depression among patients with prostate and colorectal cancer. Therefore, the incidence of depression for these cancer types found in our study were not compared to estimates from other studies.

This study found that the risk of newly-diagnosed depression varied by cancer type.

Women with colorectal cancer had a higher risk of newly-diagnosed depression as compared to women with breast cancer, even after adjustments for a comprehensive list of risk factors. Similarly, men with colorectal cancer had a higher risk of newly-diagnosed depression as compared to men with prostate cancer. These findings were robust in different model specifications and they provide new evidence on the variable risk of depression by cancer type. As stated in the introduction, it is plausible that poor survival prognosis and late stage at cancer diagnosis may have increased the risk of depression among colorectal cancer survivors. For example, in the current study, women and men colorectal cancer survivors were more likely to be diagnosed at an advanced stage as compared to women with breast cancer and men with prostate cancer. In multivariable analyses, advanced stage at cancer diagnosis was associated with higher risk of newly-diagnosed depression as compared to early-stage at cancer diagnosis. This finding is consistent with prior published studies that documented that advanced stage at cancer diagnosis is associated with high risk of depression $(6,19)$. This study also found that women with colorectal cancer had 52\% higher risk of newly-diagnosed depression as compared to men with colorectal cancer. This finding confirmed sex differences in the risk of depression which have been documented in the previous literature (18).

Clinical practice and policy implications 
Findings from our study have clinical practice and policy implications. Our findings suggest that oncologists and other healthcare providers may need to screen for depression, especially individuals with colorectal cancer and those who are diagnosed with an advanced cancer stage. Indeed, the American Society of Clinical Oncology guideline recommends screening for depression regardless of cancer types or stage at cancer diagnosis.(20) Cancer is a dominant condition and most of the care is usually directed towards treating cancer, therefore, such screening is important to diagnose depression before it becomes severe. It is reported that, as compared to non-cancer patients, cancer patients who were screened for depression often exhibited severe depressive symptoms (21); for these individuals early screening for depression is needed. Screening should occur not only in the oncology setting but also in the primary care setting, as Medicare provides reimbursement for annual screenings for depression in primary care settings (22). Our findings indicate that patients who visited a primary care providers have a higher incidence of depression diagnosis. Therefore, it is important for cancer survivors to continue visits to their primary care physicians. A national survey of physicians conducted by the Cancer Care Outcomes Research and Surveillance Consortium has shown that PCPs are more involved in detection and treatment of depression in cancer patients as compared to oncologists (50\% vs. 18\%) (23). Therefore, coordinated care between oncologists and primary care providers is needed so that oncologists can refer cancer patients to primary care providers for depression screening.

\section{Study strengths and limitations}

This study's findings need to be interpreted in the context of its advantages and limitations. One advantage is that this study used linked cancer registry and claims data in which a large cohort of patients were followed across a variety of health providers. Another advantage 
is that this study has also controlled for a comprehensive list of factors, including cancer stage and cancer treatment, that may affect the risk of newly-diagnosed depression. A third advantage is that the availability of cancer diagnosis dates enabled us to identify newly-diagnosed depression. This study also has some limitations. As the study population was restricted to feefor-service Medicare beneficiaries and those residing in SEER regions, the study findings are not generalizable to all Medicare beneficiaries. It is plausible that depression may be underrecognized and the rate of newly-diagnosed depression may have been underestimated. While many variables that may be associated with the risk of newly-diagnosed depression were captured, some important variables such as family history of depression, obesity, and physical activity were lacking.

\subsection{Conclusion}

This study has provided new evidence that there is variation in the risk of newlydiagnosed depression by cancer type. It identified cancer survivors who are more likely to suffer from depression after cancer diagnosis. Healthcare providers of cancer survivors may need to screen routinely individuals at high risk for depression, specifically those with colorectal cancer and those with an advanced stage of cancer at diagnosis. 


\subsection{References}

(1) Jayadevappa R, Malkowicz SB, Chhatre S, Johnson JC, Gallo JJ. The burden of depression in prostate cancer. Psycho- Oncology 2012;21(12):1338-1345.

(2) Prasad SM, Eggener SE, Lipsitz SR, Irwin MR, Ganz PA, Hu JC. Effect of depression on diagnosis, treatment, and mortality of men with clinically localized prostate cancer. J Clin Oncol 2014 Aug 10;32(23):2471-2478.

(3) Pallavi Balwant Rane. Burden of Colorectal Cancer among the elderly Medicare beneficiaries in West Virginia A comparative analysis with national data. United States -- West Virginia: West Virginia University; 2014.

(4) Kurtz ME, Kurtz JC, Stommel M, Given CW, Given B. Predictors of depressive symptomatology of geriatric patients with colorectal cancer: a longitudinal view. Support Care Cancer 2002 Sep;10(6):494-501.

(5) Fann JR, Thomas-Rich AM, Katon WJ, Cowley D, Pepping M, McGregor BA, et al. Major depression after breast cancer: a review of epidemiology and treatment. Gen Hosp Psychiatry 2008 Mar-Apr;30(2):112-126.

(6) Danese MD, O'Malley C, Lindquist K, Gleeson M, Griffiths RI. An observational study of the prevalence and incidence of comorbid conditions in older women with breast cancer. Ann Oncol 2012 07;23(7):1756-1765.

(7) Dalton SO, Laursen TM, Ross L, Mortensen PB, Johansen C. Risk for hospitalization with depression after a cancer diagnosis: a nationwide, population-based study of cancer patients in Denmark from 1973 to 2003. J Clin Oncol 2009 Mar 20;27(9):1440-1445.

(8) DeSantis CE, Lin CC, Mariotto AB, Siegel RL, Stein KD, Kramer JL, et al. Cancer treatment and survivorship statistics, 2014. CA: A Cancer Journal for Clinicians 2014;64(4):252-271.

(9) Reyes-Gibby C, Anderson K, O., Morrow P, Kanh, Shete S, Hassan S. Depressive Symptoms and Health-Related Quality of Life in Breast Cancer Survivors. J WOMENS HEALTH (15409996) 2012 03;21(3):311-318.

(10) Marmot M, Wilkinson R. Social determinants of health. : Oxford University Press; 2005.

(11) National Cancer Institute. Surveillance, Epidemiology and End Results (SEER) Registry Groupings for Analyses. 2015; Available at: http://seer.cancer.gov/registries/terms.html.

(12) Department of Health and Human Services. Area Health and Resources Files (AHRF). 2015; Available at: http://ahrf.hrsa.gov/overview.htm.

(13) National Committee for Quality Assurance. The Healthcare Effectiveness Data and Information Set (HEDIS). Technical Specifications. 2008; Available at:

http://www.ncqa.org/HEDISQualityMeasurement.aspx. Accessed 11/29, 2014.

(14) Chronic Conditions Data Warehouse. CCW Chronic Conditions Algorithms. 2016;

Available at: https://www.ccwdata.org/web/guest/condition-categories.

(15) Findley PA, Shen C, Sambamoorthi U. Depression Treatment Patterns among Elderly with Cancer. Depress Res Treat 2012;2012:676784.

(16) Zhang AY, Cooper GS. Recognition of Depression and Anxiety among Elderly Colorectal Cancer Patients. Nurs Res Pract 2010;2010:693961.

(17) Goodman RA. Defining and measuring chronic conditions: imperatives for research, policy, program, and practice. Preventing chronic disease 2013;10.

(18) Akincigil A, Olfson M, Walkup JT, Siegel MJ, Kalay E, Amin S, et al. Diagnosis and treatment of depression in older community-dwelling adults: 1992-2005. J Am Geriatr Soc 2011;59(6):1042-1051. 
(19) Chia VM, O'Malley CD, Danese MD, Lindquist KJ, Gleeson ML, Kelsh MA, et al. Prevalence and incidence of comorbidities in elderly women with ovarian cancer. Gynecol Oncol 2013;129(2):346-352.

(20) Andersen BL, DeRubeis RJ, Berman BS, Gruman J, Champion VL, Massie MJ, et al. Screening, assessment, and care of anxiety and depressive symptoms in adults with cancer: an American Society of Clinical Oncology guideline adaptation. J Clin Oncol 2014 May 20;32(15):1605-1619.

(21) Hopko DR, Bell JL, Armento ME, Robertson SM, Hunt MK, Wolf NJ, et al. The phenomenology and screening of clinical depression in cancer patients. J Psychosoc Oncol 2007;26(1):31-51.

(22) Centers for Medicare and Medicaid Services. Decision Memo for Screening for Depression in Adults

. 2011; Available at: https://www.cms.gov/medicare-coverage-database/details/nca-decisionmemo.aspx?NCAId=251, 2016.

(23) Klabunde CN, Ambs A, Keating NL, He Y, Doucette WR, Tisnado D, et al. The role of primary care physicians in cancer care. Journal of general internal medicine 2009;24(9):10291036. 
Table 2.1

Selected Characteristics of the Study Population by Cancer Types

Elderly Fee-for-service Medicare beneficiaries with Incident Breast, colorectal, and Prostate Cancer SEER-Medicare database 2007-2012

\begin{tabular}{|c|c|c|c|c|c|c|c|c|c|c|}
\hline & \multicolumn{2}{|c|}{ Breast Cancer } & \multirow{2}{*}{$\begin{array}{c}\begin{array}{l}\text { Women } \\
\text { Colorectal }\end{array} \\
\mathbf{N} \\
\end{array}$} & \multicolumn{3}{|c|}{$\begin{array}{l}\text { Men } \\
\text { Colorectal } \\
\end{array}$} & \multicolumn{2}{|l|}{$\begin{array}{l}\text { Prostate } \\
\text { Cancer }\end{array}$} & \multirow[b]{2}{*}{ chisq } & \multirow[b]{2}{*}{ sig } \\
\hline & $\mathbf{N}$ & $\%$ & & $\%$ & $\mathbf{N}$ & $\%$ & $\mathbf{N}$ & $\%$ & & \\
\hline \multicolumn{11}{|c|}{ Individual Physical Make-up } \\
\hline Age in years & & & & & & & & & 3104.2 & $* * *$ \\
\hline $66-69$ years & 4,768 & 34.0 & 1,042 & 7.4 & 1,171 & 8.4 & 7,026 & 50.2 & & \\
\hline $70-74$ years & 5,229 & 33.1 & 1,389 & 8.8 & 1,434 & 9.1 & 7,739 & 49.0 & & \\
\hline $75-79$ years & 4,199 & 37.2 & 1,439 & 12.8 & 1,100 & 9.8 & 4,538 & 40.2 & & \\
\hline 80 years or older & 5,382 & 42.2 & 2,877 & 22.6 & 1,389 & 10.9 & 3,099 & 24.3 & & \\
\hline Race & & & & & & & & & 283.1 & $* * *$ \\
\hline White & 16,358 & 37.7 & 5,304 & 12.2 & 3,986 & 9.2 & 17,732 & 40.9 & & \\
\hline AA & 1,627 & 32.7 & 719 & 14.5 & 374 & 7.5 & 2,253 & 45.3 & & \\
\hline Others & 1,593 & 29.1 & 724 & 13.2 & 734 & 13.4 & 2,417 & 44.2 & & \\
\hline \multicolumn{11}{|c|}{ Social Support } \\
\hline Marital Status & & & & & & & & & 8300.9 & $* * *$ \\
\hline Married & 8,126 & 28.8 & 2,152 & 7.6 & 3,309 & 11.7 & 14,663 & 51.9 & & \\
\hline Never married & 1,799 & 37.4 & 625 & 13.0 & 567 & 11.8 & 1,820 & 37.8 & & \\
\hline Sep/div/wid & 8,719 & 54.1 & 3,625 & 22.5 & 972 & 6.0 & 2,800 & 17.4 & & \\
\hline Unknown & 934 & 20.1 & 345 & 7.4 & 246 & 5.3 & 3,119 & 67.2 & & \\
\hline \multicolumn{11}{|c|}{ Access to care } \\
\hline Primary care visits & & & & & & & & & 352.9 & $* * *$ \\
\hline Quartile 1 (Low) & 2,636 & 33.9 & 844 & 10.8 & 865 & 11.1 & 3,440 & 44.2 & & \\
\hline Quartile 2 & 1,929 & 35.2 & 527 & 9.6 & 513 & 9.4 & 2,516 & 45.9 & & \\
\hline Quartile 3 & 8,242 & 40.0 & 2,474 & 12.0 & 1,890 & 9.2 & 7,986 & 38.8 & & \\
\hline Quartile 4 (High) & 6,771 & 33.9 & 2,902 & 14.5 & 1,826 & 9.1 & 8,460 & 42.4 & & \\
\hline \multicolumn{11}{|c|}{ Health behaviors } \\
\hline Tobacco Use & & & & & & & & & 99.2 & $* * *$ \\
\hline Yes & 514 & 27.0 & 213 & 11.2 & 244 & 12.8 & 931 & 48.9 & & \\
\hline No & 19,064 & 36.7 & 6,534 & 12.6 & 4,850 & 9.3 & 21,471 & 41.4 & & \\
\hline \multicolumn{11}{|c|}{ Psychological factors } \\
\hline Anxiety-PTSD & & & & & & & & & 270.3 & $* * *$ \\
\hline Yes & 1,159 & 48.1 & 414 & 17.2 & 170 & 7.0 & 669 & 27.7 & & \\
\hline No & 18,419 & 35.8 & 6,333 & 12.3 & 4,924 & 9.6 & 21,733 & 42.3 & & \\
\hline
\end{tabular}

Continued, 
Table 2.1

Selected Characteristics of the Study Population by Cancer Types

Elderly Fee-for-service Medicare beneficiaries with Incident Breast, colorectal, and Prostate Cancer SEER-Medicare database 2007-2012

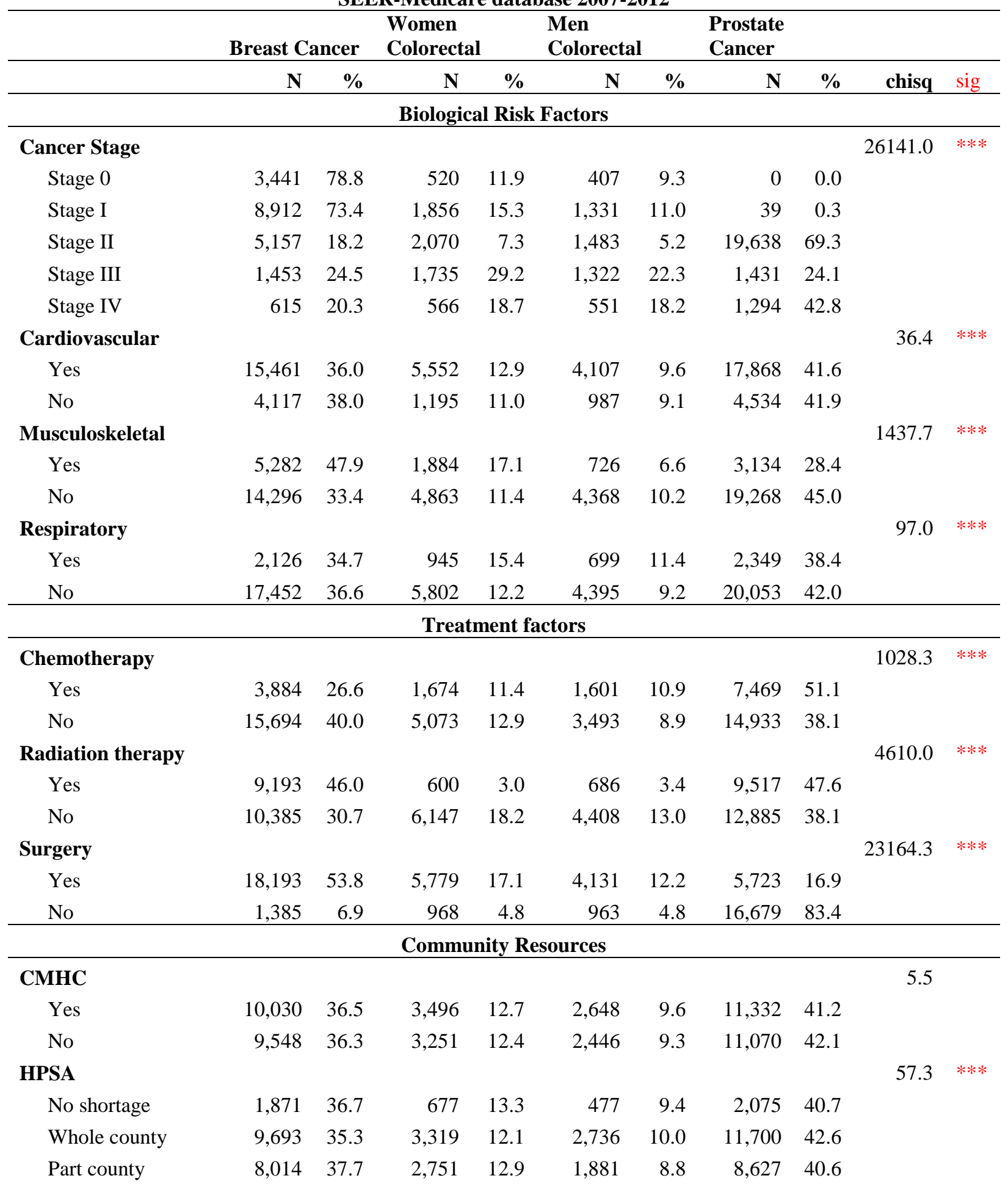

Continued, 
Table 2.1

Selected Characteristics of the Study Population by Cancer Types

Elderly Fee-for-service Medicare beneficiaries with Incident Breast, colorectal, and Prostate Cancer SEER-Medicare database 2007-2012

\begin{tabular}{|c|c|c|c|c|c|c|c|c|c|c|}
\hline & Breast $\mathrm{C}$ : & ncer & $\begin{array}{l}\text { Women } \\
\text { Colorecta }\end{array}$ & & $\begin{array}{l}\text { Men } \\
\text { Colorectal }\end{array}$ & & $\begin{array}{l}\begin{array}{l}\text { Prostate } \\
\text { Cancer }\end{array} \\
\end{array}$ & & & \\
\hline & $\mathbf{N}$ & $\%$ & $\mathbf{N}$ & $\%$ & $\mathbf{N}$ & $\%$ & $\mathbf{N}$ & $\%$ & chisq & sig \\
\hline \multicolumn{11}{|c|}{ Geographical Location } \\
\hline Region & & & & & & & & & 181.4 & $* * *$ \\
\hline Northeast & 3,852 & 37.7 & 1,515 & 14.8 & 942 & 9.2 & 3,919 & 38.3 & & \\
\hline South & 5,003 & 36.9 & 1,733 & 12.8 & 1,312 & 9.7 & 5,516 & 40.7 & & \\
\hline North-central & 2,603 & 36.8 & 987 & 13.9 & 627 & 8.9 & 2,863 & 40.4 & & \\
\hline West & 8,120 & 35.4 & 2,512 & 10.9 & 2,213 & 9.6 & 10,104 & 44.0 & & \\
\hline Metro status & & & & & & & & & 9.2 & $*$ \\
\hline Metro & 15,947 & 36.5 & 5,460 & 12.5 & 4,056 & 9.3 & 18,196 & 41.7 & & \\
\hline Non-metro & 3,631 & 35.7 & 1,287 & 12.7 & 1,038 & 10.2 & 4,206 & 41.4 & & \\
\hline Cancer diagnosis year & & & & & & & & & 31.901 & $* *$ \\
\hline 2007 & 2,876 & 34.9 & 1,068 & 13.0 & 797 & 9.7 & 3,495 & 42.4 & & \\
\hline 2008 & 3,916 & 35.2 & 1,433 & 12.9 & 1,110 & 10.0 & 4,655 & 41.9 & & \\
\hline 2009 & 4,091 & 36.6 & 1,443 & 12.9 & 1,006 & 9.0 & 4,627 & 41.4 & & \\
\hline 2010 & 4,208 & 37.2 & 1,372 & 12.1 & 1,065 & 9.4 & 4,666 & 41.3 & & \\
\hline 2011 & 4,487 & 37.4 & 1,431 & 11.9 & 1,116 & 9.3 & 4,959 & 41.3 & & \\
\hline
\end{tabular}

Note: Based on 53,821 elderly fee-for-service Medicare beneficiaries with incident breast, colorectal and prostate cancer who were continuously enrolled in Medicare Part A and B during the observation period and who were alive during the observation period. Asterisks represent significant differences in study population characteristics by breast, colorectal and prostate cancer, derived from chi-square statistics.

$* * * \mathrm{p}<.001 ; * * .001 \leq \mathrm{p}<.01 ; * .01 \leq \mathrm{p}<.05$.

AA: African American; CMHC: Community Mental Health Center; HH: household; HS: High school; HPSA: health professional shortage area; LT: less than; SEER: Surveillance Epidemiology and End Results; Sep/div/wid:

Separated/Divorced/Widowed. 
Table 2.2

Number and Percentage of Newly-Diagnosed Depression by Cancer Types and Treatment Characteristics Elderly Fee-for-service Medicare beneficiaries with Incident Breast, colorectal, and Prostate Cancer

SEER-Medicare Database, 2007-2012

\begin{tabular}{|c|c|c|c|c|c|c|}
\hline & Depression & & No Depression & & & \\
\hline & $\mathbf{N}$ & $\%$ & $\mathbf{N}$ & $\%$ & Chisq & Sig \\
\hline Cancer types & & & & & 365.7 & $* * *$ \\
\hline Women Breast Cancer & 755 & 3.9 & 18,823 & 96.1 & & \\
\hline Women Colorectal Cancer & 394 & 5.8 & 6,353 & 94.2 & & \\
\hline Men Colorectal Cancer & 173 & 3.4 & 4,921 & 96.6 & & \\
\hline Men Prostate Cancer & 364 & 1.6 & 22,038 & 98.4 & & \\
\hline Stage at cancer diagnosis & & & & & 95.8 & $* * *$ \\
\hline Stage 0 & 154 & 9.1 & 4,214 & 8.1 & & \\
\hline Stage I & 433 & 25.7 & 11,705 & 22.5 & & \\
\hline Stage II & 705 & 41.8 & 27,643 & 53.0 & & \\
\hline Stage III & 262 & 15.5 & 5,679 & 10.9 & & \\
\hline Stage IV & 132 & 7.8 & 2,894 & 5.6 & & \\
\hline Chemotherapy & & & & & 0.1 & \\
\hline Yes & 454 & 26.9 & 14,174 & 27.2 & & \\
\hline No & 1,232 & 73.1 & 37,961 & 72.8 & & \\
\hline Radiation therapy & & & & & 49.5 & $* * *$ \\
\hline Yes & 489 & 29.0 & 19,507 & 37.4 & & \\
\hline No & 1,197 & 71.0 & 32,628 & 62.6 & & \\
\hline Surgery & & & & & 110.6 & $* * *$ \\
\hline Yes & 1,265 & 75.0 & 32,561 & 62.5 & & \\
\hline No & 421 & 25.0 & 19,574 & 37.5 & & \\
\hline
\end{tabular}

Note: Based on 53,821 elderly fee-for-service Medicare beneficiaries with incident breast, colorectal and prostate cancer who were continuously enrolled in Medicare Part A and B during the observation period and who were alive during the observation period. Asterisks represent significant differences in newly-diagnosed depression by cancer types, derived from chi-square tests.

$* * * \mathrm{p}<.001 ; * * .001 \leq \mathrm{p}<.01 ; * .01 \leq \mathrm{p}<.05$.

SEER: Surveillance Epidemiology and End Results. 
Table 2.3

Adjusted Risk Ratios and 95\% Confidence Intervals (CI) of Cancer Types from Complementary Log-Log Regression on Newly-Diagnosed Depression

Elderly Fee-for-service Medicare beneficiaries with Incident Breast, colorectal, and Prostate Cancer SEER-Medicare database, 2007-2012

\begin{tabular}{|c|c|c|c|c|c|c|c|}
\hline \multicolumn{8}{|c|}{ Model 1: Included the types of cancer without adjustment } \\
\hline Cancer types & $\mathbf{R R}$ & $95 \% \mathrm{CI}$ & Sig & & $\mathbf{R R}$ & $95 \% \mathrm{CI}$ & Sig \\
\hline \multicolumn{4}{|c|}{ Reference group $=$ Women Breast Cancer } & \multicolumn{4}{|c|}{ Reference group $=$ Men Prostate Cancer } \\
\hline Women Colorectal Cancer & 1.53 & {$[1.36,1.73]$} & $* * *$ & Women Breast Cancer & 2.29 & {$[1.97,2.67]$} & $* * *$ \\
\hline Men Colorectal Cancer & 0.88 & {$[0.74,1.04]$} & & Women Colorectal Cancer & 3.10 & {$[2.62,3.66]$} & $* * *$ \\
\hline \multirow[t]{2}{*}{ Men Prostate Cancer } & 0.42 & {$[0.37,0.47]$} & $* * *$ & Men Colorectal Cancer & 2.12 & {$[1.74,2.57]$} & $* * *$ \\
\hline & ARR & $95 \% \mathrm{CI}$ & Sig & & ARR & 95\% CI & Sig \\
\hline \multicolumn{8}{|c|}{ Model 2: Adjusted for Individual Physical Make-up and access to care } \\
\hline Women Colorectal Cancer & 1.49 & {$[1.32,1.69]$} & $* * *$ & Women Breast Cancer & 2.17 & {$[1.90,2.47]$} & $* * *$ \\
\hline Men Colorectal Cancer & 0.98 & {$[0.83,1.16]$} & & Women Colorectal Cancer & 3.23 & {$[2.77,3.77]$} & $* * *$ \\
\hline Men Prostate Cancer & 0.46 & {$[0.40,0.53]$} & $* * *$ & Men Colorectal Cancer & 2.12 & {$[1.77,2.55]$} & $* * *$ \\
\hline \multicolumn{8}{|c|}{$\begin{array}{l}\text { Model } 3 \text { Adjusted for cancer type, individual physical make-up and access to care characteristics, health behaviors, and } \\
\text { biological risk factors }\end{array}$} \\
\hline Women Colorectal Cancer & 1.35 & {$[1.19,1.54]$} & $* * *$ & Women Breast Cancer & 2.33 & {$[2.00,2.72]$} & *** \\
\hline Men Colorectal Cancer & 0.92 & {$[0.78,1.10]$} & & Women Colorectal Cancer & 3.14 & {$[2.66,3.72]$} & $* * *$ \\
\hline Men Prostate Cancer & 0.44 & {$[0.37,0.51]$} & $* * *$ & Men Colorectal Cancer & 2.06 & {$[1.70,2.51]$} & $* * *$ \\
\hline \multicolumn{8}{|c|}{$\begin{array}{l}\text { Model 4: Adjusted for cancer type, individual physical make-up and access to care characteristics, health behaviors, and } \\
\text { biological risk factors, treatment factors, community resources, geographical location, and year at cancer diagnosis }\end{array}$} \\
\hline Women Colorectal Cancer & 1.28 & {$[1.12,1.46]$} & $* * *$ & Women Breast Cancer & 2.33 & {$[1.95,2.78]$} & $* * *$ \\
\hline Men Colorectal Cancer & 0.88 & {$[0.73,1.05]$} & & Women Colorectal Cancer & 2.98 & {$[2.47,3.60]$} & $* * *$ \\
\hline Men Prostate Cancer & 0.43 & {$[0.36,0.51]$} & $* * *$ & Men Colorectal Cancer & 2.04 & {$[1.65,2.51]$} & $* * *$ \\
\hline
\end{tabular}

Note: Based on 53,821 elderly fee-for-service Medicare beneficiaries with incident breast, colorectal and prostate cancer who were continuously enrolled in Medicare Part A and B during the observation period and who were alive during the observation period. Asterisks represent significant differences in newly-diagnosed depression by cancer types, derived from complementary log-log regression.

$* * * \mathrm{P}<.001 ; * * .001 \leq \mathrm{P}<.01 ; * .01 \leq \mathrm{P}<.05$.

ARR: Adjusted Risk Ratio; RR: Risk Ratio; SEER: Surveillance Epidemiology and End Results. 
Table 2.4

Sex Differences in Newly-Diagnosed Depression Adjusted Risk Ratios and 95\% Confidence Intervals of Cancer Types from Complementary Log-Log Regression on Newly-Diagnosed Depression Elderly Fee-for-service Medicare beneficiaries with Incident

Breast, colorectal, and Prostate Cancer

SEER-Medicare Database, 2007-2012

\begin{tabular}{|c|c|c|c|}
\hline \multicolumn{4}{|c|}{ Reference group $=$ Men Colorectal Cancer } \\
\hline \multicolumn{4}{|c|}{ Model 1} \\
\hline \multicolumn{4}{|c|}{ Adjusted only for cancer types } \\
\hline \multicolumn{4}{|c|}{ Reference Group = Men Colorectal Cancer } \\
\hline Cancer types & $\mathbf{R R}$ & $95 \% \mathrm{CI}$ & Sig \\
\hline Women Breast Cancer & 1.14 & {$[0.96,1.34]$} & \\
\hline Women Colorectal Cancer & 1.74 & {$[1.46,2.08]$} & $* * *$ \\
\hline \multirow[t]{2}{*}{ Men Prostate Cancer } & 0.47 & {$[0.40,0.57]$} & $* * *$ \\
\hline & ARR & $95 \% \mathrm{CI}$ & Sig \\
\hline \multirow{2}{*}{\multicolumn{4}{|c|}{$\begin{array}{c}\text { Model } 2 \\
\text { Adjusted for cancer types, individual physical make-up and access to care characteristics }\end{array}$}} \\
\hline & & & \\
\hline Women Breast Cancer & 1.02 & {$[0.86,1.21]$} & \\
\hline Women Colorectal Cancer & 1.52 & {$[1.27,1.83]$} & $* * *$ \\
\hline Men Prostate Cancer & 0.47 & {$[0.39,0.57]$} & $* * *$ \\
\hline \multicolumn{4}{|c|}{ Model 3} \\
\hline \multicolumn{4}{|c|}{$\begin{array}{c}\text { Adjusted for cancer types, individual physical make-up and access to care characteristics, health } \\
\text { behaviors, and biological risk factors }\end{array}$} \\
\hline Women Breast Cancer & 1.13 & {$[0.95,1.35]$} & \\
\hline Women Colorectal Cancer & 1.52 & {$[1.27,1.83]$} & $* * *$ \\
\hline Men Prostate Cancer & 0.48 & {$[0.40,0.59]$} & $* * *$ \\
\hline \multicolumn{4}{|c|}{$\begin{array}{c}\text { Model } 4 \\
\text { Adjusted for cancer types, individual physical make-up and access to care characteristics, health } \\
\text { behaviors, and biological risk factors, treatment factors, community resources, geographical location, } \\
\text { and year of cancer diagnosis }\end{array}$} \\
\hline Women Breast Cancer & 1.14 & {$[0.96,1.36]$} & \\
\hline Women Colorectal Cancer & 1.46 & {$[1.22,1.76]$} & $* * *$ \\
\hline Men Prostate Cancer & 0.49 & {$[0.40,0.61]$} & $* * *$ \\
\hline
\end{tabular}

Note: Based on 53,821 elderly fee-for-service Medicare beneficiaries with incident breast, colorectal and prostate cancer who were continuously enrolled in Medicare Part A and B during the observation period and who were alive during the observation period. Asterisks represent significant differences in newly-diagnosed depression by cancer types, derived from complementary log-log regression.

$* * * \mathrm{P}<.001 ; * * .001 \leq \mathrm{P}<.01 ; * .01 \leq \mathrm{P}<.05$.

ARR: Adjusted Risk Ratio; RR: Risk Ratio; SEER: Surveillance Epidemiology and End Results. 


\section{Appendix 2.1}

Adjusted Risk Ratios (ARR) and 95\% Confidence Intervals (CI) from Complementary Log-Log Regression on Newly-Diagnosed Depression Elderly Fee-for-service Medicare beneficiaries with Incident Breast, colorectal, and Prostate Cancer SEER-Medicare Database, 2007-2012

\begin{tabular}{|c|c|c|c|c|c|c|c|c|c|}
\hline & \multicolumn{3}{|c|}{ Model 2} & \multicolumn{2}{|r|}{ Model 3} & \multicolumn{4}{|c|}{ Model 4} \\
\hline & ARR & $95 \% \mathrm{CI}$ & Sig & ARR & $95 \% \mathrm{CI}$ & Sig & ARR & $95 \% \mathrm{CI}$ & Sig \\
\hline \multicolumn{10}{|c|}{ Biological Risk Factors } \\
\hline \multicolumn{10}{|l|}{ Cancer types } \\
\hline \multicolumn{10}{|l|}{$\begin{array}{l}\text { Women Breast Cancer } \\
\text { (Ref.) }\end{array}$} \\
\hline Women colorectal cancer & 1.49 & {$[1.32,1.69]$} & $* * *$ & 1.35 & {$[1.18,1.53]$} & $* * *$ & 1.28 & {$[1.12,1.46]$} & *** \\
\hline Men colorectal cancer & 0.98 & {$[0.83,1.16]$} & & 0.88 & {$[0.74,1.05]$} & & 0.84 & {$[0.70,1.00]$} & \\
\hline Men Prostate Cancer & 0.46 & {$[0.40,0.53]$} & $* * *$ & 0.43 & {$[0.37,0.50]$} & $* * *$ & 0.41 & {$[0.34,0.49]$} & **** \\
\hline \multicolumn{10}{|c|}{ Individual Physical Make-up } \\
\hline \multicolumn{10}{|l|}{ Age } \\
\hline $66-69$ & 1.25 & {$[1.09,1.43]$} & $* *$ & 1.27 & {$[1.11,1.47]$} & $* * *$ & 1.31 & {$[1.13,1.52]$} & **** \\
\hline $70-74$ & 1.05 & {$[0.92,1.21]$} & & 1.08 & {$[0.94,1.24]$} & & 1.12 & {$[0.97,1.29]$} & \\
\hline 75-79 & 1.08 & {$[0.94,1.24]$} & & 1.08 & {$[0.94,1.25]$} & & 1.11 & {$[0.96,1.28]$} & \\
\hline \multicolumn{10}{|l|}{$>=80$ (Ref.) } \\
\hline \multicolumn{10}{|l|}{ Race } \\
\hline \multicolumn{10}{|l|}{ White (Ref.) } \\
\hline African American & 0.73 & {$[0.61,0.87]$} & $* * *$ & 0.74 & {$[0.62,0.89]$} & ** & 0.72 & {$[0.59,0.86]$} & *** \\
\hline Hispanic & 1.10 & {$[0.83,1.46]$} & & 1.06 & {$[0.80,1.40]$} & & 1.03 & {$[0.77,1.37]$} & \\
\hline Others & 0.52 & {$[0.41,0.66]$} & $* * *$ & 0.56 & {$[0.44,0.71]$} & $* * *$ & 0.55 & {$[0.43,0.70]$} & *** \\
\hline Unknown & 1.78 & {$[0.66,4.79]$} & & 2.12 & {$[0.80,5.60]$} & & 2.11 & {$[0.80,5.58]$} & \\
\hline \multicolumn{10}{|c|}{ Social support } \\
\hline \multicolumn{10}{|l|}{ Married (Ref.) } \\
\hline Never married & 1.40 & {$[1.19,1.66]$} & $* * *$ & 1.32 & {$[1.11,1.56]$} & $* *$ & 1.29 & {$[1.09,1.53]$} & ** \\
\hline Sep/div/wid & 1.46 & {$[1.30,1.63]$} & $* * *$ & 1.37 & {$[1.22,1.54]$} & $* * *$ & 1.35 & {$[1.20,1.52]$} & $* * *$ \\
\hline Unknown & 1.02 & {$[0.83,1.26]$} & & 1.02 & {$[0.82,1.26]$} & & 1.00 & {$[0.81,1.23]$} & \\
\hline \multicolumn{10}{|c|}{ Access to care } \\
\hline \multicolumn{10}{|l|}{ Median HH income } \\
\hline Quartile 1 (Low) & 1.02 & {$[0.83,1.25]$} & & 0.99 & {$[0.81,1.22]$} & & 1.04 & {$[0.83,1.30]$} & \\
\hline Quartile 2 & 0.92 & {$[0.77,1.10]$} & & 0.90 & {$[0.75,1.08]$} & & 0.94 & {$[0.78,1.14]$} & \\
\hline Quartile 3 & 0.94 & {$[0.80,1.10]$} & & 0.93 & {$[0.79,1.09]$} & & 0.95 & {$[0.80,1.12]$} & \\
\hline \multicolumn{10}{|l|}{ Quartile 4 (High) } \\
\hline \multicolumn{10}{|l|}{ \% LT HS education } \\
\hline Quartile 1 (Low) & 0.79 & {$[0.64,0.97]$} & * & 0.99 & {$[0.81,1.22]$} & & 0.83 & {$[0.67,1.03]$} & \\
\hline Quartile 2 & 0.84 & {$[0.71,1.00]$} & & 0.90 & {$[0.75,1.08]$} & & 0.89 & {$[0.74,1.07]$} & \\
\hline Quartile 3 & 0.84 & {$[0.72,0.98]$} & $*$ & 0.93 & {$[0.79,1.09]$} & & 0.87 & {$[0.75,1.02]$} & \\
\hline \multicolumn{10}{|l|}{ Quartile 4 (High) } \\
\hline \multirow{2}{*}{\multicolumn{10}{|c|}{$\begin{array}{l}\text { Primary care visits } \\
\text { Quartile } 1 \text { (Low) }\end{array}$}} \\
\hline & & & & & & & & & \\
\hline Quartile 2 & 1.02 & {$[0.83,1.27]$} & & 1.02 & {$[0.83,1.27]$} & & 1.03 & {$[0.83,1.27]$} & \\
\hline Quartile 3 & 1.01 & {$[0.86,1.19]$} & & 1.00 & {$[0.85,1.18]$} & & 0.98 & {$[0.83,1.15]$} & \\
\hline Quartile 4 (High) & 1.49 & {$[1.28,1.75]$} & $* * *$ & 1.27 & {$[1.07,1.50]$} & $* *$ & 1.27 & {$[1.08,1.50]$} & $* *$ \\
\hline & & & ealth & ehavior: & & & & & \\
\hline Tobacco Use & & & & & & & & & \\
\hline Yes & & & & 1.22 & {$[0.97,1.52]$} & & 1.28 & {$[1.03,1.60]$} & * \\
\hline No (Ref.) & & & & & & & & & \\
\hline & & & holog & cal fact & & & & & \\
\hline Anxiety-PTSD & & & & & & & & & \\
\hline Yes & & & & 3.66 & {$[3.21,4.17]$} & $* * *$ & 3.72 & {$[3.26,4.24]$} & $* * *$ \\
\hline No (Ref.) & & & & & & & & & \\
\hline Continued, & & & & & & & & & \\
\hline
\end{tabular}


Appendix 2.1

Adjusted Risk Ratios (ARR) and 95\% Confidence Intervals (CI) from Complementary Log-Log Regression on Newly-Diagnosed Depression Elderly Fee-for-service Medicare beneficiaries with Incident Breast, colorectal, and Prostate Cancer SEER-Medicare Database, 2007-2012

\begin{tabular}{|c|c|c|c|c|c|c|c|c|c|}
\hline & \multicolumn{3}{|c|}{ Model 2} & \multicolumn{2}{|r|}{ Model 3} & \multicolumn{4}{|c|}{ Model 4} \\
\hline & ARR & $95 \% \mathrm{CI}$ & Sig & ARR & $95 \% \mathrm{CI}$ & Sig & ARR & $95 \% \mathrm{CI}$ & Sig \\
\hline \multicolumn{10}{|c|}{ Biological risk factors } \\
\hline \multicolumn{10}{|c|}{ Cardiovascular } \\
\hline Yes & & & & 1.00 & {$[0.87,1.15]$} & & 1.00 & {$[0.87,1.15]$} & \\
\hline \multicolumn{10}{|l|}{ No (Ref.) } \\
\hline \multicolumn{10}{|c|}{ Musculoskeletal disease } \\
\hline Yes & & & & 1.19 & {$[1.07,1.34]$} & $* *$ & 1.19 & {$[1.07,1.33]$} & $* *$ \\
\hline \multicolumn{10}{|l|}{ No (Ref.) } \\
\hline \multicolumn{10}{|l|}{ Respiratory } \\
\hline Yes & & & & 1.11 & {$[0.96,1.27]$} & & 1.10 & {$[0.96,1.27]$} & \\
\hline \multicolumn{10}{|l|}{ No (Ref.) } \\
\hline \multicolumn{10}{|c|}{ Stage at cancer diagnosis } \\
\hline Stage 0 & & & & 0.98 & {$[0.82,1.18]$} & $* * *$ & 0.98 & {$[0.82,1.18]$} & $* * *$ \\
\hline \multicolumn{10}{|c|}{ Stage I (Ref.) } \\
\hline Stage II & & & & 1.22 & {$[1.06,1.40]$} & $* *$ & 1.21 & {$[1.06,1.40]$} & $* *$ \\
\hline Stage III & & & & 1.41 & {$[1.19,1.68]$} & $* * *$ & 1.39 & {$[1.17,1.68]$} & $* * *$ \\
\hline Stage IV & & & & 1.63 & {$[1.31,2.03]$} & $* * *$ & 1.61 & {$[1.30,2.00]$} & $* * *$ \\
\hline \multicolumn{10}{|c|}{ Treatment factors } \\
\hline \multicolumn{10}{|c|}{ Chemotherapy } \\
\hline Yes & & & & & & & 1.01 & {$[0.90,1.14]$} & \\
\hline \multicolumn{10}{|l|}{ No (Ref.) } \\
\hline \multicolumn{10}{|c|}{ Radiation therapy } \\
\hline Yes & & & & & & & 0.83 & {$[0.74,0.93]$} & $* *$ \\
\hline \multicolumn{10}{|l|}{ No (Ref.) } \\
\hline \multicolumn{10}{|l|}{ Continued } \\
\hline \multicolumn{10}{|l|}{ Surgery } \\
\hline Yes & & & & & & & 0.97 & {$[0.84,1.12]$} & \\
\hline No (Ref.) & & & & & & & & & \\
\hline
\end{tabular}

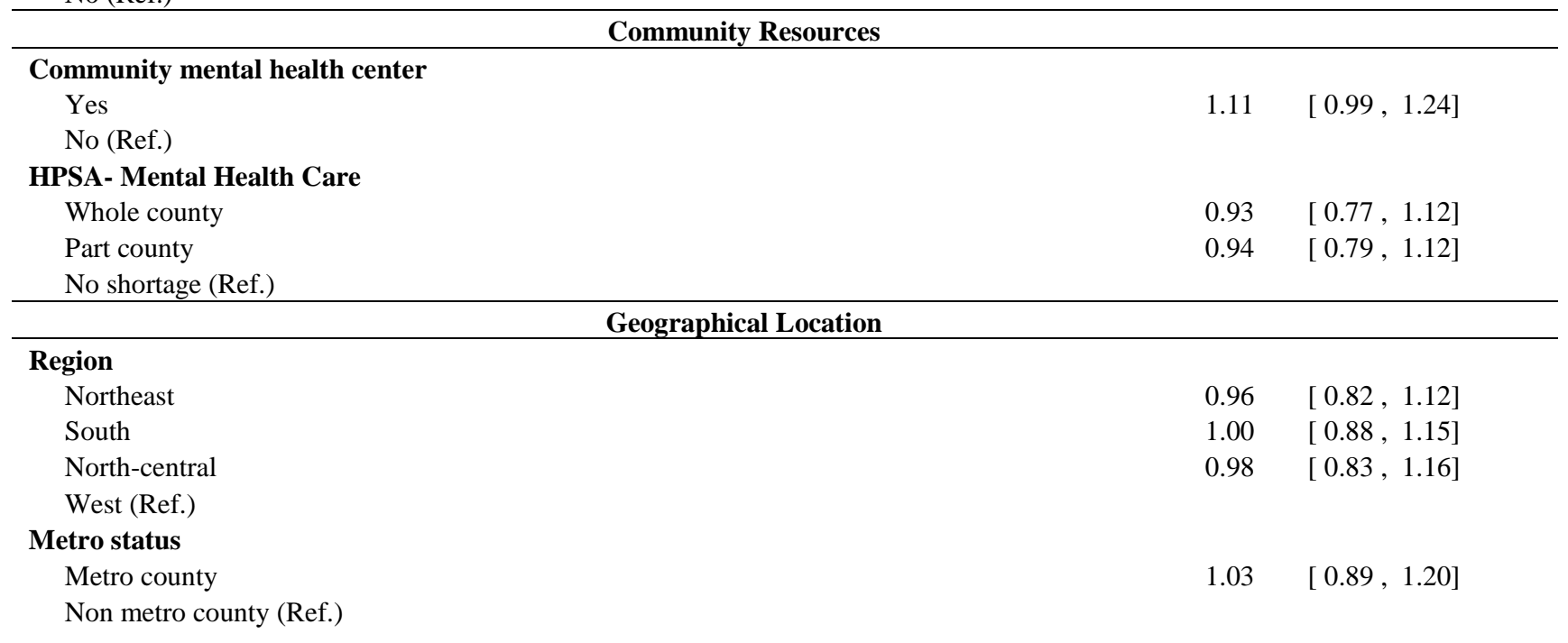

Continued, 


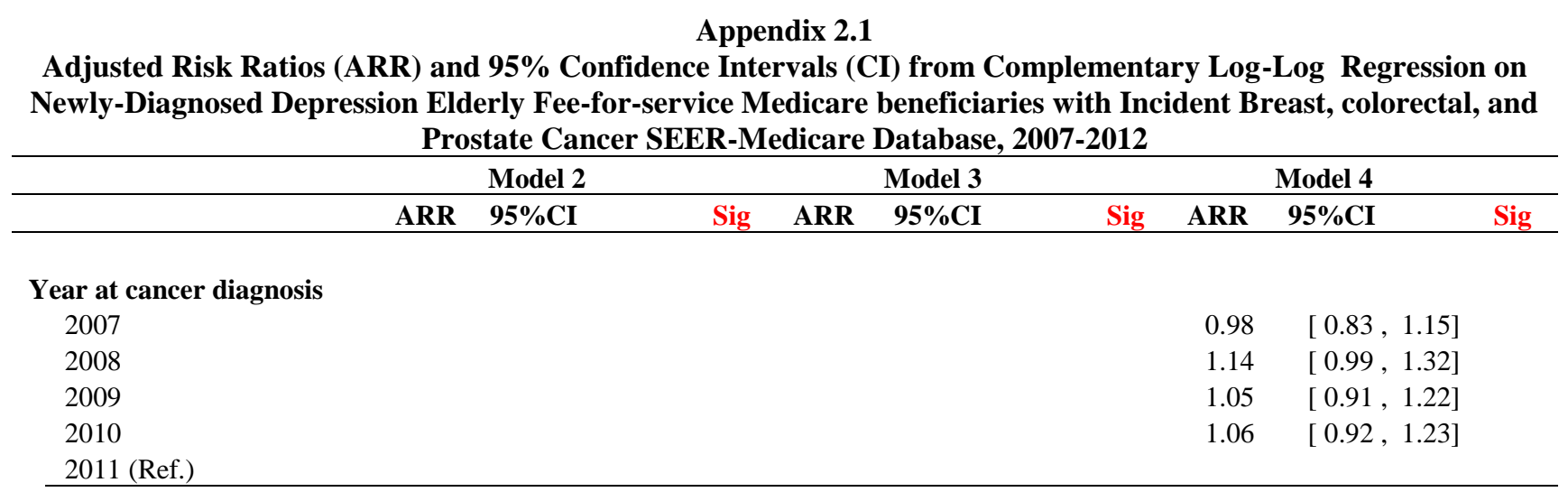

Note: Based on 53,821 elderly fee-for-service Medicare beneficiaries with incident breast, colorectal and prostate cancer who were continuously enrolled in Medicare Part A and B during the observation period and who were alive during the observation period. Asterisks represent significant differences in newly-diagnosed depression by cancer types, derived from complementary $\log$-log regression.

$* * * \mathrm{P}<.001 ; * * .001 \leq \mathrm{P}<.01 ; * .01 \leq \mathrm{P}<.05$.

Model 1: Adjusted for cancer types. Model 2: Adjusted for cancer types and individual physical make-up; Model 3: Adjusted for cancer types, access to care, health behaviors, and biological risk factors. Model 4: adjusted cancer types, access to care, health behaviors, biological risk factors, treatment factors, community resources, geographical location, and year at cancer diagnosis. Asterisks $\left(^{*}\right)$ represent significant differences based on complementary log log regressions with women cancer types as the reference groups

$* * * \mathrm{P}<.001 ; * * .001 \leq \mathrm{P}<.01 ; * .01 \leq \mathrm{P}<.05$.

AA: African American; ARR: Adjusted Risk Ratio; CMHC: Community Mental Health Center; HH: household; HS: High school; HPSA: health professional shortage area; LT: less than; RR: Risk Ratio; Ref: Reference Group; SEER: Surveillance Epidemiology and End Results; Sep/div/wid: Separated/Divorced/Widowed. 


\section{Appendix 2.2 Study Cohort Development Flow Diagram for Study Population of Elderly Medicare Beneficiaries Diagnosed with Incident Breast, Colorectal and Prostate cancer}

- $\quad$ Cancer diagnosed identified using Siterwho 1- -10 codes Breast $\mathrm{N}=392,684$, Colorectal $\mathrm{N}=291,491$, Prostate $\mathrm{N}=461,994$

- $\quad$ Diagnosed with cancer from April 2007 to Dec 2011

Breast $\mathrm{N}=169,955$, Colorectal $\mathrm{N}=125,261$, Prostate $\mathrm{N}=205,505$

- $\quad$ Diagnosed with cancer from April 2007 to Dec 2011

- Primary cancer only in the patient's lifetime (Seq1 in " 00 ")

- Not diagnosed with cancer at autopsy or death certificate

- Incident cases

Breast $\mathrm{N}=129,206$, Colorectal $\mathrm{N}=89,272$, Prostate $\mathrm{N}=168,783$

- $\quad$ Elderly with cancer from April 2007 to Dec 2011

- With primary cancer (Seq1 in "00")

- Not diagnosed with cancer at autopsy or death certificate

- Incident cases, $>=66$, alive

Breast $\mathrm{N}=73,496$, Colorectal $\mathrm{N}=45,571$, Prostate $\mathrm{N}=107,585$

- Diagnosed with cancer from April 2007 to Dec 2011

- With primary cancer (Seq1 in "00")

- Not diagnosed with cancer at autopsy or death certificate , Incident cases, $>=66$, alive

- Fee-for-service continuous enrollment and part D enrollment $3 \mathrm{~m}$ before cancer $\mathrm{dx}$

Breast $\mathrm{N}=23,632$, Colorectal $\mathrm{N}=13,988$, Prostate $\mathrm{N}=24,726$

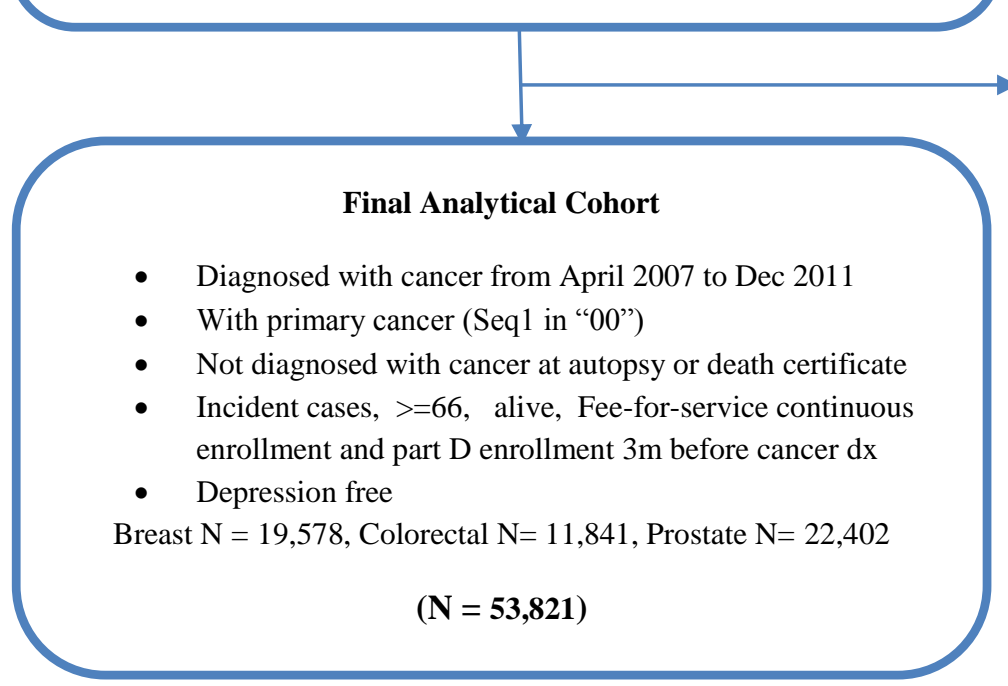




\section{Chapter 3 \\ Depression Treatment among Elderly Medicare Beneficiaries with Incident Cancer and Newly-Diagnosed Depression}

\subsection{Abstract}

Objective. Depression treatment can improve the health outcomes of elderly cancer survivors. However, there is a paucity of studies on the extent to which newly-diagnosed depression is treated among elderly cancer survivors. Therefore, the primary objective of this study is to estimate the rates of treatment for newly-diagnosed depression and to identify the factors affecting depression treatment among elderly individuals with incident cancer.

Methods. This study adopted a retrospective cohort study design with data from the linked Surveillance, Epidemiology and End Results (SEER) and Medicare database. Elderly individuals ( $\geq 66$ years) with incident breast, colorectal or prostate cancer and newly diagnosed depression $(\mathrm{N}=1,673)$ were followed for six months after depression diagnosis date to identify depression treatment. Depression treatment was categorized into four mutually exclusive categories: 1) treatment with only antidepressants; 2) treatment with only psychotherapy; 3) combined treatment with both antidepressants and psychotherapy; and 4) no depression treatment. Chisquare tests and multinomial logistic regressions were used to analyze the factors (predisposing, enabling and need factors as well as the external environment) associated with depression treatment.

Results. In our study population, $45.7 \%$ received only antidepressants, $8.8 \%$ received only psychotherapy, $18.4 \%$ received combined therapy and $27.1 \%$ received no treatment for depression. This study found that cancer survivors who received cancer treatment after depression diagnosis were less likely to receive psychotherapy only (Adjusted Odds Ratio $(\mathrm{AOR})=0.40[95 \% \mathrm{CI}, 0.22-0.72])$, or combined therapy $(\mathrm{AOR}=0.51[95 \% \mathrm{CI}, 0.34-0.79])$, as 
compared to those who received cancer treatment before depression diagnosis. This study also found that residents living in counties with a higher percentage of psychologists were more likely to receive psychotherapy only (Adjusted Odds Ratio $(\mathrm{AOR})=2.17$ [95\%CI, 1.20-3.90]), or combined therapy $(\mathrm{AOR}=1.55[95 \% \mathrm{CI}, 1.03-2.33])$. Other factors associated with depression treatment were: race, the number of primary care physician visits, the presence of other chronic conditions, and anxiety.

Conclusion. The study findings indicate that two-third of cancer survivors received some depression treatment in the first six months after depression diagnosis. The majority of cancer survivors received antidepressants only to treat newly-diagnosed depression. Certain predisposing, enabling and need factors as well as external environmental factors were associated with depression treatment.

Implications. Despite the clinical guidelines' recommendations for treating depression among cancer survivors, one-fourth of cancer survivors do not receive any depression treatment. Future research needs to investigate whether these individuals receive alternative therapies for newlydiagnosed depression. 


\subsection{Introduction}

Depression is a treatable and highly prevalent mental health condition among cancer survivors $(1,2)$. Relief from clinical depression can be achieved with either pharmacotherapy or psychotherapy or a combination of pharmacotherapy and psychotherapy (3). Pharmacotherapy typically consists of antidepressants such as selective serotonin reuptake inhibitors (SSRIs), selective norepinephrine reuptake inhibitors (SNRIs), tricyclic antidepressants (TCAs), monoamine oxidase inhibitors (MAOIs) and others (mirtazapine, bupropion) (3). Different forms of psychotherapy are used to treat depression such as cognitive-behavioral therapy and problemsolving therapy (3).

The efficacy of antidepressants for treating depression among older adults (age $\geq 65$ years) in the general population $(4,5)$ and cancer survivors (6-12) has been evaluated by many randomized clinical trials (RCTs). These trials have not yet established the efficacy of antidepressants in treating depression among older adults. For example, a meta-analysis of six double-blind RCTs involving patients aged 65 and older found no statistically significant differences between the treatment with antidepressants and the placebo groups $($ Relative Risk $=$ 1.13; 95\% CI: $0.93-1.37, \mathrm{p}=0.265)(4,5)$. Among cancer survivors, there is mixed evidence from seven RCTs on the efficacy of antidepressants in treating cancer patients with depression. In five RCTs, cancer patients who used antidepressants were more likely to achieve a therapeutic response as compared to the placebo (6-10). However, in two RCTs antidepressants were not found to be efficacious $(11,12)$. The efficacy of psychotherapy alone in treating depression has been established efficacy for elderly individuals in the general population (13) and among adults with cancer (14-18). In addition, the combination of antidepressants and psychotherapy has an 
established efficacy in reducing depressive symptoms, in some RCTs, among the elderly in the general population $(19,20)$ but not among adults with cancer $(21)$.

As various depression treatment modalities have been found to be efficacious among older adults, clinical practice guidelines have recommended depression treatment for cancer patients (22-24). These guidelines do not recommend antidepressants over psychotherapy alone or in combination with antidepressants, nor do they recommend one antidepressant over another. Although depression treatment is recommended to reduce the depressive symptoms for cancer survivors, it is not known how depression is treated in the real-world clinical practice settings among elderly with cancer. Research on treatment of newly-diagnosed depression among cancer survivors has not received much attention. In the United States, only two cross-sectional studies examined depression treatment among cancer survivors seeking care in real-world clinicalpractice settings $(25,26)$. Of these two studies, one study focused on elderly (age $\geq 65$ years) Medicare beneficiaries with cancer using data between 2000 and 2005 (25) and another study used MEPS from multiple years 2006-2008 among adults with both cancer and depression (26). Findings from these studies revealed that an estimated $76 \%$ and $84 \%$ of elderly cancer survivors received any depression treatment. These studies were among cancer survivors with prevalent depression and any type of cancer. These studies did not include cancer-related clinical factors such as stage at cancer diagnosis and cancer treatment, which might affect depression treatment. Furthermore, these studies used self-reported data on either antidepressant use or depression diagnosis.

There are no studies that examined the treatment of depression among cancer survivors with newly-diagnosed depression. In addition, no studies distinguish depression treatment among specific types of cancer such as breast, colorectal, or prostate cancer. Therefore, the primary 
objective of the current study was to fill the knowledge gap in estimating depression treatment and the factors associated with depression treatment among breast, colorectal or prostate cancer survivors with newly-diagnosed depression. This study used a retrospective cohort design with data from clinical care encounters and prescription drug claims to analyze depression treatment among cancer survivors with newly-diagnosed depression. These cancers were selected due to their high prevalence; they are projected to be the most common types of cancer by 2024 , with breast cancer among women expected to be $41 \%$, prostate cancer among men to be $45 \%$, and colorectal cancer among men and women to be $8 \%$.

\subsection{Conceptual framework}

The expanded behavioral model on healthcare utilization, the Andersen Behavioral Model, was used to guide the selection of factors that may affect depression treatment (27). According to this model, depression treatment (i.e. health services utilization) is a function of: 1) an individual's predisposition to utilize the services - predisposing factors; 2) factors which enable individuals to use healthcare services - enabling factors; 3) an individual's level of need need factors; 4) personal health practices, and 5) the external environment.

\subsection{Methods}

\subsubsection{Study Design}

This study utilized retrospective cohort study design with baseline and follow-up periods. The first observed date of depression diagnosis after cancer diagnosis was considered as an index date. The baseline period was defined as 12 months before this index date and the follow-up period was defined as six months after this index date. 


\subsubsection{Data Sources}

The current study linked data from several sources including the SEER-Medicare linked database and the AHRF files. The detailed description of the data sources are provided in Chapter 1.

\subsubsection{Study population}

Identification of Cancer Survivors

The study population composed of elderly cancer survivors (age $\geq 66$ years) who were diagnosed with primary only incident breast, colorectal or prostate cancer and newly-diagnosed depression between 2007 and 2011. Cancer types (breast, colorectal or prostate cancer) was identified using the International Classification of Diseases for Oncology, 3rd Edition (ICD-O3) histology codes and the primary site variable.

Cancer Survivors with newly-diagnosed depression

This study identified cancer survivors with newly-diagnosed depression based on the National Committee on Quality Assurance (NCQA) criteria (30). To accomplish this, a depression-free cancer cohort with incident cancer diagnosis between April 2007 and December 2011 was first established. To identify newly-diagnosed depression after cancer diagnosis, only those who were diagnosed with depression after cancer diagnosis and did not have any antidepressant use 90 days prior to depression diagnosis were included. This study used a validated algorithm developed by the Centers for Medicare and Medicaid Services (CMS) Chronic Conditions Data Warehouse (CCW) to identify depression (31) using the International Classifications of Diseases $-9^{\text {th }}$ edition, Clinical Modification (ICD-9-CM) Codes (296.2, 296.3, 298.0, 300.4, 309.1, and 311.0). These codes are widely used in the literature to identify depression diagnoses among Medicare beneficiaries $(1,25,32)$. 


\section{Inclusion/exclusion criteria}

This study required that all individuals have continuous enrollment in Medicare part A, B and no enrollment in managed care plans during the baseline and follow-up periods. This study also required that individuals have continuous enrollment in Medicare part D six months after depression diagnosis to identify depression treatment in the follow-up period. This study excluded individuals with unknown cancer stage at diagnosis, those diagnosed through autopsy or death certificate, or those who died during the follow-up period. Appendix 1.1 demonstrates the analytical population selection process. The final study population consisted of 1,673 elderly Medicare beneficiaries with newly-diagnosed depression and incident breast, colorectal or prostate cancer.

\subsubsection{Dependent Variable: Depression Treatment}

This study identified depression treatment during the first six months after depression diagnosis. Antidepressant use was derived from Medicare Part D claims using the National Drug Codes (NDC) and generic names. Antidepressants included SSRIs, SNRIs, TCAs, MAOIs and others (mirtazapine, bupropion). Any cancer survivors with at least one prescription for antidepressants was considered as using antidepressants. Psychotherapy visits were derived from Medicare outpatient claims using the Current Procedural Terminology (CPT) codes. Any cancer survivor with at least one psychotherapy visit was considered as receiving psychotherapy.

Based on antidepressant prescriptions and psychotherapy visits, depression treatment was categorized into four mutually exclusive categories: (1) treatment with antidepressants only: individuals received, at least, one prescription of antidepressants and no psychotherapy visit; (2) treatment with psychotherapy only: individuals had, at least, one psychotherapy office visit and no prescription for antidepressants; (3) both antidepressants and psychotherapy: individuals 
received, at least, one prescription for antidepressants with at least one psychotherapy visit; (4) no treatment: individuals received no antidepressants and no psychotherapy.

\subsubsection{Independent Variables}

Predisposing factors included age in years at cancer diagnosis (66-69, 70-74, 75-79, $>=80$ ) and race (White, African American, and others). Enabling factors consisted of marital status (married, divorced/separated/widowed, and never married); number of visits to primary care physicians (PCP) by patients (measured in quartiles); cancer types (women with breast cancer, women with colorectal cancer, men with colorectal cancer, men with prostate cancer); stage at cancer diagnosis (categorized using American Joint Committee on Cancer (AJCC) grouped staging (stage 0/I, stage II, and stage III, stage IV) and cancer treatment with chemotherapy, radiation therapy, radiation therapy or surgery. As cancer is often considered a dominant condition and cancer treatment after depression diagnosis may compete with depression care, cancer treatment was cateorized into three groups:1) cancer treatment before depression diagnosis; 2) cancer treatment at or after depression diagnosis, and 3) no cancer treatment. Need factors composed of chronic conditions, which were selected, based on the Multiple Chronic Conditions working group framework (33). The following chronic conditions were used: Alzheimer's disease and related disorders (ADRD); anxiety; cardiovascular (diabetes, heart disease (cardiac arrythmia, coronary heart disease, congestive heart faliure), hyperlipidemia, hypertension, and stroke); musculoskeletal (arthritis, and osteoporosis) and respiratory conditions (asthma and chronic obstructive pulmonary disorder). This study identified these conditions based on a validated algorithm developed by the CMS Chronic Conditions Data Warehouse (31); according to this algorithm, individuals had, at least, one inpatient visit or two outpatient visits during the baseline period. External Environment factors included the county-level percentage of psychologists and SEER region (Northeast, South, 
North-central, and West). This study also controlled for year of cancer diagnosis by grouping the years into two groups: 1) 2007-2009, the period when FDA issued a black box warning due to the risk of suicides with antidepressants use (34,35) and 2) 2010-2011, the period when published articles reported the association between antidepressants and the risk of new-onset diabetes (36). This study did not use metro status because it was highly correlated with the county-level percentage of psychologists.

\subsection{Statistical Analysis}

This study used Chi-square tests and multinomial logistic regressions to examine the unadjusted differences in subgroups by depression treatment categories. This study used multivariable multinomial logistic regressions to examine the adjusted association between the independent variables and depression treatment categories. In these regressions, predisposing, enabling, need, and external environment factors were included. In all these models, the reference group for the dependent variable was "no depression treatment". All statistical analyses were carried out in SAS 9.4 (SAS Institute Inc., Cary, NC).

\subsection{Results}

\subsubsection{Characteristics of the study population}

The study population consisted of 1,673 elderly fee-for-service Medicare beneficiaries with incident breast, colorectal or prostate cancer who had newly-diagnosed depression after cancer diagnosis. In this study population, $44.9 \%$ were women with breast cancer; $22.8 \%$ were women with colorectal cancer; $10.1 \%$ were men with colorectal cancer, and $22.2 \%$ were men with prostate cancer. This study found that $35.0 \%$ were diagnosed with early stage cancers (stage 0/I) and 7.1\% diagnosed at an advanced stage (stage IV); 68.0\% received cancer treatment before depression diagnosis, $21.4 \%$ received cancer treatment on or after depression diagnosis, and 
$10.6 \%$ did not receive cancer treatment. The description of the study population is presented in Table 1.

Tables 2 and 3 display the unadjusted associations between predisposing, enabling and need factors, and external environment and depression treatment categories. Among elderly cancer survivors with newly-diagnosed depression, This study found that $27.1 \%$ did not receive any depression treatment; $45.7 \%$ received antidepressants only; $8.8 \%$ received psychotherapy only, and $18.4 \%$ received both antidepressants and psychotherapy. There was a significant difference in antidepressant use only by predisposing characteristics (race). For example, a significantly lower percentage of African American (odds ratio $(\mathrm{OR})=0.49,95 \%$ Confidence interval $(\mathrm{CI})=0.31,0.77)$ used antidepressants only as compared to whites $(28.3 \%$ versus 47.9\%); similarly, a lower percentage of other racial minorities (odds ratio $(\mathrm{OR})=0.54,95 \%$ $(\mathrm{CI})=0.36,0.82)$ used antidepressants only as compared to whites $(41.5$ versus $47.9 \%)$.

With regard to the use of psychotherapy only, This study found significant differences in psychotherapy use by enabling factors (marital status, PCP visits, cancer treatment), need factors (ADRD, anxiety, respiratory conditions), and external environmental characteristics (countylevel percentage of psychologists and region of residence). For example, a significantly lower percentage of individuals who received cancer treatment after depression diagnosis ( $O R=0.40$, $95 \%(\mathrm{CI})=0.23,0.70)$ used psychotherapy as compared to those who received cancer treatment before depression diagnosis (4.7\% versus 9.3\%). Individuals with ADRD had a higher use of psychotherapy $(\mathrm{OR}=3.27,95 \%(\mathrm{CI})=1.93,5.56)$ as compared to those without $\mathrm{ADRD}(15.1 \%$ versus $7.9 \%)$.

This study found significant group differences in the use of combination of antidepressant and psychotherapy by predisposing factor (race), enabling factors (never married, 
cancer treatment, and the number of PCP visits), need factors (ADRD, cardiovascular), and external environment (county-level number of psychologists and region of residence). For example, other racial minorities were less likely to receive combination of antidepressant and psychotherapy $(\mathrm{OR}=0.41,95 \%(\mathrm{CI})=0.23,0.74)$ as compared to whites $(11.9 \%$ versus $18.1 \%)$. Individuals with a higher number of PCP visits had higher use of combined antidepressant/psychotherapy $(\mathrm{OR}=1.03,95 \%(\mathrm{CI})=1.01,1.05)$.

Table 4 presents the adjusted odds ratios (AOR) and 95\% CIs from multinomial logistic regressions of depression treatment categories. In these regressions, "no depression treatment" was used as the reference group of the dependent variable. The results were generally consistent with the unadjusted analyses. This study found significant associations between a predisposing factor (race) and only antidepressants use. African Americans were less likely to receive antidepressants only as compared to White $(\mathrm{AOR}=0.44,95 \%(\mathrm{CI})=0.27,0.70)$. This study also found a significant association between psychotherapy use and enabling factors (marital status, PCP visits, and cancer treatment), need factors (ADRD, anxiety, cardiovascular, and respiratory conditions), and external environment (county-level percentage of psychologists, region of residence). For example, Individuals with higher number of PCP visits were more likely to use psychotherapy $(\mathrm{AOR}=1.02,95 \%(\mathrm{CI})=1.00,1.04)$. Individuals who received cancer treatment after depression diagnosis were less likely to use psychotherapy as compared to those who received cancer treatment before depression diagnosis $(\mathrm{AOR}=0.40,95 \%(\mathrm{CI})=0.22,0.72)$. With regard to combined antidepressants/psychotherapy, this study found a significant association between combined antidepressants/psychotherapy use and predisposing factor (race), enabling factors (PCP visits, cancer treatment), need factors (ADRD) and external environment (county-level percentage of psychologists, region of residence). For example, residents living in 
counties with a higher percentage of psychologists were more likely to receive combined antidepressants/psychotherapy $(\mathrm{AOR}=1.05$ [95\%CI, 1.00-1.09]). AOR and 95\% CI for other independent variables are presented in Table 4.

Of particular interest was the cancer types (Appendix 1.2). This study found that there were not significant differences in depression treatment categories between women with colorectal cancer as compared to women with women with breast cancer $(\mathrm{AOR}=0.93[95 \% \mathrm{CI}$, 0.67-1.29]); and between men with colorectal cancer as compared to men with prostate cancer $(\mathrm{AOR}=0.79[95 \% \mathrm{CI}, 0.48-1.30])$

\subsection{Discussion}

In this study, the rates of depression treatment and the factors associated with depression treatment for newly-diagnosed depression were estimated among elderly cancer survivors with incident breast, colorectal or prostate cancer. In our study population, one in four cancer survivors did not receive either antidepressants or psychotherapy for depression. This finding is consistent with the one published study depression treatment rate among elderly Medicare beneficiaries with cancer (25). Less than $50 \%$ of cancer survivors were treated with antidepressants only and $27.2 \%$ used psychotherapy with or without antidepressants. The percentage of antidepressant use is somewhat lower, and the psychotherapy use is higher than the estimated rates reported in one published study of Medicare beneficiaries with cancer (25). The differences between our study and the published study could be due to differences in the study designs (retrospective cross-sectional versus retrospective cohort), measurement of antidepressants (self-report versus prescription claims), and identification of depression (prevalent versus newly-diagnosed depression). 
This study also found that only one predisposing factor (race) was associated with the use of "antidepressants only." African Americans and other racial minorities were less likely to use antidepressants only as compared to whites. Such racial disparities have been documented among elderly Medicare beneficiaries with cancer (25) as well as in the elderly population. Some studies have attributed the racial disparities in antidepressant use to cultural factors. For example, it has been documented that African Americans and other racial minorities were less likely to accept antidepressants medications as compared to whites (37). A meta-analysis of cultural mistrust and mental health services for African Americans suggested a significant association between cultural mistrust with mental health services use (38).

Psychotherapy only or combined use of antidepressants and psychotherapy were associated with many factors (enabling, need, and external environment factors). Regarding enabling factors, cancer survivors with a higher number of PCP visits were more likely to receive psychotherapy and a combination of antidepressants and psychotherapy as compared to those with a lower number of PCP visits. This finding suggests that PCP visits may play an important role in referring cancer survivors to mental healthcare providers for psychotherapy treatment. A national survey of physicians conducted by the Cancer Care Outcomes Research and Surveillance Consortium has shown that PCPs are more involved in detection and treatment of depression in cancer survivors as compared to oncologists (50\% vs. 18\%) (39).

As expected, This study found that those who had initiated cancer treatment after depression diagnosis were less likely to receive psychotherapy as compared to those who had initiated cancer treatment before depression diagnosis. As psychotherapy sessions involve faceto-face visits to the mental health providers, cancer survivors may not be able to receive psychotherapy while cancer treatment is ongoing. These findings provide some evidence to 
support the theory of competing demands for care, which suggests that cancer is a dominant condition and may "eclipse the management of other health conditions." (40).

Further, This study found that many co-existing chronic conditions were associated with depression treatment. Cancer survivors with respiratory conditions were more likely to receive psychotherapy treatment as compared to those without respiratory conditions. This is not surprising because psychotherapy is a standard part of the rehabilitation therapy regimen, which is used to treat respiratory conditions such as asthma and COPD $(41,42)$. This study also found that individuals with ADRD were more likely to receive psychotherapy and a combination of antidepressants and psychotherapy as compared to those without ADRD. Cognitive therapy and other psychotherapies are some treatment modalities that are used to improve dementia symptoms (43). Further, the presence of cardiovascular conditions and anxiety were negatively associated with depression treatment. For example, those with cardiovascular conditions were less likely to use psychotherapy only as compared to those without cardiovascular conditions. While the reasons for this are not known, the lack of robust evidence of depression treatment on cardiac outcomes from RCTs $(44,45)$ may discourage physicians from recommending treatment for depression. For example, one of the RCTs, which used psychotherapy as the main modality of treatment for individuals with depression and heart disease, found no significant differences in cardiac outcomes (44). As none of the trials have shown improvement in cardiac outcomes, there have been calls for more trials to establish the efficacy of depression treatment on chronic care outcomes (46). This study also found that those with pre-existing anxiety were less likely to receive treatment as compared to those without anxiety. However, existing studies have shown that comorbid anxiety is associated with higher treatment rates among elderly Medicare 
beneficiaries. Thus, the difference in findings could be attributed to the measurement period in which anxiety was identified.

External environmental characteristics were also associated with depression treatment categories. This study found that the supply of mental health services was associated with psychotherapy use. For example, This study observed that a higher percentage of psychologists in a county was significantly associated with psychotherapy use and with a combination of antidepressants and psychotherapy use. This is also consistent with the published literature, which found that the availability of psychotherapy providers influences psychotherapy use (47).

This study has filled a knowledge gap by estimating the rates and identifing the factors associated with depression treatment categories among those with newly-diagnosed depression and incident breast, colorectal or prostate cancer. Our study findings indicate that racial disparities in depression treatment persist, competing demands may impede depression care and that the availability of psychologists may influence receipt of psychotherapy among cancer survivors. The current study made unique contributions to the nascent literature on depression care among cancer survivors. It has to be noted that once diagnosed with depression, neither type of cancer nor stage of cancer were associated with depression treatment, suggesting that detecting depression and diagnosing depression is critical to depression management among cancer survivors.

\section{Strengths and limitations}

This study's findings need to be interpreted in the context of its advantages and limitations. One advantage is that this study used linked cancer registry and claims data in which a large cohort of cancer survivors were followed six months to identify their depression treatment. Another advantage is that this study used different data sources and controlled for a 
comprehensive list of factors including the county-level percentage of psychologists and clinical factors such as cancer stage and cancer treatment that may affect the rates of depression treatment. A third advantage is that this study used Medicare part D to identify antidepressant treatment rates. This study also has some limitations. As the study population was restricted to fee-for-service Medicare beneficiaries, those residing in SEER regions and those who had Medicare part D coverage the study findings are not generalizable to all Medicare beneficiaries. Although other effective treatments for depression exist such as electroconvulsive therapy, this study focused on antidepressants and psychotherapy because they are the most commonly used depression treatment. While this study captured many variables that may be associated with the rates of depression treatment, some important variables such patient preferences were lacking. In addition, the reasons for no depression treatment was not explored in this study. This study can speculate that some elderly with cancer may not receive depression treatment because of competing demands of healthcare management and the prioritization of treatment of cancer. Also, providers may not prescribe antidepressants for treating depression due to the lack of robust evidence base.

\subsection{Conclusion}

Even with a successful diagnosis of depression in the oncology setting, a treatment gap exists. One-fourth of cancer survivors with newly-diagnosed depression did not receive any depression treatment. Therefore, greater effort is needed to ensure that cancer survivors are receiving depression treatment, especially for cancer survivors who initiated cancer treatment after depression diagnosis, as competing demands can impede depression care. Depression care can be imrpved by increasing the contact of cancer survivors with primary care providers and 
increase the supply of mental health services. Also, reducing racial disparities is important to improve depression care. 


\subsection{References}

(1) Jayadevappa R, Malkowicz SB, Chhatre S, Johnson JC, Gallo JJ. The burden of depression in prostate cancer. Psycho-Oncology 2012;21(12):1338-1345.

(2) Pallavi Balwant Rane. Burden of Colorectal Cancer among the elderly Medicare beneficiaries in West Virginia A comparative analysis with national data. United States -- West Virginia: West Virginia University; 2014.

(3) American Psychiatric Association. Practice guideline for the treatment of patients with major depressive disorder. : American Psychiatric Association; 2010.

(4) Tedeschini E, Levkovitz Y, Iovieno N, Ameral VE, Nelson JC, Papakostas GI. Efficacy of antidepressants for late-life depression: a meta-analysis and meta-regression of placebocontrolled randomized trials. J Clin Psychiatry 2011 Dec;72(12):1660-1668.

(5) Calati R, Salvina Signorelli M, Balestri M, Marsano A, De Ronchi D, Aguglia E, et al. Antidepressants in elderly: Metaregression of double-blind, randomized clinical trials. J Affect Disord 2013;147(1):1-8.

(6) Navari RM, Brenner MC, Wilson MN. Treatment of depressive symptoms in patients with early stage breast cancer undergoing adjuvant therapy. Breast Cancer Res Treat 2008 Nov;112(1):197-201.

(7) Fisch MJ, Loehrer PJ, Kristeller J, Passik S, Jung S, Shen J, et al. Fluoxetine versus placebo in advanced cancer outpatients: a double-blinded trial of the Hoosier Oncology Group. J Clin Oncol 2003 05/15;21(10):1937-1943.

(8) Holland JC, Romano SJ, Heiligenstein JH, Tepner RG, Wilson MG. A controlled trial of fluoxetine and desipramine in depressed women with advanced cancer. Psycho-Oncology 1998;7(4):291-300.

(9) Costa D, Mogos I, Toma T. Efficacy and safety of mianserin in the treatment of depression of women with cancer. Acta Psychiatr Scand 1985;72:85-92.

(10) van Heeringen K, Zivkov M. Pharmacological treatment of depression in cancer patients. A placebo-controlled study of mianserin. Br J Psychiatry 1996 Oct;169(4):440-443.

(11) Musselman DL, Somerset WI, Guo Y, Manatunga AK, Porter M, Penna S, et al. A doubleblind, multicenter, parallel-group study of paroxetine, desipramine, or placebo in breast cancer patients (stages I, II, III, and IV) with major depression. J Clin Psychiatry 2006 Feb;67(2):288296.

(12) Razavi D, Allilaire JF, Smith M, Salimpour A, Verra M, Desclaux B, et al. The effect of fluoxetine on anxiety and depression symptoms in cancer patients. Acta Psychiatr Scand 1996 Sep;94(3):205-210.

(13) Huang AX, Delucchi K, Dunn LB, Nelson JC. A Systematic Review and Meta-analysis of Psychotherapy for Late-Life Depression. The American Journal of Geriatric Psychiatry 2014. (14) SAVARD J, SIMARD S, GIGUÈRE I, IVERS H, MORIN CM, MAUNSELL E, et al. Randomized clinical trial on cognitive therapy for depression in women with metastatic breast cancer: psychological and immunological effects. Palliative \& supportive care 2006;4(03):219237.

(15) Qiu J, Chen W, Gao X, Xu Y, Tong H, Yang M, et al. A randomized controlled trial of group cognitive behavioral therapy for Chinese breast cancer patients with major depression. J Psychosom Obstet Gynaecol 2013 Jun;34(2):60-67.

(16) Simpson JS, Carlson LE, Trew ME. Effect of group therapy for breast cancer on healthcare utilization. Cancer Pract 2001 01;9(1):19-26. 
(17) Kissane DW, Grabsch B, Clarke DM, Smith GC, Love AW, Bloch S, et al. Supportiveexpressive group therapy for women with metastatic breast cancer: survival and psychosocial outcome from a randomized controlled trial. Psychooncology 2007 Apr;16(4):277-286.

(18) Spiegel D, Bloom JR, Yalom I. Group support for patients with metastatic cancer: A randomized prospective outcome study. Arch Gen Psychiatry 1981;38(5):527-533.

(19) Reynolds III CF, Miller MD, Pasternak RE, Frank E, Perel JM, Cornes C, et al. Treatment of bereavement-related major depressive episodes in later life: a controlled study of acute and continuation treatment with nortriptyline and interpersonal psychotherapy. 2014.

(20) Thompson LW, Coon DW, Gallagher-Thompson D, Sommer BR, Koin D. Comparison of desipramine and cognitive/behavioral therapy in the treatment of elderly outpatients with mildto-moderate depression. Am J Geriatr Psychiatry 2001 Summer;9(3):225-240.

(21) Rodriguez Vega B, Palao A, Torres G, Hospital A, Benito G, Perez E, et al. Combined therapy versus usual care for the treatment of depression in oncologic patients: a randomized controlled trial. Psychooncology 2011 Sep;20(9):943-952.

(22) Rodin G, Lloyd N, Katz M, Green E, Mackay JA, Wong RK, et al. The treatment of depression in cancer patients: a systematic review. Support Care Cancer 2007 Feb;15(2):123136.

(23) Howell D, Keller-Olaman S, Oliver T, Hack T, Broadfield L, Biggs K, et al. A panCanadian practice guideline: screening, assessment and care of psychosocial distress (depression, anxiety) in adults with cancer. Toronto: Canadian Partnership Against Cancer (Cancer Journey Action Group) and the Canadian Association of Psychosocial Oncology 2010.

(24) Andersen BL, DeRubeis RJ, Berman BS, Gruman J, Champion VL, Massie MJ, et al.

Screening, assessment, and care of anxiety and depressive symptoms in adults with cancer: an American Society of Clinical Oncology guideline adaptation. J Clin Oncol 2014 May 20;32(15):1605-1619.

(25) Findley PA, Shen C, Sambamoorthi U. Depression Treatment Patterns among Elderly with Cancer. Depress Res Treat 2012;2012:676784.

(26) Rane PB, Sambamoorthi U, Madhavan S. Depression treatment in individuals with cancer: a comparative analysis with cardio-metabolic conditions. Health Psychology Research 2013;1(1):e2.

(27) Andersen RM. Revisiting the behavioral model and access to medical care: does it matter? J Health Soc Behav 1995:1-10.

(28) National Cancer Institute. Surveillance, Epidemiology and End Results (SEER) Registry Groupings for Analyses. 2015; Available at: http://seer.cancer.gov/registries/terms.html.

(29) Department of Health and Human Services. Area Health and Resources Files (AHRF). 2015; Available at: http://ahrf.hrsa.gov/overview.htm.

(30) National Committee for Quality Assurance. The Healthcare Effectiveness Data and Information Set (HEDIS). Technical Specifications. 2008; Available at: http://www.ncqa.org/HEDISQualityMeasurement.aspx. Accessed 11/29, 2014.

(31) Chronic Conditions Data Warehouse. CCW Chronic Conditions Algorithms. 2016; Available at: https://www.ccwdata.org/web/guest/condition-categories.

(32) Zhang AY, Cooper GS. Recognition of Depression and Anxiety among Elderly Colorectal Cancer Patients. Nurs Res Pract 2010;2010:693961.

(33) Goodman RA. Defining and measuring chronic conditions: imperatives for research, policy, program, and practice. Preventing chronic disease 2013;10. 
(34) Suicidality and antidepressants in the elderly. Baylor University Medical Center. Proceedings: Baylor University Medical Center; 2008.

(35) Szanto K, Gildengers A, Mulsant BH, Brown G, Alexopoulos GS, Reynolds III CF. Identification of suicidal ideation and prevention of suicidal behaviour in the elderly. Drugs Aging 2002;19(1):11-24.

(36) Bhattacharjee S, Bhattacharya R, Kelley GA, Sambamoorthi U. Antidepressant use and new-onset diabetes: a systematic review and meta-analysis. Diabetes Metab Res 2013;29(4):273284.

(37) Cooper LA, Gonzales JJ, Gallo JJ, Rost KM, Meredith LS, Rubenstein LV, et al. The acceptability of treatment for depression among African-American, Hispanic, and white primary care patients. Med Care 2003 Apr;41(4):479-489.

(38) Whaley AL. Cultural mistrust and mental health services for African Americans a review and meta-analysis. The Counseling Psychologist 2001;29(4):513-531.

(39) Klabunde CN, Ambs A, Keating NL, He Y, Doucette WR, Tisnado D, et al. The role of primary care physicians in cancer care. Journal of general internal medicine 2009;24(9):10291036.

(40) Rost K, Nutting P, Smith J, Coyne JC, Cooper-Patrick L, Rubenstein L. The role of competing demands in the treatment provided primary care patients with major depression. Arch Fam Med 2000 Feb;9(2):150-154.

(41) Eiser N, West C, Evans S, Jeffers A, Quirk F. Effects of psychotherapy in moderately severe COPD: a pilot study. Eur Respir J 1997 Jul;10(7):1581-1584.

(42) Huntley A, White AR, Ernst E. Relaxation therapies for asthma: a systematic review. Thorax $2002 \mathrm{Feb} ; 57(2): 127-131$.

(43) Cheston 1 R, Jones 2 K, Gilliard 2 J. Group psychotherapy and people with dementia. Aging \& Mental Health 2003;7(6):452-461.

(44) Berkman LF, Blumenthal J, Burg M, Carney RM, Catellier D, Cowan MJ, et al. Effects of treating depression and low perceived social support on clinical events after myocardial infarction: the Enhancing Recovery in Coronary Heart Disease Patients (ENRICHD) Randomized Trial. JAMA: Journal of the American Medical Association 2003. (45) Lespérance F, Frasure-Smith N, Koszycki D, Laliberté M, van Zyl LT, Baker B, et al. Effects of citalopram and interpersonal psychotherapy on depression in patients with coronary artery disease: the Canadian Cardiac Randomized Evaluation of Antidepressant and Psychotherapy Efficacy (CREATE) trial. JAMA 2007;297(4):367-379.

(46) Liu SS, Ziegelstein RC. Depression in patients with heart disease: the case for more trials. Future cardiology 2010;6(4):547-556.

(47) Wei W, Sambamoorthi U, Olfson M, Walkup JT, Crystal S. Use of psychotherapy for depression in older adults. Am J Psychiatry 2005;162(4):711-717. 
Table 3.1

Description of the Study Population Elderly Fee-for-service Medicare beneficiaries with Breast, Colorectal or Prostate Cancer and Newly-diagnosed Depression,

SEER-Medicare Database, 2007-2012

\begin{tabular}{|c|c|c|}
\hline & $\mathbf{N}$ & $\%$ \\
\hline Total & 1,673 & 100.0 \\
\hline \multicolumn{3}{|c|}{ Predisposing factors } \\
\hline \multicolumn{3}{|c|}{ Age in years } \\
\hline $66-69$ & 434 & 25.9 \\
\hline $70-74$ & 430 & 25.7 \\
\hline $75-79$ & 342 & 20.4 \\
\hline$>=80$ & 467 & 27.9 \\
\hline \multicolumn{3}{|l|}{ Race } \\
\hline White & 1,393 & 83.3 \\
\hline AA & 145 & 8.7 \\
\hline Others & 135 & 8.1 \\
\hline
\end{tabular}

\section{Marital Status}

Married

$\begin{array}{ll}649 & 38.8 \\ 177 & 10.6 \\ 847 & 50.6\end{array}$

Sep/div/wid/Unkn

$10.18(10.08)$

Primary care visits (mean (SD))

$\begin{array}{lcr}\text { Cancer type } & & \\ \text { Breast } & 752 & 44.9 \\ \text { Women colorectal } & 381 & 22.8 \\ \text { Men colorectal } & 169 & 10.1 \\ \text { Prostate } & 371 & 22.2 \\ \text { Cancer Stage } & & \\ \text { Stage O-I } & 586 & 35.0 \\ \text { Stage II } & 720 & 43.0 \\ \text { Stage III } & 249 & 14.9 \\ \text { Stage IV } & 118 & 7.1 \\ \text { Cancer treatment } & & \\ \text { Before dep. Dx } & 1,137 & 68.0 \\ \text { After dep. Dx } & 358 & 21.4 \\ \text { No treatment } & 178 & 10.6\end{array}$

Continued, 
Table 3.1

Description of the Study Population Elderly Fee-for-service Medicare

beneficiaries with Breast, Colorectal or Prostate Cancer and Newly-diagnosed

Depression,

SEER-Medicare Database, 2007-2012

\begin{tabular}{|c|c|c|}
\hline & $\mathbf{N}$ & $\%$ \\
\hline \multicolumn{3}{|l|}{ Need factors } \\
\hline \multicolumn{3}{|l|}{ Cardiovascular } \\
\hline Yes & 1,469 & 90.8 \\
\hline No & 148 & 9.2 \\
\hline \multicolumn{3}{|l|}{ Musculoskeletal } \\
\hline Yes & 543 & 33.6 \\
\hline No & 1,074 & 66.4 \\
\hline \multicolumn{3}{|l|}{ Respiratory } \\
\hline Yes & 379 & 23.4 \\
\hline No & 1,238 & 76.6 \\
\hline \multicolumn{3}{|l|}{ Dementia } \\
\hline Yes & 219 & 13.1 \\
\hline No & 1,454 & 86.9 \\
\hline \multicolumn{3}{|l|}{ Anxiety } \\
\hline Yes & 437 & 26.1 \\
\hline No & 1,236 & 73.9 \\
\hline \multicolumn{3}{|c|}{ External Environment } \\
\hline \% Psychologists (mean (SD)) & $2.37(4.21)$ & \\
\hline \multicolumn{3}{|l|}{ Region } \\
\hline Northeast & 323 & 19.3 \\
\hline south & 457 & 27.3 \\
\hline North-central & 212 & 12.7 \\
\hline West & 681 & 40.7 \\
\hline \multicolumn{3}{|l|}{ Cancer diagnosis year } \\
\hline $2007-2009$ & 954 & 57.0 \\
\hline $2010-2012$ & 719 & 43.0 \\
\hline
\end{tabular}

Note: Based on 1,673 elderly fee-for-service Medicare beneficiaries with incident breast, colorectal and prostate cancer and Newly-diagnosed depression who were continuously enrolled in Medicare Part A and B during the observation period and Part D during the follow-up period and who were alive during the observation period.

AA: African American; ADRD: Alzheimer's disease and related disorders; dep: Depression; dx: diagnosis; SEER: Surveillance Epidemiology and End Results; Sep/div/wid/unkn: Separated/Divorced/Widowed/unknown; SD: Standard deviation. 
Table 3.2

Description of the Study Population by Depression Treatment Categories

Elderly Fee-for-service Medicare beneficiaries with Breast, Colorectal or Prostate Cancer and Newlydiagnosed Depression

SEER-Medicare Database, 2007-2012

\begin{tabular}{|c|c|c|c|c|c|c|c|c|c|c|}
\hline & \multicolumn{2}{|c|}{$\begin{array}{l}\text { Antidepressants } \\
\text { Only }\end{array}$} & \multicolumn{2}{|c|}{$\begin{array}{l}\text { Psychotherapy } \\
\text { Only }\end{array}$} & \multicolumn{2}{|c|}{$\begin{array}{l}\text { Combined } \\
\text { ADs/Psych } \\
\end{array}$} & \multicolumn{2}{|c|}{$\begin{array}{l}\text { No } \\
\text { Treatment }\end{array}$} & \multirow[b]{2}{*}{ chisq } & \multirow[b]{2}{*}{ sig } \\
\hline & $\mathbf{N}$ & $\%$ & $\mathbf{N}$ & $\%$ & $\mathbf{N}$ & $\%$ & $\mathbf{N}$ & $\%$ & & \\
\hline All & 764 & 45.7 & 148 & 8.8 & 308 & 18.4 & 453 & 27.1 & & \\
\hline \multicolumn{11}{|c|}{ Predisposing factors } \\
\hline Age in years & & & & & & & & & 8.6 & \\
\hline $66-69$ & 208 & 47.9 & 39 & 9.0 & 82 & 18.9 & 105 & 24.2 & & \\
\hline $70-74$ & 199 & 46.3 & 36 & 8.4 & 71 & 16.5 & 124 & 28.8 & & \\
\hline $75-79$ & 158 & 46.2 & 23 & 6.7 & 63 & 18.4 & 98 & 28.7 & & \\
\hline$>=80$ & 199 & 42.6 & 50 & 10.7 & 92 & 19.7 & 126 & 27.0 & & \\
\hline Race & & & & & & & & & 38.8 & $* * *$ \\
\hline White & 667 & 47.9 & 115 & 8.3 & 252 & 18.1 & 359 & 25.8 & & \\
\hline AA & 41 & 28.3 & 23 & 15.9 & 40 & 27.6 & 41 & 28.3 & & \\
\hline Others & 56 & 41.5 & 13 & 7.4 & 16 & 11.9 & 53 & 39.3 & & \\
\hline \multicolumn{11}{|c|}{ Enabling factors } \\
\hline Marital Status & & & & & & & & & 28.7 & $* * *$ \\
\hline Married & 305 & 47.0 & 41 & 6.3 & 112 & 17.3 & 191 & 29.4 & & \\
\hline Never married & 64 & 36.2 & 26 & 14.7 & 49 & 27.7 & 38 & 21.5 & & \\
\hline Sep/div/wid/Unkn & 395 & 46.6 & 81 & 9.6 & 147 & 17.4 & 224 & 26.4 & & \\
\hline $\begin{array}{l}\text { Primary care visits } \\
(\text { mean }(\text { SD)) }\end{array}$ & \multicolumn{2}{|c|}{$9.23(9.06)$} & \multicolumn{2}{|c|}{$13.07(13.83)$} & \multicolumn{2}{|c|}{12.27 ( 11.75$)$} & \multicolumn{2}{|c|}{$9.41(8.58)$} & & $* * *$ \\
\hline Cancer type & & & & & & & & & 12.4 & \\
\hline Breast & 369 & 49.1 & 58 & 7.7 & 130 & 17.3 & 195 & 25.9 & & \\
\hline $\begin{array}{l}\text { Women } \\
\text { colorectal }\end{array}$ & 165 & 43.3 & 40 & 10.5 & 71 & 18.6 & 105 & 27.6 & & \\
\hline Men colorectal & 67 & 39.6 & 22 & 13.0 & 31 & 18.3 & 49 & 29.0 & & \\
\hline Prostate & 163 & 43.9 & 28 & 7.5 & 76 & 20.5 & 104 & 28.0 & & \\
\hline Cancer Stage & & & & & & & & & 4.9 & \\
\hline Stage $0 / \mathrm{I}$ & 276 & 47.1 & 50 & 8.5 & 106 & 18.1 & 154 & 26.3 & & \\
\hline Stage II & 321 & 44.6 & 59 & 8.2 & 137 & 19.0 & 203 & 28.2 & & \\
\hline Stage III & 115 & 46.2 & 27 & 10.8 & 47 & 18.9 & 60 & 24.1 & & \\
\hline Stage IV & 52 & 44.1 & 12 & 10.2 & 18 & 15.3 & 36 & 30.5 & & \\
\hline Cancer treatment & & & & & & & & & 36.4 & $* * *$ \\
\hline Before dep $\mathrm{dx}$ & 507 & 44.6 & 106 & 9.3 & 227 & 20.0 & 297 & 26.1 & & \\
\hline After dep dx & 194 & 54.2 & 17 & 4.7 & 41 & 11.5 & 106 & 29.6 & & \\
\hline No treatment & 63 & 35.4 & 25 & 14.0 & 40 & 22.5 & 50 & 28.1 & & \\
\hline
\end{tabular}


Table 3.2

Description of the Study Population by Depression Treatment Categories

Elderly Fee-for-service Medicare beneficiaries with Breast, Colorectal or Prostate Cancer and Newlydiagnosed Depression

SEER-Medicare Database, 2007-2012

\begin{tabular}{|c|c|c|c|c|c|c|c|c|c|c|}
\hline & \multicolumn{2}{|c|}{$\begin{array}{l}\text { Antidepressants } \\
\text { Only } \\
\end{array}$} & \multicolumn{2}{|c|}{$\begin{array}{l}\text { Psychotherapy } \\
\text { Only } \\
\end{array}$} & \multicolumn{2}{|c|}{$\begin{array}{r}\text { Combined } \\
\text { ADs/Psych } \\
\end{array}$} & \multicolumn{2}{|c|}{$\begin{array}{l}\text { No } \\
\text { Treatment }\end{array}$} & \multirow[b]{2}{*}{ chisq } & \multirow[b]{2}{*}{ sig } \\
\hline & $\mathbf{N}$ & $\%$ & $\mathbf{N}$ & $\%$ & $\mathbf{N}$ & $\%$ & $\mathbf{N}$ & $\%$ & & \\
\hline \multicolumn{11}{|l|}{ Continued, } \\
\hline \multicolumn{11}{|c|}{ Need factors } \\
\hline Cardiovascular & & & & & & & & & 10.6 & $*$ \\
\hline Yes & 691 & 47.0 & 127 & 8.6 & 292 & 19.9 & 359 & 24.4 & & \\
\hline No & 73 & 49.3 & 21 & 14.2 & 16 & 10.8 & 38 & 25.7 & & \\
\hline Musculoskeletal & & & & & & & & & 5.7 & \\
\hline Yes & 243 & 44.8 & 48 & 8.8 & 121 & 22.3 & 131 & 24.1 & & \\
\hline No & 521 & 48.5 & 100 & 9.3 & 187 & 17.4 & 266 & 24.8 & & \\
\hline Respiratory & & & & & & & & & 9.5 & $*$ \\
\hline Yes & 174 & 45.9 & 47 & 12.4 & 79 & 20.8 & 79 & 20.8 & & \\
\hline No & 590 & 47.7 & 101 & 8.2 & 229 & 18.5 & 318 & 25.7 & & \\
\hline ADRD & & & & & & & & & 55.7 & $* * *$ \\
\hline Yes & 83 & 37.9 & 33 & 15.1 & 71 & 32.4 & 32 & 14.6 & & \\
\hline No & 681 & 46.8 & 115 & 7.9 & 237 & 16.3 & 421 & 29.0 & & \\
\hline Anxiety & & & & & & & & & 13.7 & $* *$ \\
\hline Yes & 205 & 46.9 & 25 & 5.7 & 99 & 22.7 & 108 & 24.7 & & \\
\hline No & 559 & 45.2 & 123 & 10.0 & 209 & 16.9 & 345 & 27.9 & & \\
\hline \multicolumn{11}{|c|}{ External Environment } \\
\hline $\begin{array}{l}\text { \% Psychologists } \\
(\text { mean (SD)) }\end{array}$ & 2.0 & $(3.92)$ & 3.08 & 4.85) & & (4.56) & 2.49 & (4.23) & & $* * *$ \\
\hline Region & & & & & & & & & 59.3 & $* * *$ \\
\hline Northeast & 121 & 37.5 & 43 & 13.3 & 89 & 27.6 & 70 & 21.7 & & \\
\hline south & 243 & 53.2 & 24 & 5.3 & 60 & 13.1 & 130 & 28.4 & & \\
\hline North-central & 92 & 43.4 & 23 & 10.8 & 49 & 23.1 & 48 & 22.6 & & \\
\hline West & 308 & 45.2 & 58 & 8.5 & 110 & 16.2 & 205 & 30.1 & & \\
\hline Cancer diagnosis year & & & & & & & & & 19.4 & \\
\hline 2007-2009 & 104 & 39.8 & 30 & 11.5 & 45 & 17.2 & 82 & 31.4 & & \\
\hline 2010-2012 & 178 & 48.1 & 36 & 9.7 & 61 & 16.5 & 95 & 25.7 & & \\
\hline
\end{tabular}

Note: Based on 1,673 elderly fee-for-service Medicare beneficiaries with incident breast, colorectal or prostate cancer and Newly-diagnosed depression who were continuously enrolled in Medicare Part A and B during the observation period and Part D during the follow-up period. Asterisks represent significant differences in study population characteristics by depression treatment categories, derived from chi-square statistics.

$* * * \mathrm{p}<.001 ; * * .001 \leq \mathrm{p}<.01 ; * .01 \leq \mathrm{p}<.05$. 
AA: African American; ADs: Antidepressants; ADRD: Alzheimer's disease and related disorders; dep: Depression; dx: diagnosis; SEER: Surveillance Epidemiology and End Results; Sep/div/wid/unkn:

Separated/Divorced/Widowed/unknown; SD: Standard deviation; Psych: psychotherapy. 
Table 3.3

Unadjusted Odds Ratios and 95\% Confidence Intervals of Depression Treatment Categories from Multinomial Logistic Regression on Depression Treatment Categories Elderly Fee-for-service Medicare beneficiaries with Breast, Colorectal or Prostate Cancer and Newly-diagnosed Depression SEER-Medicare database, 2007-2012

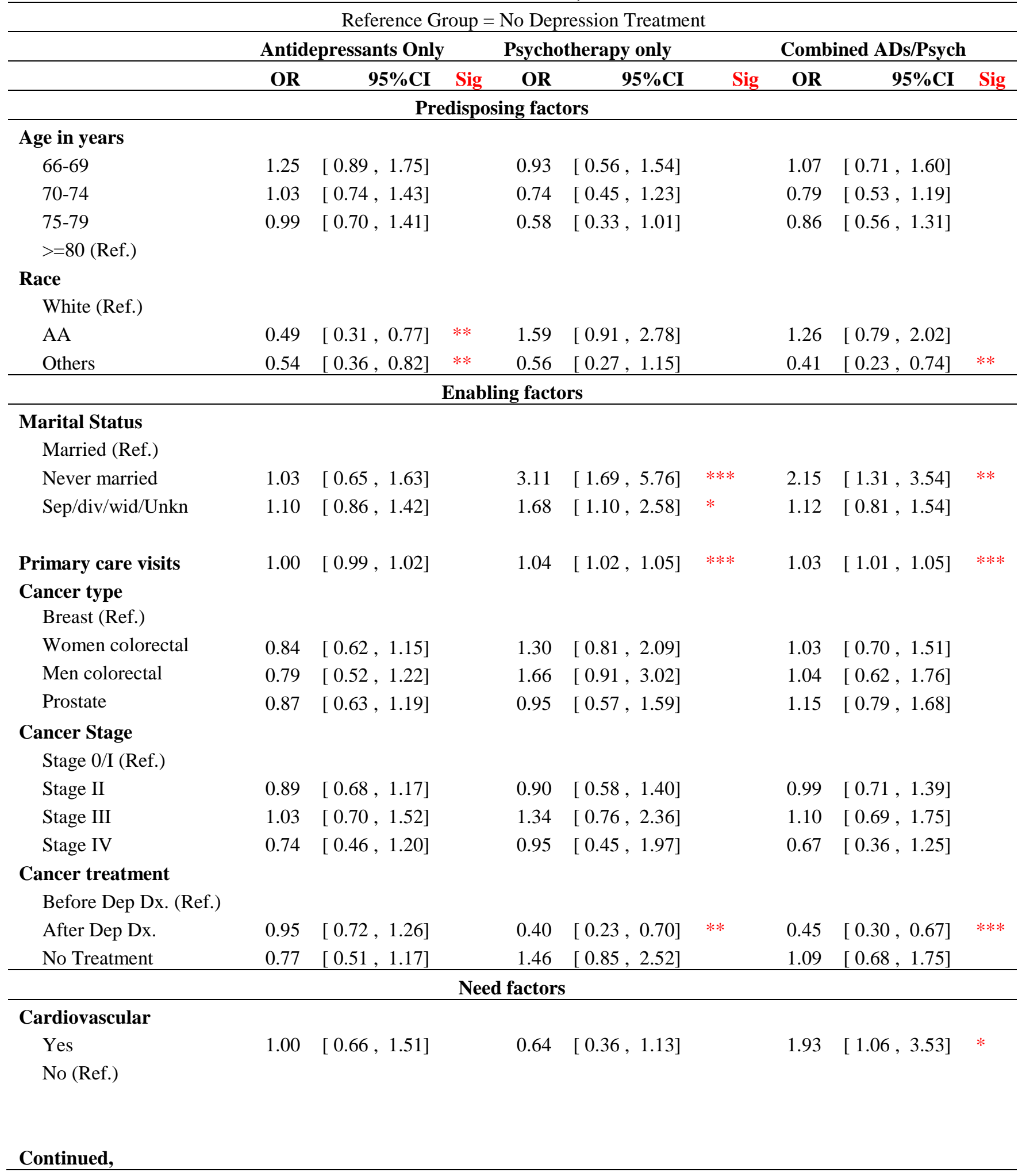


Table 3.3

Unadjusted Odds Ratios and 95\% Confidence Intervals of Depression Treatment Categories from Multinomial Logistic Regression on Depression Treatment Categories Elderly Fee-for-service Medicare beneficiaries with Breast, Colorectal or Prostate Cancer and Newly-diagnosed Depression SEER-Medicare database, 2007-2012

\begin{tabular}{|c|c|c|c|c|c|c|c|c|c|}
\hline \multicolumn{10}{|c|}{ Reference Group = No Depression Treatment } \\
\hline & \multicolumn{3}{|c|}{ Antidepressants Only } & \multicolumn{2}{|c|}{ Psychotherapy only } & \multicolumn{4}{|c|}{ Combined ADs/Psych } \\
\hline & OR & $95 \% \mathrm{CI}$ & Sig & OR & $95 \% \mathrm{CI}$ & Sig & OR & $95 \% \mathrm{CI}$ & Sig \\
\hline \multicolumn{10}{|l|}{ Musculoskeletal } \\
\hline Yes & 0.95 & {$[0.73,1.23]$} & & 0.97 & {$[0.65,1.46]$} & & 1.31 & {$[0.96,1.79]$} & \\
\hline \multicolumn{10}{|l|}{ No (Ref.) } \\
\hline \multicolumn{10}{|l|}{ Respiratory } \\
\hline Yes & 1.19 & {$[0.88,1.60]$} & & 1.87 & {$[1.22,2.86]$} & $* *$ & 1.39 & {$[0.97,1.98]$} & \\
\hline \multicolumn{10}{|l|}{ No (Ref.) } \\
\hline \multicolumn{10}{|l|}{ ADRD } \\
\hline Yes & 1.39 & {$[0.91,2.13]$} & & 3.27 & {$[1.93,5.56]$} & $* * *$ & 3.42 & {$[2.18,5.35]$} & $* * *$ \\
\hline \multicolumn{10}{|l|}{ No (Ref.) } \\
\hline \multicolumn{10}{|l|}{ Anxiety } \\
\hline Yes & 0.98 & {$[0.75,1.29]$} & & 0.54 & {$[0.34,0.88]$} & $*$ & 1.27 & {$[0.92,1.76]$} & \\
\hline \multicolumn{10}{|l|}{ No (Ref.) } \\
\hline \multicolumn{10}{|c|}{ External Environment } \\
\hline \% Psychologists & 0.99 & {$[0.96,1.02]$} & & 1.05 & {$[1.00,1.11]$} & $*$ & 1.05 & {$[1.00,1.09]$} & $*$ \\
\hline \multicolumn{10}{|l|}{ Region } \\
\hline Northeast & 1.08 & {$[0.76,1.54]$} & & 2.04 & {$[1.25,3.32]$} & $* *$ & 2.23 & {$[1.49,3.32]$} & $* * *$ \\
\hline south & 1.17 & {$[0.88,1.55]$} & & 0.61 & {$[0.36,1.04]$} & & 0.81 & {$[0.55,1.19]$} & \\
\hline North-central & 1.38 & {$[0.91,2.11]$} & & 1.84 & {$[1.01,3.34]$} & $*$ & 2.06 & {$[1.27,3.35]$} & $* *$ \\
\hline \multicolumn{10}{|l|}{ West (Ref.) } \\
\hline \multicolumn{10}{|l|}{ Cancer diagnosis } \\
\hline \multicolumn{10}{|l|}{2007 (Ref.) } \\
\hline 2008 & 0.84 & {$[0.66,1.07]$} & & 0.82 & {$[0.56,1.20]$} & & 0.99 & {$[0.73,1.33]$} & \\
\hline
\end{tabular}

Note: Based on 1,673 elderly fee-for-service Medicare beneficiaries with incident breast, colorectal or prostate cancer and Newly-diagnosed depression who were continuously enrolled in Medicare Part A and B during the observation period and Part D during the follow-up period. Asterisks represent significant differences in study population characteristics by depression treatment categories, derived from multinomial logistic regression.

$* * * \mathrm{p}<.001 ; * * .001 \leq \mathrm{p}<.01 ; * .01 \leq \mathrm{p}<.05$

AA: African American; ADRD: Alzheimer's disease and related disorders; CI: Confidence interval; dep: Depression; dx: diagnosis; OR: Odds ratio; SEER: Surveillance Epidemiology and End Results; Sep/div/wid/unkn: Separated/Divorced/Widowed/unknown; SD: Standard deviation; Ref: Reference group; Psych: psychotherapy. 
Table 3.4

Adjusted Odds Ratios and 95\% Confidence Intervals of Depression Treatment Categories from Multinomial Logistic Regression on Depression Treatment Categories Elderly Fee-for-service Medicare beneficiaries with Breast, Colorectal or Prostate Cancer and Newly-diagnosed Depression

SEER-Medicare database, 2007-2012

\begin{tabular}{|c|c|c|c|c|c|c|c|c|c|}
\hline \multicolumn{10}{|c|}{ Reference Group $=$ No Depression Treatment } \\
\hline & \multicolumn{3}{|c|}{ Antidepressants Only } & \multicolumn{2}{|c|}{ Psychotherapy only } & \multicolumn{4}{|c|}{ Combined AD/Psych } \\
\hline & AOR & $95 \% \mathrm{CI}$ & Sig & AOR & $95 \% \mathrm{CI}$ & Sig & AOR & $95 \% \mathrm{CI}$ & Sig \\
\hline \multicolumn{10}{|c|}{ Predisposing factors } \\
\hline \multicolumn{10}{|l|}{ Age in years } \\
\hline $66-69$ & 1.39 & {$[0.97,2.01]$} & & 1.41 & {$[0.80,2.47]$} & & 1.52 & {$[0.96,2.39]$} & \\
\hline $70-74$ & 1.14 & {$[0.80,1.62]$} & & 1.15 & {$[0.66,2.00]$} & & 1.07 & {$[0.68,1.68]$} & \\
\hline $75-79$ & 1.01 & {$[0.71,1.45]$} & & 0.75 & {$[0.42,1.37]$} & & 0.96 & {$[0.61,1.51]$} & \\
\hline \multicolumn{10}{|l|}{$>=80$ (Ref.) } \\
\hline \multicolumn{10}{|l|}{ Race } \\
\hline \multicolumn{10}{|l|}{ White (Ref.) } \\
\hline African Americans & 0.44 & {$[0.27,0.70]$} & $* * *$ & 1.19 & {$[0.64,2.21]$} & & 1.02 & {$[0.61,1.71]$} & \\
\hline Other races & 0.59 & {$[0.38,0.92]$} & $*$ & 0.49 & {$[0.22,1.06]$} & & 0.38 & {$[0.20,0.71]$} & $* *$ \\
\hline \multicolumn{10}{|c|}{ Enabling factors } \\
\hline \multicolumn{10}{|l|}{ Marital Status } \\
\hline \multicolumn{10}{|l|}{ Married (Ref.) } \\
\hline Never married & 1.14 & {$[0.71,1.83]$} & & 2.33 & {$[1.21,4.48]$} & $*$ & 1.68 & {$[0.98,2.86]$} & \\
\hline Sep/div/wid/Unkn & 1.15 & {$[0.87,1.51]$} & & 1.57 & {$[0.98,2.50]$} & & 1.02 & {$[0.71,1.45]$} & \\
\hline PCP visits & 1.00 & {$[0.99,1.02]$} & & 1.02 & {$[1.00,1.04]$} & $*$ & 1.02 & {$[1.00,1.04]$} & * \\
\hline \multicolumn{10}{|l|}{ Cancer types } \\
\hline \multicolumn{10}{|l|}{ Women Breast (Ref.) } \\
\hline $\begin{array}{l}\text { Women Colorectal } \\
\text { Men Colorectal }\end{array}$ & 0.93 & {$[0.67,1.29]$} & & 0.97 & {$[0.59,1.60]$} & & 0.72 & {$[0.47,1.09]$} & \\
\hline Cancer & 0.87 & {$[0.55,1.35]$} & & 1.54 & {$[0.81,2.95]$} & & 1.04 & {$[0.60,1.81]$} & \\
\hline Men Prostate Cancer & 1.10 & {$[0.76,1.57]$} & & 1.01 & {$[0.56,1.82]$} & & 1.17 & {$[0.74,1.85]$} & \\
\hline \multicolumn{10}{|l|}{ Cancer Stage } \\
\hline \multicolumn{10}{|l|}{ Stage 0/I (Ref.) } \\
\hline Stage II & 0.89 & {$[0.65,1.22]$} & & 0.78 & {$[0.47,1.31]$} & & 0.83 & {$[0.55,1.25]$} & \\
\hline Stage III & 1.14 & {$[0.76,1.71]$} & & 1.11 & {$[0.60,2.07]$} & & 1.01 & {$[0.61,1.69]$} & \\
\hline Stage IV & 0.83 & {$[0.50,1.37]$} & & 0.78 & {$[0.36,1.73]$} & & 0.66 & {$[0.34,1.30]$} & \\
\hline \multicolumn{10}{|l|}{ Cancer treatment } \\
\hline \multicolumn{10}{|l|}{ Before dep. Dx (Ref.) } \\
\hline After dep dx. & 0.95 & {$[0.70,1.27]$} & & 0.40 & {$[0.22,0.72]$} & $* *$ & 0.51 & {$[0.34,0.79]$} & $* *$ \\
\hline No Treatment & 0.83 & {$[0.53,1.28]$} & & 1.31 & {$[0.72,2.40]$} & & 0.90 & {$[0.54,1.51]$} & \\
\hline
\end{tabular}

Continued, 
Table 3.4

Adjusted Odds Ratios and 95\% Confidence Intervals of Depression Treatment Categories from Multinomial Logistic Regression on Depression Treatment Categories Elderly Fee-for-service Medicare beneficiaries with Breast, Colorectal or Prostate Cancer and Newly-diagnosed Depression

SEER-Medicare database, 2007-2012

\begin{tabular}{|c|c|c|c|c|c|c|c|c|c|}
\hline \multicolumn{10}{|c|}{ Reference Group = No Depression Treatment } \\
\hline & \multicolumn{3}{|c|}{ Antidepressants Only } & \multicolumn{2}{|c|}{ Psychotherapy only } & \multicolumn{4}{|c|}{ Combined AD/Psych } \\
\hline & AOR & $95 \% \mathrm{CI}$ & Sig & AOR & $95 \% \mathrm{CI}$ & Sig & AOR & $95 \% \mathrm{CI}$ & Sig \\
\hline \multicolumn{10}{|c|}{ Need factors } \\
\hline \multicolumn{10}{|l|}{ Cardiovascular } \\
\hline Yes & 1.04 & {$[0.68,1.61]$} & & 0.39 & {$[0.21,0.74]$} & $* *$ & 1.41 & {$[0.75,2.68]$} & \\
\hline No (Ref.) & & & & & & & & & \\
\hline \multicolumn{10}{|l|}{ Musculoskeletal } \\
\hline Yes & 0.94 & {$[0.71,1.24]$} & & 0.88 & {$[0.57,1.38]$} & & 1.15 & {$[0.82,1.63]$} & \\
\hline \multicolumn{10}{|l|}{ No (Ref.) } \\
\hline \multicolumn{10}{|l|}{ Respiratory } \\
\hline Yes & 1.22 & {$[0.90,1.67]$} & & 1.64 & {$[1.04,2.58]$} & $*$ & 1.20 & {$[0.82,1.75]$} & \\
\hline \multicolumn{10}{|l|}{ No (Ref.) } \\
\hline \multicolumn{10}{|l|}{ ADRD } \\
\hline Yes & 1.53 & {$[0.98,2.40]$} & & 2.58 & {$[1.44,4.61]$} & $* *$ & 2.94 & {$[1.81,4.76]$} & $* * *$ \\
\hline \multicolumn{10}{|l|}{ No (Ref.) } \\
\hline \multicolumn{10}{|l|}{ Anxiety } \\
\hline Yes & 0.94 & {$[0.71,1.24]$} & & 0.48 & {$[0.29,0.80]$} & $* *$ & 1.17 & {$[0.82,1.66]$} & \\
\hline \multicolumn{10}{|l|}{ No (Ref.) } \\
\hline \multicolumn{10}{|c|}{ External Environment } \\
\hline \% Psychologists & 0.99 & {$[0.96,1.02]$} & & 1.05 & {$[1.00,1.11]$} & $*$ & 1.05 & {$[1.00,1.09]$} & $*$ \\
\hline \multicolumn{10}{|l|}{ Region } \\
\hline Northeast & 0.99 & {$[0.67,1.46]$} & & 2.53 & {$[1.42,4.52]$} & $* *$ & 2.48 & {$[1.56,3.95]$} & $* * *$ \\
\hline south & 1.07 & {$[0.77,1.51]$} & & 0.74 & {$[0.39,1.39]$} & & 0.84 & {$[0.52,1.34]$} & \\
\hline North-central & 1.27 & {$[0.81,1.99]$} & & 2.27 & {$[1.15,4.51]$} & $*$ & 2.18 & {$[1.26,3.77]$} & $* *$ \\
\hline West (Ref.) & & & & & & & & & \\
\hline \multicolumn{10}{|l|}{ Cancer diagnosis } \\
\hline 2007-2009 (Ref.) & & & & & & & & & \\
\hline 2010-2012 & 0.82 & {$[0.64,1.05]$} & & 0.88 & {$[0.59,1.33]$} & & 1.02 & {$[0.75,1.40]$} & \\
\hline
\end{tabular}

Note: Based on 1,673 elderly fee-for-service Medicare beneficiaries with incident breast, colorectal or prostate cancer and Newly-diagnosed depression who were continuously enrolled in Medicare Part A and B during the observation period and Part D during the follow-up period. Asterisks represent significant differences in study population characteristics by depression treatment categories, derived from multinomial logistic regression.

*** $\mathrm{p}<.001 ; * * .001 \leq \mathrm{p}<.01 ; * .01 \leq \mathrm{p}<.05$.

AOR: adjusted odds ratio; AA: African American; ADRD: Alzheimer's disease and related disorders; CI: Confidence interval; dep: Depression; dx: diagnosis; SEER: Surveillance Epidemiology and End Results; 
Sep/div/wid/unkn: Separated/Divorced/Widowed/unknown; SD: Standard deviation; Ref: Reference group; Psych: psychotherapy. 
Appendix 3.1 Study Cohort Development Flow Diagram for Study Population of Elderly Medicare Beneficiaries Diagnosed with Incident Breast, Colorectal or Prostate cancer and Newly-diagnosed Depression

- $\quad$ Cancer diagnosed identified using Siterwho 1- -10 codes

Breast $\mathrm{N}=392,684$, Colorectal $\mathrm{N}=291,491$, Prostate $\mathrm{N}=461,994$

- $\quad$ Diagnosed with cancer from April 2007 to Dec 2011

Breast $\mathrm{N}=169,955$, Colorectal $\mathrm{N}=125,261$, Prostate $\mathrm{N}=205,505$

- $\quad$ Diagnosed with cancer from April 2007 to Dec 2011

- Primary cancer only in the patient's lifetime (Seq1 in "00")

- Not diagnosed with cancer at autopsy or death certificate

- Incident cases

Breast $\mathrm{N}=129,206$, Colorectal $\mathrm{N}=89,272$, Prostate $\mathrm{N}=168,783$

- $\quad$ Elderly with cancer from April 2007 to Dec 2011

- With primary cancer (Seq1 in " 00 ”)

- Not diagnosed with cancer at autopsy or death certificate

- Incident cases, >=66, alive

Breast $\mathrm{N}=73,496$, Colorectal $\mathrm{N}=45,571$, Prostate $\mathrm{N}=107,585$

- $\quad$ Diagnosed with cancer from April 2007 to Dec 2011

- With primary cancer (Seq1 in "00”), Not diagnosed with cancer at autopsy or death certificate, Incident cases, $>=66$, alive

- Have depression diagnosis

- Depression free at cancer diagnosis

- Developed newly-diagnosed depression at the $12 \mathrm{~m}$ follow-up period

Final Analytical Cohort

- $\quad$ Diagnosed with cancer from April 2007 to Dec 2011

- With primary cancer (Seq1 in "00"), Not diagnosed with cancer at autopsy or death certificate, Incident cases, >=66, alive, Newlydiagnosed depression.

- Fee-for-service continuous enrollment A and B $12 \mathrm{~m}$ before depression dxdt and part D 12m after depression dxdt

Breast $\mathrm{N}=752$, Colorectal $\mathrm{N}=550$, Prostate $\mathrm{N}=371$

$$
(\mathrm{N}=1,673)
$$

Reason for exclusion:

- $\quad$ Not one primary cancer $(n=39,257$, $\mathrm{n}=34,683, \mathrm{n}=34,738$ )

- Diagnosed at autopsy or death cert. $(\mathrm{n}=854, \mathrm{n}=1,061, \mathrm{n}=1,545)$

- $\quad$ Not incident cases $(n=33,418$, $\mathrm{n}=30,827, \mathrm{n}=32232$ )

Reasons for exclusion:

- $\quad<66$ years old $(n=47,290, n=23,744$, $\mathrm{n}=56,295$ )

- Unknown stage of cancer $(n=6,614$, $\mathrm{n}=4,619, \mathrm{n}=10,185$ )

- Death $(n=4,063, n=14,434, n=3,822)$

Reasons for exclusion:

- No depression diagnoses $(n=65,216$, $\mathrm{n}=40,934, \mathrm{n}=102,155$ )

- Not depression free at cancer diagnosis $(\mathrm{n}=3,810, \mathrm{n}=1,774, \mathrm{n}=2,340)$

- No developed depression during the 12 months follow-up period $(n=2,665, n=1,430$, $\mathrm{n}=2,040$ )

Reasons for exclusion:

- HMO enrollment and NO Continuous enroll in Part A \& B ( $=443, n=461, n=296)$

- No Continuous enroll in Part D ( $n=533$, $\mathrm{n}=392, \mathrm{n}=346$ ) 
Appendix 3.2

Adjusted Odds Ratios and 95\% Confidence Intervals of Depression Treatment Categories by Cancer Types from Multinomial Logistic Regression on Depression Treatment Categories Elderly Fee-for-service Medicare beneficiaries with Breast, Colorectal or Prostate Cancer, SEER-Medicare data from 2007-2012

\begin{tabular}{|c|c|c|c|c|c|c|c|c|c|}
\hline & \multicolumn{3}{|c|}{ Antidepressants Only } & \multicolumn{2}{|c|}{ Psychotherapy only } & \multicolumn{4}{|c|}{ Combined ADs/Psych } \\
\hline & AOR & $95 \% \mathrm{CI}$ & Sig & AOR & $95 \% \mathrm{CI}$ & Sig & AOR & $95 \% \mathrm{CI}$ & Sig \\
\hline \multicolumn{10}{|c|}{ Reference Group = Women Breast Cancer } \\
\hline \multicolumn{10}{|l|}{ Cancer types } \\
\hline Women Colorectal Cancer & 0.93 & {$[0.67,1.29]$} & & 0.97 & {$[0.59,1.60]$} & & 0.72 & {$[0.47,1.09]$} & \\
\hline Men Colorectal Cancer & 0.87 & {$[0.55,1.35]$} & & 1.54 & {$[0.81,2.95]$} & & 1.04 & {$[0.60,1.81]$} & \\
\hline Men Prostate Cancer & 1.10 & {$[0.76,1.57]$} & & 1.01 & {$[0.56,1.82]$} & & 1.17 & {$[0.74,1.85]$} & \\
\hline \multicolumn{10}{|c|}{ Reference Group = Men Prostate Cancer } \\
\hline Women Breast Cancer & 0.91 & {$[0.64,1.31]$} & & 0.99 & {$[0.55,1.79]$} & & 0.85 & {$[0.54,1.35]$} & \\
\hline Women Colorectal Cancer & 0.85 & {$[0.57,1.28]$} & & 0.96 & {$[0.51,1.81]$} & & 0.61 & {$[0.37,1.03]$} & \\
\hline Men Colorectal Cancer & 0.79 & {$[0.48,1.30]$} & & 1.53 & {$[0.74,3.18]$} & & 0.89 & {$[0.48,1.65]$} & \\
\hline
\end{tabular}

Note: Based on 1,673 elderly fee-for-service Medicare beneficiaries with incident breast, Colorectal or prostate cancer and Newly-diagnosed depression who were continuously enrolled in Medicare Part A and B during

the observation period and Part D during the follow-up period. Asterisks represent significant differences in study population characteristics by depression treatment categories, derived from multinomial logistic regression.

$* * * \mathrm{p}<.001 ; * * .001 \leq \mathrm{p}<.01 ; * .01 \leq \mathrm{p}<.05$.

ADs: Antidepressants; AOR: Adjusted odds ratio; CI: Confidence interval; Psych: Psychotherapy. 


\section{Chapter 4 \\ Depression Treatment and Short-term Healthcare Expenditures \\ among Elderly Medicare Beneficiaries with Newly-diagnosed Depression and Incident \\ Breast, Colorectal or Prostate Cancer}

\subsection{Abstract}

Objectives. Depression is associated with high healthcare expenditures and depression treatment may reduce healthcare expenditures. However, to date there have not been any studies on the effect of depression treatment on healthcare expenditures among cancer survivors. Therefore, the purpose of this study is to examine the association between depression treatment and healthcare expenditures among elderly Medicare beneficiaries with newly-diagnosed depression and incident breast, colorectal or prostate cancer.

Methods. The current study utilized a retrospective longitudinal study design using the linked Surveillance, Epidemiology and End Results (SEER)-Medicare database. Elderly ( $\geq 66$ years) fee-for-service Medicare beneficiaries with newly diagnosed depression and incident breast, colorectal or prostate cancer $(\mathrm{N}=1,502)$ were followed for a period of 12 months after depression diagnosis. Healthcare expenditures were measured every month for a period of 12 months after depression diagnosis. Depression treatment was identified during the six months after depression diagnosis and was categorized into four mutually exclusive categories: 1) treatment with antidepressants only, 2) treatment with psychotherapy only, 3) combined treatment with both antidepressants and psychotherapy and 4) no depression treatment. The adjusted associations between depression treatment and healthcare expenditures were analyzed with Generalized Linear Mixed Model (GLMM) regressions with gamma distribution and loglink. These regressions controlled for predisposing, enabling, need, and external environmental 
factors. Additionally, the inverse probability weighting technique (IPTW) was used to adjust for observed selection bias in depression treatment categories.

Results. The average 1-year total healthcare expenditures after depression diagnosis were $\$ 38,219$ for those who did not receive depression treatment; $\$ 42,090$ for those treated with antidepressants only; $\$ 46,913$ for those treated with psychotherapy only and $\$ 51,008$ for those treated with a combination of antidepressants and psychotherapy. As compared to no depression treatment, those who received antidepressants had $\$ 1,317$ higher total healthcare expenditures those who received psychotherapy had $\$ 2,186$ higher total healthcare expenditures; and those who received combination of antidepressants and psychotherapy had $\$ 2,754$ higher total healthcare expenditures, after adjusting for selection bias and predisposing, enabling, need, and external environment factors. The associations between depression treatment and the higher healthcare expenditures were observed across all types of healthcare expenditures.

Conclusions. Among cancer survivors with newly-diagnosed depression, treatment for depression was associated with higher short-term healthcare expenditures as compared to no depression treatment. 


\subsection{Introduction}

Depression is highly prevalent among cancer survivors and it has been reported that cancer survivors with depression incur higher healthcare expenditures as compared to those without depression (1). Among elderly prostate cancer survivors, those with depression had $33.3 \%$ higher healthcare expenditures during the 12 months after cancer diagnosis as compared to those without depression (1). Among adults with cancer, those with depression had $31.7 \%$ higher one-year healthcare expenditures as compared to those without depression (2).

While depression leads to increased healthcare expenditures, depression treatment may lead to a reduction in healthcare expenditures due to improved health outcomes. However, to date there have not been any studies that have examined the association between depression treatment and healthcare expenditures in real-world settings. Therefore, this study infer the association between depression treatment and healthcare expenditures using findings from studies among elderly individuals. These studies have shown mixed results on the association between depression treatment and healthcare expenditures. The Improving Mood-Promoting Access to Collaborative Treatment (IMPACT) randomized controlled trial (RCT), which included 418 individuals aged 60 years or older, found that at the end of 24 months the intervention group had $\$ 896$ lower expenditures as compared to the usual care group (3). Among adults with cancer, a RCT found that collaborative care for depression was cost-effective as compared to usual care $(4,5)$. However, these trials did not compare the healthcare expenditures of those who received depression treatment to those who did not receive any depression treatment. A study among elderly fee-for-service Medicare beneficiaries with prevalent depression and chronic physical conditions seeking care in real-world practice settings found that treatment for depression with antidepressants (20\%) and treatment with psychotherapy 
with/without antidepressants (29\%) was associated with an increase in short-term total healthcare expenditures (6). A longitudinal study in real-world practice settings found that elderly who received antidepressant treatment had $32 \%$ higher outpatient expenditures as compared to those without antidepressant treatment (Fischer et al., 2002).

The above-mentioned studies suggest that the relationship between depression treatment and healthcare expenditures is not yet established. To the best of our knowledge, there are no studies that examine whether depression treatment can reduce healthcare expenditures among cancer survivors seeking care in real-world settings. It is important to understand the association between depression treatment and healthcare expenditures for many reasons. First, depression is associated with poor Health-related Quality of Life (HRQoL), higher healthcare utilization and expenditures $(1,7)$, and unplanned readmissions (8-10). Depression treatment can improve health outcomes and may reduce healthcare utilization and expenditures. Understanding this association is particularly important as a large portion of Medicare healthcare expenditures for cancer patients is attributed to the treatment of coexisting health conditions (11). Furthermore, Medicare has implemented many payment reforms to ensure high quality care at lower costs (12). Given the importance of reducing healthcare spending among Medicare beneficiaries, the current study can provide important information on comparative effectiveness of depression treatment to payers, policy makers and providers. The primary objective of the current study is to compare healthcare expenditures by depression treatment categories among elderly fee-for-service Medicare beneficiaries with newly-diagnosed depression and incident breast, colorectal or prostate cancer. 


\subsection{Conceptual framework}

This study utilized the expanded behavioral model on healthcare utilization, the Andersen Behavioral Model, to help our selection of the variables that may affect healthcare expenditures (13). The model suggests that the utilization of health services varies as a function of 1) an individual's unique predisposition for using services (predisposing factors - age and race); 2) the resources available to each individual for obtaining services (enabling factors: cancer type, cancer stage, cancer treatment, marital status and Primary Care Physican (PCP) visits), 3) the individual's need (need factors - depression treatment, the number of chronic physical and mental health conditions); and 4) the external environment: SEER region and year of cancer diagnosis.

\subsection{Methods}

\subsubsection{Design}

This study utilized a retrospective longitudinal study design with a 12-month baseline (April 2006 through December 2011) and a 12-month follow-up period (April 2007 through December 2012). The baseline period was based on depression diagnosis date and consisted of the 12 months before the depression diagnosis date. Healthcare expenditures were measured every month for a period of 12 months after depression diagnosis. To capture the variations in healthcare expenditures at different time point of follow-up period. This study used the repeated measures statistical models. As independent measure design often measure aggregated healthcare expenditures at the follow-up period, repeated measures were used because it allowed us to capture the expenditures during and after depression treatment.

Depression treatment was measured during the first six months after depression diagnosis. Other explanatory variables were measured during the 12-months before depression diagnosis and during the follow-up period. 


\subsubsection{Data Sources}

The current study linked data from several sources including the SEER-Medicare linked database, ACS estimates from census, and the AHRF files. The detailed description of the data sources are provided in Chapter 1.

\subsubsection{Study population}

The study population is composed of elderly cancer survivors (age $\geq 66$ years) who were diagnosed with incident breast, colorectal or prostate cancer and who were newly-diagnosed with depression after cancer diagnosis between 2007 and 2011. This study identified the cancer types (breast, colorectal or prostate cancer) using the International Classification of Diseases for Oncology, 3rd Edition (ICD-O-3) histology codes and the primary site variable.

\section{Cancer Survivors with newly-diagnosed depression}

This study identified cancer survivors with newly-diagnosed depression based on the National Committee on Quality Assurance (NCQA) criteria (15). To achieve this, a depressionfree cancer cohort with incident cancer diagnosis between April 2007 and December 2011 was first established. This study used a validated algorithm to identify newly-diagnosed depression after cancer diagnosis by including only those who were diagnosed with depression after cancer diagnosis and who did not have any antidepressant use 90 days prior to depression diagnosis (16). This study used the following codes from the International Classifications of Diseases $-9^{\text {th }}$ edition, Clinical Modification (ICD-9-CM): 296.2, 296.3, 298.0, 300.4, 309.1 and 311.0. These codes are widely used to identify depression diagnoses in Medicare beneficiaries $(1,17,18)$.

\section{Inclusion/exclusion criteria}

This study required that all individuals have continuous enrollment in Medicare part A, B and no enrollment in Medicare managed care plans during the baseline and follow-up periods. 
This study also required that individuals have continuous enrollment in Medicare part D during three months prior to and 12 months after depression diagnosis in order to identify depression treatment in the follow-up period. This study excluded individuals with unknown cancer stage at diagnosis, those diagnosed through autopsy or death certificate, or those who died during the follow-up period. Appendix 1.1 summarizes the analytical population selection process. The final study population consisted of 1,502 elderly Medicare beneficiaries with newly-diagnosed depression and incident breast, colorectal or prostate cancer.

\subsubsection{Dependent Variables}

\section{Type and Total Healthcare Expenditures}

Healthcare expenditures were derived from the Medicare claims files and included the amount paid by Medicare. This study identified the type of healthcare expenditure based on whether the services were provided in an inpatient, outpatient, prescription drug or home healthcare setting. The following types of healthcare expenditures were analyzed; inpatient, outpatient, prescription drugs, and other. Other expenditures consisted of DME and HHA expenditures. Total healthcare expenditures were derived as the sum of inpatient, outpatient, prescription drugs, durable medical equipment and home health agency expenditures.

Total and type of healthcare expenditures were classified into yearly and monthly expenditures during the follow-up period. Yearly expenditures consisted of expenditures for the entire 12-month period after depression diagnosis. Monthly expenditures were calculated for every month after depression diagnosis. All healthcare expenditures were adjusted by the Consumer Price Index and expressed in 2012 constant dollars.

\subsubsection{Key Independent Variable}

The key independent variable was the depression treatment during the first six months after depression diagnosis. Antidepressant use was derived from Medicare Part D claims using 
the National Drug Codes (NDC) and generic names. Antidepressants included selective serotonin reuptake inhibitors (SSRIs), selective norepinephrine reuptake inhibitors (SNRIs), tricyclic antidepressants (TCAs), monoamine oxidase inhibitors (MAOIs) and others (mirtazapine, bupropion). Any cancer survivor with at least one prescription for antidepressants was considered to be using antidepressants. Psychotherapy visits were derived from Medicare outpatient claims using the Current Procedural Terminology (CPT) codes.

Based on antidepressant use and psychotherapy visits, depression treatment was categorized into four mutually exclusive categories: (1) treatment with antidepressants only: individuals received, at least, one prescription of antidepressants and no psychotherapy visits; (2) treatment with psychotherapy only: individuals had, at least, one psychotherapy office visit and no prescription for antidepressants; (3) both antidepressants and psychotherapy: individuals received, at least, one prescription for antidepressants with at least one psychotherapy visit; (4) no treatment: individuals received no antidepressants and no psychotherapy.

\subsubsection{Other Independent Variables}

\section{Time-Invariant Variables}

These variables were measured during the baseline period (i.e. 12 months before depression diagnosis). Predisposing characteristics included age in years at cancer diagnosis (66-69, 70-74, 75-79, >=80) and race (White, African American, and others). Enabling factors, included marital status (married, divorced/separated/widowed, and never married), cancer types (women with breast cancer, women with colorectal cancer, men with colorectal cancer, men with prostate cancer); and stage at cancer diagnosis, categorized using the American Joint Committee on Cancer (AJCC) grouped staging (stage 0/I, stage II, and stage III/ IV). Need factors composed of the number of chronic physical and mental health conditions during the baseline period. 
External environmental characteristics included SEER region (Northeast, South, North-central, and West) and the year of cancer diagnosis.

Time-varying independent variables

These were measured every month during the follow-up period (i.e. 12-months after depression diagnosis) and included PCPs visits and cancer treatment (chemotherapy, radiation therapy or surgery).

\subsection{Statistical Analysis}

Bivariate Analyses

T-tests and F-tests were used to examine the unadjusted differences in average healthcare expenditures by depression treatment categories. Mean, standard deviation and median were used to describe healthcare expenditures by depression treatment categories.

Analyses with repeated measures

As healthcare expenditures were measured for every month during the follow-up period, each individual had 12 observations. These 12 observations were not independent, so standard regression techniques can not be applied. Therefore, the associations between depression treatment and total healthcare expenditures were analyzed with a repeated measures design using Generalized Mixed Linear Model (GLMM) regressions with gamma distribution and log link. The GLMM model was selected because this study found that $65 \%$ of the variation in healthcare expenditures was due to differences within individuals. GLMM regressions account for correlated error terms due to repeated measures from the same person. In these regressions, predisposing, enabling and need factors affecting depression treatment as well as external environmental characteristics were included. Based on the regression co-efficient estimates, 
expenditures associated with depression treatment categories, as compared to no depression treatment, were calculated.

Observed Selection Bias: Adjusting for inverse probability weighting technique (IPTW)

The inverse probability weighting technique (IPTW) was used to adjust for observed group differences in depression treatment categories. The IPTW approach calculates weight for each individual based on the inverse of their propensity to receive a specific type of depression treatment or no treatment. Under this approach, individuals with lower propensity will be upweighted and those with higher propensity will be down-weighted. This helps balance the probability of treatment across the treatment groups. In order to account for the differences in group sizes of the treatment groups, the weights were further stabilized by dividing them with the sample size of each treatment group.

\subsection{Results}

\subsubsection{Characteristics of the study population}

The study population consisted of 1,502 elderly fee-for-service Medicare beneficiaries with incident breast, colorectal or prostate cancer who had newly-diagnosed depression after cancer diagnosis. In this study population, $45.0 \%$ were women with breast cancer, $22.8 \%$ were women with colorectal cancer, $10.1 \%$ were men with colorectal cancer and $22.1 \%$ were men with prostate cancer. Also, this study found that $47.4 \%$ received antidepressants only, $9.3 \%$ received psychotherapy only, $18.9 \%$ received both antidepressants and psychotherapy and $24.4 \%$ did not receive any depression treatment. The description of time-invariant and time-varying explanatory variables by depression treatment categories are presented in Tables 1 and 2 respectively. 


\subsubsection{IPTW-adjusted Yearly Healthcare Expenditures by Depression Treatment Categories}

Table 3 summarizes the average 1-year expenditures for depression treatment categories. The mean 1-year total healthcare expenditures after depression diagnosis were $\$ 38,219$ for those who did not receive depression treatment, $\$ 42,090$ for those treated with antidepressants only, $\$ 46,913$ for those treated with psychotherapy only and $\$ 51,008$ for those treated with a combination of antidepressants and psychotherapy. Average 1-year total healthcare expenditures were significantly higher for those treated with a combination of antidepressants and psychotherapy ( $\mathrm{p}$ value $<0.001$ ). Also, the average 1-year inpatient and prescription drugs healthcare expenditures after depression diagnosis were significantly higher for those treated with a combination of antidepressants and psychotherapy ( $\mathrm{p}$ value $<0.001$ ).

\subsubsection{IPTW-Adjusted Generalized Mixed Linear Models of Monthly Expenditures}

As compared to no depression treatment, depression treatment with antidepressants only was associated with a $\$ 1,317$ increase in total healthcare expenditures, treatment with psychotherapy only was associated with a $\$ 2,186$ increase while treatment with combination of antidepressants and psychotherapy was associated with $\$ 2,754$ increase. As compared to no therapy, this study found that treatment with antidepressants only, psychotherapy only, and the combination of antidepressants and psychotherapy were associated with high inpatient, outpatient and other healthcare expenditures as compared to no therapy (Table 4).

\subsubsection{Sensitivity Analyses}

To ensure robustness of the association between depression treatment categories and healthcare expenditures, sensitivity analyses were conducted. These included healthcare expenditures without repeated measures (i.e. measuring 1-year healthcare expenditures), mixed effect linear models with log-transformed healthcare expenditures (Tables 4 and 5), and instrumental variable regressions that controlled for unobserved selection bias. In the 
instrumental variable regression, the percentage of psychologists at the county-level was used as an instrument and depression treatment was considered as endogenous. Across all models and even after controlling for the unobserved selection bias, depression treatment was associated with higher expenditures as compared to no depression treatment. For example, depression treatment with psychotherapy only was associated with higher total healthcare expenditures as compared to no depression treatment in the GLMM model (Beta: 0.31; SE:0.07), the Mixed Linear model with log-transformed expenditures (Beta: 0.40; SE:0.10), the adjusted 1-year healthcare expenditures model (Beta: 0.31; SE:0.08) and in the instrumental variable regression model (Beta: 0.01; SE:0.01). Depression treatment with antidepressants only was associated with higher total healthcare expenditures as compared to no depression treatment in the GLMM model (Beta: 0.20; SE:0.04), the Mixed Linear model with log-transformed expenditures (Beta: 0.38; SE:0.06), the adjusted 1-year healthcare expenditures model (Beta: 0.13; SE:0.07) and in the instrumental variable regression model (Beta: 0.02; SE:0.01). Depression treatment with a combination of antidepressants and psychotherapy was associated with higher total healthcare expenditures as compared to no depression treatment in the GLMM model (Beta: 0.38; SE:0.05), the Mixed Linear model with log-transformed expenditures (Beta: 0.68; SE:0.07), the adjusted 1year healthcare expenditures model (Beta: 0.31; SE:0.08) and in the instrumental variable regression model (Beta: 0.12; SE:0.02).

\subsection{Discussion}

The current study examined the association between depression treatment categories and healthcare expenditures among elderly Medicare beneficiaries with newly-diagnosed depression and incident breast, colorectal or prostate cancer. To date, the current study is the first one to analyze the association between depression treatment categories and healthcare expenditures. 
The study findings suggest that depression treatment was associated with an increase in shortterm healthcare expenditures as compared to no depression treatment. Our results are consistent with the one published study on depression treatment and expenditures among elderly with chronic physical conditions, which found that depression treatment with antidepressants or psychotherapy was associated with increase in short-term healthcare expenditures (6). The positive association between depression treatment and healthcare expenditures was robust and persisted even after adjustment for other factors and across different model specifications.

The positive association between depression treatment categories and healthcare expenditures among cancer survivors has many plausible explanations. There is evidence of depression treatment failure in many individuals. For example, the STAR*D (Sequenced Treatment Alternatives to Relieve Depression) trial found that only one-third of patients get relief for their depressive symptoms with depression treatment (19). Therefore, there may be many cancer survivors who did not respond to depression treatment, which may have resulted in poor health outcomes and increased healthcare expenditures. However, this study did not measure if those who received depression treatment responded to their therapy or not. It is also known that adequate depression treatment is critical in improving health outcomes. A study among adults found that adherence to antidepressant medication treatment for at least 90 days reduced healthcare expenditures (20). However, our study did not measure the adequacy of depression treatment or adherence to depression treatment. Therefore, future studies need to explore the relationship between adherence to depression treatment and healthcare expenditures among cancer survivors. It is also plausible that under fee-for-service healthcare systems, many individuals with both physical and mental health conditions receive fragmented care and such fragmented care may result in increased expenditures regardless of treatment for depression. 
Our findings have significant policy implications. This study estimated the average healthcare expenditures over a 12-month period among elderly Medicare with newly-diagnosed depression and incident cancer. Therefore, these estimates can be considered as expenditures following a new episode of depression in elderly with incident cancer. Such estimates have an important implication for Accountable Care Organization's (ACO's) Medicare Shared Saving Programs for risk adjustment while also setting the expected expenditure benchmark for individuals with cancer and newly-diagnosed depression. Also, our study findings have implications for the Centers for Medicare and Medicaid Services's new bundled payment models as well as a new payment and delivery model, the Oncology Care Model (OCM), which aims to improve the quality of care and care coordination while lowering costs for patients receiving chemotherapy. Our findings can help these payment models in building the quality metrics that providers must achieve to maximize their payment.

Further, our study findings also have clinical practice implications. It has been shown that collaborative care rather than usual care for depression leads to a reduction in depressive symptoms and decreases expenditures (21). As compared to usual care, the SMaRT Oncology2 (Symptom Management Research Trial, Oncology-2) found that integrated collaborative treatment for depression among cancer patients was associated with higher remission rates as compared to usual care treatment for depression $(4,5)$. This trial also found that depression treatment delivered within a collaborative care model was cost-effective $(4,5)$. Our findings suggest that treating depression in the usual care setting may not be sufficient to achieve lower costs and collaborative care models may need to become standard clinical practice. In this context, it may be important to enroll Medicare beneficiaries with cancer and newly-diagnosed depression into patient-centered medical homes which have many elements of collaborative care 
including the use of evidence-based treatment of depression, collaboration between health care providers and monitoring depression treatment adherence $(22,23)$.

Our study has many strengths; it is the first that has examined the impact of depression treatment on total healthcare expenditures in real-world fee-for-service settings. The use of SEER-Medicare data allowed us to use a longitudinal study design and follow patients for a long period of time across different providers. Data from Medicare Part D enabled us to identify pharmacological therapy for depression and include expenditures related to prescription drugs. This study also tested the robustness of the relationship between depression treatment and healthcare expenditures using various model specifications. The current study has some limitations: the SEER-Medicare data are not developed for research purposes and therefore have limitations associated with its use for estimating total healthcare expenditures. This study only observed filled antidepressant prescriptions and not antidepressant use. The study findings cannot be generalizable to all Medicare beneficiaries because the study population is restricted to those residing in SEER regions and to those with fee-for-service Medicare plans. Another limitation related to the observational study was the selection bias, although the observable and unobservable selection bias were controlled using the inverse probability weighting technique and the instrumental variables approach these biases cannot be completely eliminated.

\subsection{Conclusions}

Our study has provided new evidence for the literature on the impact of depression treatment on healthcare expenditures among elderly fee-for-service Medicare beneficiaries with newly-diagnosed depression and incident cancer seeking care in real-world clinical practice settings. This study found that treatment for depression was associated with higher short-term healthcare expenditures as compared to no depression treatment. Our findings were robust to 
different model specifications, even after adjusting for observed and non-observed selection bias.

Future studies may need to examine whether factors such as adequacy of depression treatment and adherence to treatment among cancer survivors can lead to reduction in short-term healthcare expenditures. 


\subsection{References}

(1) Jayadevappa R, Malkowicz SB, Chhatre S, Johnson JC, Gallo JJ. The burden of depression in prostate cancer. Psycho- Oncology 2012;21(12):1338-1345.

(2) Pan X, Sambamoorthi U. Health care expenditures associated with depression in adults with cancer. J Community Support Oncol 2015 Jul;13(7):240-247.

(3) Unutzer J, Katon WJ, Fan MY, Schoenbaum MC, Lin EH, Della Penna RD, et al. Long-term cost effects of collaborative care for late-life depression. Am J Manag Care 2008 Feb;14(2):95100 .

(4) Sharpe M, Walker J, Holm Hansen C, Martin P, Symeonides S, Gourley C, et al. Integrated collaborative care for comorbid major depression in patients with cancer (SMaRT Oncology-2): a multicentre randomised controlled effectiveness trial. Lancet 2014 Sep 20;384(9948):10991108.

(5) Duarte A, Walker J, Walker S, Richardson G, Hansen CH, Martin P, et al. Cost-effectiveness of integrated collaborative care for comorbid major depression in patients with cancer. $\mathrm{J}$ Psychosom Res 2015;79(6):465-470.

(6) Shen C, Shah N, Findley PA, Sambamoorthi U. Depression treatment and short-term healthcare expenditures among elderly Medicare beneficiaries with chronic physical conditions. J Negat Results Biomed 2013 10/22;12:15-15.

(7) Jeffery DD, Linton A. The impact of depression as a cancer comorbidity: rates, health care utilization, and associated costs. Community Oncology 2012;9(7):216-221.

(8) Mudge AM, Kasper K, Clair A, Redfern H, Bell JJ, Barras MA, et al. Recurrent readmissions in medical patients: A prospective study. Journal of Hospital Medicine 2011;6(2):61-67.

(9) Allaudeen N, Vidyarthi A, Maselli J, Auerbach A. Redefining readmission risk factors for general medicine patients. Journal of Hospital Medicine 2011;6(2):54-60.

(10) Marcantonio ER, McKean S, Goldfinger M, Kleefield S, Yurkofsky M, Brennan TA.

Factors associated with unplanned hospital readmission among patients 65 years of age and older in a Medicare managed care plan. Am J Med 1999;107(1):13-17.

(11) Pfizer Facts. The Burden of Cancer in American Adults 2003; Available at:

http://www.pfizer.com/files/products/The Burden_of Cancer_in American_Adults.pdf.

(12) Centers for Medicare \& Medicaid Services. Bundled Payments for Care Improvement (BPCI) Initiative: General Information. Available at:

http://innovation.cms.gov/initiatives/bundled-payments/.

(13) Andersen RM. Revisiting the behavioral model and access to medical care: does it matter? J Health Soc Behav 1995:1-10.

(14) National Cancer Institute. Surveillance, Epidemiology and End Results (SEER) Registry Groupings for Analyses. 2015; Available at: http://seer.cancer.gov/registries/terms.html.

(15) National Committee for Quality Assurance. The Healthcare Effectiveness Data and Information Set (HEDIS). Technical Specifications. 2008; Available at:

http://www.ncqa.org/HEDISQualityMeasurement.aspx. Accessed 11/29, 2014.

(16) Chronic Conditions Data Warehouse. CCW Chronic Conditions Algorithms. 2016;

Available at: https://www.ccwdata.org/web/guest/condition-categories.

(17) Findley PA, Shen C, Sambamoorthi U. Depression Treatment Patterns among Elderly with Cancer. Depress Res Treat 2012;2012:676784.

(18) Zhang AY, Cooper GS. Recognition of Depression and Anxiety among Elderly Colorectal Cancer Patients. Nurs Res Pract 2010;2010:693961. 
(19) Warden D, Rush AJ, Trivedi MH, Fava M, Wisniewski SR. The STAR* D Project results: a comprehensive review of findings. Curr Psychiatry Rep 2007;9(6):449-459.

(20) Eaddy MT, Druss BG, Sarnes MW, Regan TS, Frankum LE. Relationship of total health care charges to selective serotonin reuptake inhibitor utilization patterns including the length of antidepressant therapy results from a managed care administrative claims database. Journal of Managed Care Pharmacy 2005;11(2):145-150.

(21) Sharpe M, Walker J, Holm Hansen C, Martin P, Symeonides S, Gourley C, et al. Integrated collaborative care for comorbid major depression in patients with cancer (SMaRT Oncology-2): a multicentre randomised controlled effectiveness trial. Lancet 2014 Sep 20;384(9948):10991108 .

(22) Jacobsen PB, Holland JC, Steensma DP. Caring for the whole patient: the science of psychosocial care. J Clin Oncol 2012 Apr 10;30(11):1151-1153.

(23) Sprandio JD. Oncology patient-centered medical home. J Oncol Pract 2012 May;8(3 Suppl):47s-9s. 
Table 4.1

Description of the Study Population by Depression Treatment Categories Elderly Fee-for-service Medicare beneficiaries with newly-diagnosed Depression and Incident Breast, colorectal, or Prostate Cancer SEER-Medicare Database, 2007-2012

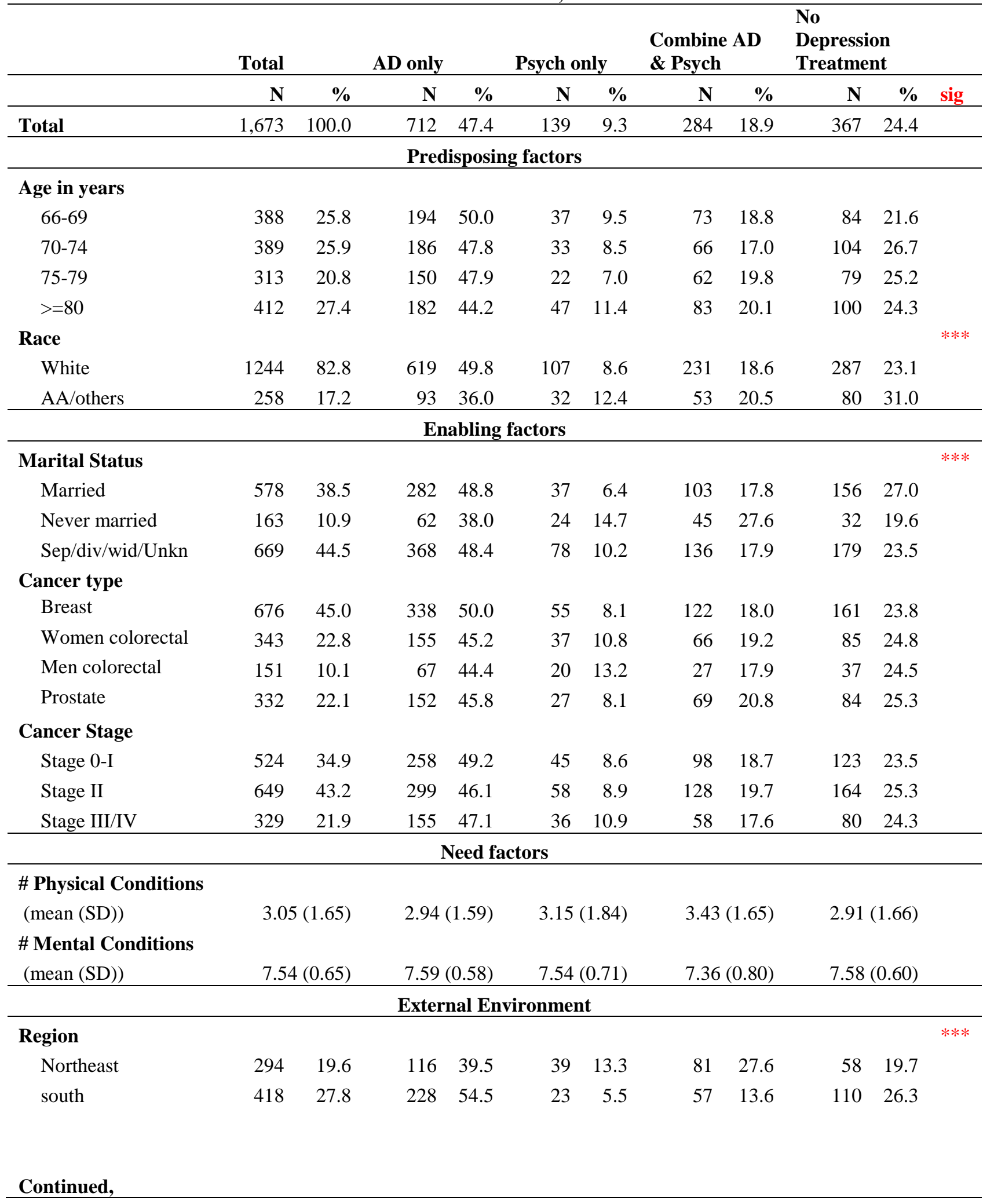


Table 4.1

Description of the Study Population by Depression Treatment Categories Elderly Fee-for-service Medicare beneficiaries with newly-diagnosed Depression and Incident Breast, colorectal, or Prostate Cancer SEER-Medicare Database, 2007-2012

\begin{tabular}{|c|c|c|c|c|c|c|c|c|c|c|c|}
\hline & Total & & AD only & & Psych o & & $\begin{array}{l}\text { Combine } \\
\text { \& Psych }\end{array}$ & AD & $\begin{array}{l}\text { No } \\
\text { Depressi } \\
\text { Treatme }\end{array}$ & & \\
\hline & $\mathbf{N}$ & $\%$ & $\mathbf{N}$ & $\%$ & $\mathbf{N}$ & $\%$ & $\mathbf{N}$ & $\%$ & $\mathbf{N}$ & $\%$ & sig \\
\hline North-central & 189 & 12.6 & 85 & 45.0 & 23 & 12.2 & 46 & 24.3 & 35 & 18.5 & \\
\hline West & 601 & 40.0 & 283 & 47.1 & 54 & 9.0 & 100 & 16.6 & 164 & 27.3 & \\
\hline \multicolumn{12}{|c|}{ Cancer diagnosis year } \\
\hline 2007-2009 & 913 & 60.8 & 445 & 48.7 & 87 & 9.5 & 167 & 18.3 & 214 & 23.4 & \\
\hline 2010-2012 & 589 & 39.2 & 267 & 45.3 & 52 & 8.8 & 117 & 19.9 & 153 & 26.0 & \\
\hline
\end{tabular}

Note: Based on 1,502 elderly fee-for-service Medicare beneficiaries with newly-diagnosed depression and incident breast, colorectal or prostate cancer who were continuously enrolled in Medicare Part A and B during the observation period and Part D during the follow-up period. Asterisks represent significant differences in study population characteristics by depression treatment categories, derived from chi-square statistics.

$* * * \mathrm{p}<.001 ; * * .001 \leq \mathrm{p}<.01 ; * .01 \leq \mathrm{p}<.05$.

Physical conditions included diabetes, heart disease, hyperlipidemia, hypertension, stroke, arthritis, osteoporosis, asthma and chronic obstructive pulmonary disorder. Mental conditions included Alzheimer and other related disorders, anxiety, and other mental disorders.

AA: African American; AD: Antidepressants; Psych: Psychotherapy; SEER: Surveillance Epidemiology and End Results; Sep/div/wid/unkn: Separated/Divorced/Widowed/unknown; SD: Standard deviation. 
Table 4.2

Description of Time Varying Independent Variables for the Study Population by Depression Treatment Categories Elderly Fee-for-service Medicare beneficiaries with Newly-diagnosed Depression and Incident Breast, colorectal, or Prostate Cancer SEER-Medicare Database, 2007-2012

\begin{tabular}{|c|c|c|c|c|c|c|c|c|c|c|c|}
\hline & \multicolumn{2}{|l|}{ Total } & \multicolumn{2}{|l|}{ AD only } & \multicolumn{2}{|c|}{ Psycho only } & \multicolumn{2}{|c|}{$\begin{array}{l}\text { Combine AD } \\
\text { \& Psych }\end{array}$} & \multicolumn{3}{|c|}{$\begin{array}{l}\text { No Depression } \\
\text { Treatment } \\
\end{array}$} \\
\hline & $\mathbf{N}$ & $\%$ & $\mathbf{N}$ & $\%$ & $\mathbf{N}$ & $\%$ & $\mathbf{N}$ & $\%$ & $\mathrm{~N}$ & $\%$ & sig \\
\hline Total & 18,024 & 100.0 & 6,476 & 35.9 & 677 & 3.8 & 660 & 3.7 & 10,211 & 56.7 & \\
\hline Chemotherapy & & & & & & & & & & & $* *$ \\
\hline Yes & 1,860 & 10.3 & 707 & 38 & 55 & 3.0 & 49 & 2.6 & 1,049 & 56.4 & \\
\hline No & 16,164 & 89.7 & 5,769 & 35.7 & 622 & 3.8 & 611 & 3.8 & 9,162 & 56.7 & \\
\hline \multicolumn{12}{|c|}{ Radiation Therapy } \\
\hline Yes & 947 & 5.3 & 357 & 37.7 & 28 & 3.0 & 32 & 3.4 & 530 & 56.0 & \\
\hline No & 17,077 & 94.7 & 6,119 & 35.8 & 649 & 3.8 & 628 & 3.7 & 9,681 & 56.7 & \\
\hline \multicolumn{12}{|l|}{ Surgery } \\
\hline Yes & 450 & 2.5 & 153 & 34.0 & 25 & 5.6 & 14 & 3.1 & 258 & 57.3 & \\
\hline No & 17,574 & 97.5 & 6,323 & 36.0 & 652 & 3.7 & 646 & 3.7 & 9,953 & 56.6 & \\
\hline $\begin{array}{l}\text { PCP visits } \\
(\text { mean }(\mathrm{SD}))\end{array}$ & $1.49(0.5$ & & $1.46(0.50$ & & $1.38(0.4 \mathrm{C}$ & & $1.36(0.48)$ & & $1.52(0.50)$ & & \\
\hline
\end{tabular}

Note: Based on 12 repeated measures for 1,502 elderly fee-for-service Medicare beneficiaries with newly-diagnosed depression and incident breast, colorectal or prostate cancer who were continuously enrolled in Medicare Part A and $\mathrm{B}$ during the observation period and Part D during the follow-up period. Asterisks represent significant differences in study population characteristics by depression treatment categories, derived from chi-square statistics.

$* * * \mathrm{p}<.001 ; * * .001 \leq \mathrm{p}<.01 ; * .01 \leq \mathrm{p}<.05$.

AD: Antidepressants; Psych: Psychotherapy; PCP: Primary Care Provider; SEER: Surveillance Epidemiology and End Results; SD: Standard deviation. 
Table 4.3

IPTW adjusted Mean Expenditures by Depression Treatment Categories Elderly Fee-for-service Medicare beneficiaries with Newly-diagnosed Depression and Incident Breast, colorectal, or Prostate Cancer

SEER-Medicare database, 2007-2012

\begin{tabular}{|c|c|c|c|c|c|}
\hline Mean \$ (SE) & sig & Mean \$ (SE) & Mean \$ (SE) & sig & Mean \$ (SE) \\
\hline AD only $(N=712)$ & & Psycho only $(\mathrm{N}=139)$ & $\begin{array}{l}\text { Combine AD \& } \\
\text { Psych }(\mathrm{N}=284)\end{array}$ & & $\begin{array}{l}\text { No Depression } \\
\text { Treatment }(\mathrm{N}=367)\end{array}$ \\
\hline \multicolumn{6}{|c|}{ Total Healthcare Expenditures } \\
\hline $42,090(2,805)$ & & $46,913(4,615)$ & $51,008(3,530)$ & $* * *$ & $38,217(2,227)$ \\
\hline \multicolumn{6}{|c|}{ Outpatient Expenditures } \\
\hline $16,812(1,062)$ & & $17,165(1,748)$ & $15,571(1,337)$ & & $14,815(844)$ \\
\hline \multicolumn{6}{|c|}{ Inpatient Expenditures } \\
\hline $18,039(2,160)$ & & $22,344(3,554)$ & $27,040(2,718)$ & **** & $18,012(1,716)$ \\
\hline \multicolumn{6}{|c|}{ Prescription Drugs Expenditures } \\
\hline 4,787 (299) & $* * *$ & $3,584(493)$ & $5,674(377)$ & $* * *$ & $3,340(238)$ \\
\hline \multicolumn{6}{|c|}{ Other Expenditures } \\
\hline $2,451(312)$ & & $3,821(513)$ & $2,724(392)$ & & $2,053(247)$ \\
\hline \multicolumn{6}{|c|}{ Among Users of Inpatient and Other Services } \\
\hline \multicolumn{6}{|c|}{ Inpatient Expenditures } \\
\hline AD only $(\mathrm{N}=399)$ & & Psycho only $(\mathrm{N}=76)$ & $\begin{array}{l}\text { Combine AD \& } \\
\text { Psych }(\mathrm{N}=189)\end{array}$ & & $\begin{array}{l}\text { No o Depression } \\
\text { Treatment }(N=202)\end{array}$ \\
\hline $31,692(3,299)$ & & $41,902(5,561)$ & $40,910(3,973)$ & $*$ & $31,789(2,623)$ \\
\hline \multicolumn{6}{|c|}{ Prescription Drugs Expenditures } \\
\hline AD only $(N=712)$ & & Psycho only $(\mathrm{N}=136)$ & $\begin{array}{l}\text { Combine AD \& } \\
\text { Psych }(\mathrm{N}=284)\end{array}$ & & $\begin{array}{l}\text { No Depression } \\
\text { Treatment }(\mathrm{N}=361)\end{array}$ \\
\hline $4,787(301)$ & $* * *$ & $3,660(498)$ & $5,674(379)$ & **** & $3,389(240)$ \\
\hline \multicolumn{6}{|c|}{ Other Expenditures } \\
\hline AD only $(N=441)$ & & Psycho only $(\mathrm{N}=94)$ & $\begin{array}{l}\text { Combine AD \& } \\
\text { Psych }(\mathrm{N}=167)\end{array}$ & & $\begin{array}{l}\text { No o Depression } \\
\text { Treatment (N 222) }\end{array}$ \\
\hline $3,978(456)$ & & $5,102(713)$ & $4,653(595)$ & * & $3,292(369)$ \\
\hline
\end{tabular}

Note: Based on 1,502 elderly fee-for-service Medicare beneficiaries with newly-diagnosed depression and incident breast, colorectal or prostate cancer who were continuously enrolled in Medicare Part A and B and Part D during the observation period.

Total healthcare expenditures were the sum of inpatient, outpatient, prescription drug, durable medical equipment, and home health agency expenditures. Other expenditures consisted of durable medical equipment and home health agency.

Asterisks indicate statistical significance the average healthcare expenditures by depression treatment categories based on T-tests.

$* * * \mathrm{p}<.001 ; * * .001 \leq \mathrm{p}<.01 ; * .01 \leq \mathrm{p}<.05$.

AD: Antidepressants; Psych: Psychotherapy; N: Number; SEER: Surveillance Epidemiology and End Results; SD: Standard deviation. 
Table 4.4

Parameter Estimates of Depression Treatment Categories From GLMM and Mixed Effects linear Model On Monthly Healthcare Expenditures, Elderly Fee-for-service Medicare Beneficiaries with Newlydiagnosed Depression and Incident Breast, Colorectal or Prostate Cancer

SEER-Medicare Database, 2007-2012

\begin{tabular}{|c|c|c|c|c|c|c|c|}
\hline \multicolumn{8}{|c|}{$\begin{array}{l}\text { Generalized Mixed Linear Model with gamma distribution and log-link } \\
\text { (Reference Group for Depression Treatment = No Depression Treatment) }\end{array}$} \\
\hline & $\begin{array}{l}\text { Intercept } \\
\text { (SE) }\end{array}$ & $\begin{array}{l}\text { AD only } \\
\text { (SE) }\end{array}$ & Change $^{\#}$ & $\begin{array}{l}\text { Psych } \\
\text { only (SE) }\end{array}$ & Change $^{\#}$ & $\begin{array}{c}\text { AD \& } \\
\text { Psych (SE) }\end{array}$ & Change $^{\#}$ \\
\hline \multirow{3}{*}{ Total } & $8.70^{* * *}$ & $0.20 * * *$ & & $0.31 * * *$ & & $0.38 * * *$ & \\
\hline & $(0.11)$ & $(0.04)$ & $\$ 1,137$ & $(0.07)$ & $\$ 2,186$ & $(0.05)$ & $\$ 2,754$ \\
\hline & $7.06 * * *$ & $0.13^{* *}$ & & $0.23 * * *$ & & $0.26 * * *$ & \\
\hline \multirow[t]{2}{*}{ Outpatient } & (0.09) & $(0.04)$ & $\$ 164$ & $(0.06)$ & $\$ 302$ & $(0.05)$ & $\$ 340$ \\
\hline & $9.13 * * *$ & $0.56^{* *}$ & & $0.88 * *$ & & $0.51 * *$ & \\
\hline \multirow[t]{2}{*}{ Inpatient } & $(0.38)$ & $(0.17)$ & $\$ 6,906$ & $(0.34)$ & $\$ 13,139$ & $(0.18)$ & $\$ 6,195$ \\
\hline & $5.34 * * *$ & $0.33 * *$ & & $0.12 *$ & & $0.53 * * *$ & \\
\hline \multirow[t]{2}{*}{ Prescription Drugs } & (0.08) & $(0.03)$ & $\$ 82$ & $(0.05)$ & $\$ 26$ & $(0.04)$ & $\$ 146$ \\
\hline & $5.63 * * *$ & $0.21 *$ & & $0.59 * *$ & & 0.21 & \\
\hline Other & $(0.27)$ & $(0.10)$ & $\$ 66$ & $(0.18)$ & $\$ 224$ & $(0.13)$ & $\$ 65$ \\
\hline \multicolumn{8}{|c|}{$\begin{array}{l}\text { Mixed Linear Model with Log-transformed Expenditures } \\
\text { (Reference Group for Depression Treatment = No Depression Treatment) }\end{array}$} \\
\hline \multicolumn{2}{|r|}{$\begin{array}{l}\text { Intercept } \\
\text { (SE) }\end{array}$} & $\begin{array}{l}\text { AD only } \\
\text { (SE) }\end{array}$ & $\begin{array}{c}\% \\
\text { Change }\end{array}$ & $\begin{array}{l}\text { Psych } \\
\text { only (SE) }\end{array}$ & $\begin{array}{c}\% \\
\text { Change }\end{array}$ & $\begin{array}{c}\text { AD \& } \\
\text { Psych (SE) }\end{array}$ & $\begin{array}{c}\% \\
\text { Change }\end{array}$ \\
\hline \multirow{3}{*}{ Total } & $6.91 * * *$ & $0.38 * * *$ & & $0.42 * * *$ & & $0.68 * * *$ & \\
\hline & $(0.15)$ & $(0.06)$ & $38 \%$ & $(0.10)$ & $42 \%$ & $(0.07)$ & $68 \%$ \\
\hline & $6.86 * * *$ & $0.18^{* *}$ & & $0.52 * * *$ & & $0.58 * * *$ & \\
\hline \multirow[t]{2}{*}{ Outpatient } & $(0.16)$ & $(0.07)$ & $18 \%$ & $(0.11)$ & $52 \%$ & $(0.09)$ & $58 \%$ \\
\hline & $1.82 * * *$ & 0.03 & & 0.08 & & $0.25^{* *}$ & \\
\hline \multirow[t]{2}{*}{ Inpatient } & $(0.18)$ & $(0.06)$ & $3 \%$ & $(0.10)$ & $8 \%$ & $(0.08)$ & $25 \%$ \\
\hline & $4.00 * * *$ & $0.77 * * *$ & & -0.16 & & $0.77 * * *$ & \\
\hline \multirow[t]{2}{*}{ Prescription Drugs } & (0.19) & $(0.09)$ & $77 \%$ & $(0.17)$ & $16 \%$ & $(0.11)$ & $77 \%$ \\
\hline & $0.48 *$ & 0.09 & & 0.25 & & 0.03 & \\
\hline Other & $(0.20)$ & $(0.09)$ & $9 \%$ & $(0.17)$ & $25 \%$ & $(0.12)$ & $3 \%$ \\
\hline
\end{tabular}

Note: Based on 1,502 elderly fee-for-service Medicare beneficiaries with newly-diagnosed depression and incident breast, colorectal or prostate cancer who were continuously enrolled in Medicare Part A, B, and D during the observation period. Other expenditures consisted of durable medical equipment and home health agency costs. Total healthcare expenditures consisted of inpatient, outpatient, prescription drug, durable medical equipment, and home health agency expenditures.

\# Change was calculated by first exponentiating the intercept term to calculate the expenditures for no depression treatment. Then, the sum of the intercept and the parameter estimate for depression treatment type were exponentiated to get the expenditures for depression treatment. The differences in these two estimates was reported as the change in healthcare expenditures associated with depression treatment.

$\%$ change in expenditures was calculated by exponentiating the parameter estimate and subtracting one $(\mathrm{e} \beta-1)$.

Models adjusted for time in months, depression treatment, age, race/ethnicity, marital status, PCP visits during each month of follow-up, cancer type, cancer treatment during each month of follow-up, cancer stage, and number of physical and mental conditions, SEER region, Year of cancer diagnosis. Asterisks indicate significant differences by depression categories as compared to no depression treatment based on GLMM regressions and Mixed linear model regressions on healthcare expenditures.

$* * * \mathrm{P}<.001 ; * * .001 \leq \mathrm{P}<.01 ; * .01 \leq \mathrm{P}<.05$. 
AD: Antidepressants; IPTW: Inverse Probability Treatment Weights; Psych: Psychotherapy; SE: Standard Error; SEER: Surveillance Epidemiology and End Results 
Table 4.5

Parameter Estimates of Depression Treatment Categories from Generalized Linear Models on One-year Healthcare Expenditures Elderly Fee-for-service Medicare beneficiaries with newly-diagnosed Depression and Incident Breast, colorectal, or Prostate Cancer

SEER-Medicare Database, 2007-2012

\begin{tabular}{|c|c|c|c|c|c|c|c|}
\hline \multicolumn{8}{|c|}{$\begin{array}{c}\text { IPTW Adjusted Generalized Linear Model with gamma distribution and Log link } \\
\text { (Reference Group for Depression Treatment = No Depression Treatment) }\end{array}$} \\
\hline & $\begin{array}{l}\text { Intercept } \\
\text { (SE) }\end{array}$ & $\begin{array}{l}\text { AD only } \\
\text { (SE) }\end{array}$ & $\begin{array}{l}\% \\
\text { Change }\end{array}$ & $\begin{array}{l}\text { Psych } \\
\text { only (SE) }\end{array}$ & $\begin{array}{l}\% \\
\text { Change }\end{array}$ & $\begin{array}{l}\text { AD \& } \\
\text { Psych (SE) }\end{array}$ & $\begin{array}{l}\% \\
\text { Change }\end{array}$ \\
\hline \multirow{3}{*}{ Total } & $9.70 * * *$ & 0.13 & & $0.25^{*}$ & & $0.31 * * *$ & \\
\hline & $(0.41)$ & $(0.07)$ & $\$ 2,265$ & $(0.13)$ & $\$ 4,635$ & $(0.08)$ & $\$ 5,930$ \\
\hline & $8.17 * * *$ & $0.14 *$ & & 0.22 & & $0.12^{* * * *}$ & \\
\hline \multirow[t]{2}{*}{ Outpatient } & $(0.41)$ & $(0.07)$ & $\$ 581$ & $(0.12)$ & $\$ 951$ & $(0.07)$ & $\$ 493$ \\
\hline & $8.95 * * *$ & 0.06 & & 0.33 & & $0.41 * *$ & \\
\hline \multirow[t]{2}{*}{ Inpatient } & $(0.68)$ & $(0.13)$ & $\$ 477$ & $(0.21)$ & $\$ 3,014$ & $(0.14)$ & $\$ 3,906$ \\
\hline & $7.48 * * *$ & $0.33 * * *$ & & 0.09 & & $0.54 * * *$ & \\
\hline \multirow[t]{2}{*}{ Prescription Drugs } & $(0.36)$ & $(0.08)$ & $\$ 693$ & $(0.13)$ & $\$ 167$ & $(0.09)$ & $\$ 1,269$ \\
\hline & $6.68 * * *$ & 0.21 & & $0.47 *$ & & 0.18 & \\
\hline Other & $(0.84)$ & $(0.13)$ & $\$ 188$ & $(0.21)$ & $\$ 478$ & $(0.17)$ & $\$ 157$ \\
\hline \multicolumn{8}{|c|}{$\begin{array}{l}\text { Unadjusted Generalized Linear Model with gamma distribution and Log link } \\
\text { (Reference Group for Depression Treatment = No Depression Treatment) }\end{array}$} \\
\hline & $\begin{array}{l}\text { Intercept } \\
\text { (SE) }\end{array}$ & $\begin{array}{l}\text { AD only } \\
\text { (SE) }\end{array}$ & $\begin{array}{l}\% \\
\text { Change }\end{array}$ & $\begin{array}{l}\text { Psych } \\
\text { only (SE) }\end{array}$ & $\begin{array}{l}\% \\
\text { Change }\end{array}$ & $\begin{array}{l}\text { AD \& } \\
\text { Psych (SE) }\end{array}$ & $\begin{array}{l}\% \\
\text { Change }\end{array}$ \\
\hline \multirow{3}{*}{ Total } & $9.32 * * *$ & $0.13^{*}$ & & $0.27^{*}$ & & $0.33 * * *$ & \\
\hline & $(0.34)$ & $(0.07)$ & $\$ 1,549$ & $(0.11)$ & $\$ 3,459$ & $(0.08)$ & $\$ 4,363$ \\
\hline & $8.10 * * *$ & 0.12 & & $0.20 *$ & & 0.10 & \\
\hline \multirow[t]{2}{*}{ Outpatient } & $(0.34)$ & $(0.06)$ & $\$ 420$ & $(0.10)$ & $\$ 729$ & $(0.07)$ & $\$ 346$ \\
\hline & $8.35 * * *$ & 0.06 & & 0.35 & & $0.44 * *$ & \\
\hline \multirow[t]{2}{*}{ Inpatient } & $(0.62)$ & $(0.13)$ & $\$ 262$ & $(0.21)$ & $\$ 1,773$ & $(0.14)$ & $\$ 2,338$ \\
\hline & $7.21 * * *$ & $0.33 * * *$ & & 0.22 & & $0.55 * * *$ & \\
\hline \multirow[t]{2}{*}{ Prescription Drugs } & $(0.34)$ & $(0.08)$ & $\$ 529$ & $(0.12)$ & $\$ 333$ & $(0.08)$ & $\$ 992$ \\
\hline & $6.19 * * *$ & 0.20 & & $0.48 *$ & & 0.20 & \\
\hline Other & $(0.79)$ & (0.13) & $\$ 108$ & (0.19) & $\$ 301$ & $(0.17)$ & $\$ 188$ \\
\hline
\end{tabular}

Note: Based on 1,502 elderly fee-for-service Medicare beneficiaries with newly-diagnosed depression and incident breast, colorectal or prostate cancer who were continuously enrolled in Medicare Part A, B, and D during the observation period. Other expenditures consisted of durable medical equipment and home health agency costs. Total healthcare expenditures consisted of inpatient, outpatient, prescription drug, durable medical equipment, and home health agency expenditures.

$\%$ change in expenditures was calculated by exponentiating the parameter estimate and subtracting one (e $\beta-1)$.

Models adjusted for depression treatment, age, race/ethnicity, marital status, PCP visits, cancer type, cancer treatment, cancer stage, and number of physical and mental conditions, SEER region, Year of cancer diagnosis. Asterisks indicate significant differences by depression categories as compared to no depression treatment based on GLM regressions on one-year healthcare expenditures.

$* * * \mathrm{P}<.001 ; * * .001 \leq \mathrm{P}<.01 ; * .01 \leq \mathrm{P}<.05$.

AD: Antidepressants; IPTW: Inverse Probability Treatment Weights; Psych: Psychotherapy; SE: Standard Error; SEER: Surveillance Epidemiology and End Results. 
Appendix 4.1 Study Cohort Development Flow Diagram for Study Population of Elderly Medicare Beneficiaries Diagnosed with Incident Breast, Colorectal or Prostate cancer and Newly-diagnosed Depression

- Cancer diagnosed identified using Siterwho 1- -10 codes Breast $\mathrm{N}=392,684$, Colorectal $\mathrm{N}=291,491$, Prostate $\mathrm{N}=461,994$

- $\quad$ Diagnosed with cancer from April 2007 to Dec 2011

Breast $\mathrm{N}=169,955$, Colorectal $\mathrm{N}=125,261$, Prostate $\mathrm{N}=205,505$

- $\quad$ Diagnosed with cancer from April 2007 to Dec 2010

- Primary cancer only in the patient's lifetime (Seq1 in "00")

- Not diagnosed with cancer at autopsy or death certificate

- Incident cases Breast $\mathrm{N}=129,206$, Colorectal $\mathrm{N}=89,272$, Prostate $\mathrm{N}=168,783$

- $\quad$ Elderly with cancer from April 2007 to Dec 2011

- With primary cancer (Seq1 in " 00 ")

- Not diagnosed with cancer at autopsy or death certificate

- Incident cases, $>=66$, alive

Breast $\mathrm{N}=73,496$, Colorectal $\mathrm{N}=45,571$, Prostate $\mathrm{N}=107,585$

- $\quad$ Diagnosed with cancer from April 2007 to Dec 2011

- With primary cancer (Seq1 in "00"), Not diagnosed with cancer at autopsy or death certificate, Incident cases, >=66, alive

- Have depression diagnosis

- Depression free at cancer diagnosis

- $\quad$ Developed newly-diagnosed depression from April 2007-Dec 2011 Breast $\mathrm{N}=1,662$, Colorectal $\mathrm{N}=1,351$, Prostate $\mathrm{N}=973$

Final Analytical Cohort

- $\quad$ Diagnosed with cancer from April 2007 to Dec 2011

- With primary cancer (Seq1 in “00"), Not diagnosed with cancer at autopsy or death certificate, Incident cases, >=66, alive, Newlydiagnosed depression.

- Fee-for-service continuous enrollment A and B $12 \mathrm{~m}$ before depression diagnosis and part D $12 \mathrm{~m}$ after depression diagnosis Breast $\mathrm{N}=676$, Colorectal $\mathrm{N}=494$, Prostate $\mathrm{N}=332$ $(\mathrm{N}=\mathbf{1 , 5 0 2})$

Reasons for exclusion:

- HMO enrollment and NO Continuous enroll in Part A \& B 12 months after depression diagnosis $(n=399, n=401, n=264)$

- No Continuous enroll in Part D 12 month after depression diagnosis $(n=210, n=441, n=366)$ 


\section{Chapter 5 \\ SUMMARY AND CONCLUSIONS}

\subsection{Study Summary and Discussion}

This study set out to investigate a new and emerging area of research in the management of multiple chronic conditions, specifically the presence and management of depression among elderly cancer survivors. While there is a substantial literature on the prevalence of depression and its negative impact on health outcomes in cancer, issues related to the incidence and treatment of newly-diagnosed depression have received much less attention. Only recently, interest has emerged in the ways that treatment of one condition (e.g., depression) influences outcomes and costs associated with another condition (e.g., cancer). To date, there have not been any studies on variations in the risk of newly-diagnosed depression among cancer types. Also, there are no studies on depression treatment and its impact on healthcare expenditures among cancer survivors. Our work will be a landmark study in this new generation of research. It will point clinicians to opportunities for improved cancer outcomes, and policy-makers to potential cost-saving strategies.

This dissertation focused on answering three related research questions: (1) what is the variation in the risk of newly-diagnosed depression by cancer types among elderly cancer survivors with incident breast, colorectal or prostate cancer, (2) what are the depression treatment rates and what factors affect treatment in cancer survivors and (3) what impact does this depression treatment have on healthcare expenditures among cancer survivors? Breast, colorectal and prostate cancers were selected as they are the most common types of cancer in which depression is highly prevalent. 
Although there is evidence that all cancer survivors are at risk for developing depression as compared to matched non-cancer cohorts, it is unknown if there are variations in the risk of depression between different cancer types. For example, it is possible that some cancer types have a higher risk of depression due to poor survival rates or the late stage at which that type of cancer is diagnosed. Identifying these variations can help to determine which cancer survivors might have a higher risk of depression, thus identifying who can benefit from routine depression screening and monitoring to help in early detection and treatment of depression. Therefore, the first aim of this study was to evaluate the relationship between cancer types and the risk of newly-diagnosed depression with the following comparisons: women with breast cancer were compared to women with colorectal cancer while men with prostate cancer were compared to men with colorectal cancer.

It was observed that elderly women with colorectal cancer had a higher risk of newlydiagnosed depression as compared to elderly women with breast cancer while elderly men with colorectal cancer had a higher risk of newly-diagnosed depression as compared to elderly men with prostate cancer. The highest rates of newly-diagnosed depression among colorectal cancer survivors, who are typically diagnosed at a later stage, suggest that cancer survival prognosis may affect the risk of developing depression. This study found that cancer survivors with a latestage diagnosis were more likely to be diagnosed with depression as compared to those with an early-stage diagnosis. This finding suggests that stage at cancer diagnosis can affect the risk of developing depression. Further, this study found that cancer survivors who had a higher number of primary care visits had a higher rate of newly-diagnosed depression as compared to those with fewer primary care visits. Therefore, primary care providers may play an important role in the recognition of depression among elderly cancer survivors. 
While diagnosing depression is the first step, treating depression with either antidepressants, psychotherapy or combined antidepressants and psychotherapy is the next critical step to reduce depressive symptoms and improve the clinical outcomes of cancer survivors. Even though clinical guidelines recommend depression treatment for cancer survivors regardless of cancer types or stage at cancer diagnosis $(1,2)$, elderly cancer survivors may be undertreated for depression because cancer is often considered the dominant condition and it "eclipses" the management of depression. While there is some research on depression treatment rates among cancer survivors with prevalent depression, there are no studies on the rates of depression treatment among cancer survivors with newly-diagnosed depression. Therefore, the second aim of this study was to estimate depression treatment rates among cancer survivors and to examine the factors that affect depression treatment among elderly with newly-diagnosed depression and incident breast, colorectal or prostate cancer.

This study found that nearly $27 \%$ of cancer survivors with newly-diagnosed depression did not receive any treatment for depression. The majority of the study population received antidepressants only to treat newly-diagnosed depression. This study also found that ongoing cancer treatment after depression diagnosis was associated with lower rates of depression treatment. This finding suggests that the competing demand to treat cancer affects the management of depression. Also, individuals with a higher number of primary care provider visits were more likely to receive psychotherapy or a combination of antidepressants and psychotherapy. This indicates the importance of primary care providers in the management of depression. Further, there is evidence that a higher county-level percentage of psychologists was associated with a higher use of psychotherapy and a higher use of combination of antidepressants and psychotherapy. In other words, this study found that the supply of mental 
healthcare providers is important in receiving depression treatment. Another finding was that there are racial disparities in depression treatment. African American and other racial minorities were less likely to receive antidepressant treatment. This suggests that there is a need to reduce racial disparities in depression treatment.

Depression treatment can improve clinical as well as economic outcomes for cancer survivors. However, the economic benefits of treating depression have not been evaluated previously in cancer survivors. Evidence from real-world clinical practice studies among elderly with chronic conditions have suggested that depression treatment for prevalent depression can increase short-term healthcare expenditures $(5,6)$. However, the economic benefits of depression treatment among cancer survivors with newly-diagnosed depression are yet to be established. Therefore, the third aim of this study was to investigate the relationship between depression treatment and short-term healthcare expenditures among elderly Medicare beneficiaries with newly-diagnosed depression and incident breast, colorectal or prostate cancer.

The findings indicated that depression treatment during the six months after depression diagnosis increased short-term healthcare expenditures. Even after adjustment for observed and unobserved selection bias, the positive association between depression treatment and short-term healthcare expenditures persisted. This finding was robust using different model specifications.

\subsection{Implications of the Findings}

\subsubsection{Clinical Implications}

The findings from the current dissertation suggests that oncologists and other healthcare providers need to provide routine screening for depression especially for individuals who are diagnosed with colorectal cancer and those diagnosed at an advanced stage at cancer diagnosis. Such screening for depression after cancer diagnosis is important to detect depression and treat it 
before it becomes severe. In addition, the study findings indicate that detection and treatment of depression can be enhanced by visiting primary care providers, suggesting that oncologists can play an important role by ensuring that cancer survivors continue visiting their primary care providers.

As competing demands to treat cancer may impede the management of depression, oncologists and other healthcare providers may need to recognize that ongoing cancer treatment should not delay the management of depression as early depression treatment can improve not only depression but also cancer clinical outcomes. However, our study findings suggest that receiving depression treatment alone may not be sufficient to improve the economic outcomes of cancer survivors in usual care setting. Therefore, integrated coordinated care for depression which provides treatment, assessment of response and monitoring adherence to depression treatment may be needed to improve depressive symptoms which in turn can improve the economic outcomes of cancer survivors.

\subsubsection{Policy Implications}

Recognition and treatment of depression are critical cancer care priorities. The findings from the current study highlights the need for practice and policy measures to increase the screening for depression in cancer survivors with high risk of newly-diagnosed depression. Such screening can help in early detection and early management of depression. There is a vital need to reduce racial disparities in receiving depression treatment. African-Americans simply do not have the same receive antidepressants relative to white Americans, whether due to access to care, cultural or economic factors. Further, the management of depression depends very much on the availability of psychologists to provide psychotherapy treatment and insufficient supply of psychologists can impede the provision of evidence based depression treatment. Therefore, there 
is a need for policy measures to reduce racial disparities and improve the supply of mental healthcare providers.

The current study suggests that depression treatment is associated with an increase in healthcare expenditures. Such findings have implications for the Accountable Health Organization (ACOs) Medicare Shared Saving Program expenditures benchmarking and the new payment models' "bundled payment" (3). Under the ACOs, healthcare expenditure estimates can be used for risk adjustment while setting the expected expenditures benchmark for individuals with cancer and depression who received depression treatment. In addition, it can help the new payment models in setting the quality metrics that providers must achieve to maximize their payment or for setting the prospective payment for the episode of care provided for cancer patients who received depression treatment.

\subsection{Unique Contributions of the Study}

This is the first study that has investigated the variations in the risk of newly-diagnosed depression among elderly with incident breast, colorectal or prostate cancer and identified cancer types with high risk of newly-diagnosed depression. This study's findings are therefore significant since the risk of depression in cancer survivors has, until now, always been compared to matched non-cancer cohorts. This study fills this gap. Furthermore, the current study focused on depression treatment received after depression diagnosis. Although previous studies have estimated depression treatment rates among cancer survivors, all of them have examined prevalent depression treatment, which can be before or after depression diagnosis $(4,5)$. This study identified many barriers to receive depression treatment which have not been considered in the previous studies such as cancer treatment and availability of mental healthcare providers. 
Moreover, this dissertation provides a knowledge base on the association between depression treatment on short-term healthcare expenditures among cancer survivors. Previous studies among cancer survivors focused mainly on how depression increases healthcare expenditures, but none of the previous studies investigated whether depression treatment itself can lead to cost savings or not.

\subsection{Strengths}

The current study has many strengths related to the data sources used and the study design. This study used the most recent available SEER-Medicare data for years 2007 to 2012. This data enabled us to use a cohort study design and follow a large number of individuals to identify newly-diagnosed depression after cancer diagnosis. Also, the availability of a prescription drugs in the SEER-Medicare database enabled us to identify depression treatment after depression diagnoses in a real world setting. Further, this study controlled for many variables that affect the risk of depression and the treatment of depression, such as cancer stage and cancer treatment. Finally, to control for observable and non-observable selection bias this study used the inverse probability weighting technique (IPTW) and the instrumental variable approach.

\subsection{Limitations}

Depression diagnosis may be under-coded in claims data, so this study may have underestimated the risk of depression. Additionally, the antidepressants were identified from claims, so it is not certain if they were actually used. This study cannot exclude misclassification bias; individuals who may have received depression treatment in inpatient and emergency department settings and had no claims, were considered as receiving no depression treatment. This study cannot eliminate observable and non-observable selection biases, although the inverse 
probability weighting technique and the instrumental variable technique were used to control for these biases. Further, claims data do not provide information about the severity of depression, pain and fatigue, body mass index, attitude, or preferences, which can affect the risk of depression and its treatment. The study findings are not generalizable as the study population is restricted to those residing in SEER regions, to those with fee-for-service Medicare plans, and to those with breast, colorectal and prostate cancer.

Despite these limitations, this study provides a knowledge base on the risk of newly diagnosed depression after cancer diagnosis, on depression treatment rates and factors affecting depression treatment and on the impact of depression treatment on economic outcomes among elderly Medicare beneficiaries with incident breast, colorectal or prostate cancer.

\subsection{Suggestions for Future Research}

This study identified some unanswered questions that need further investigation in future research. As the focus of this study was on the most common types of cancer, future studies may need to investigate the risk of newly-diagnosed depression and depression treatment rates among elderly with other types of cancer. As the current study found that one-quarter of the individuals with depression did not receive any depression treatment, there is a need to explore the reasons why so many patients are not receiving therapy and to investigate if these individuals are receiving alternative therapy. In addition, as the findings of this study unexpectedly indicated that depression treatment increased short-term healthcare expenditures, there is a need to investigate whether or not adherence or adequacy of depression treatment can lead to cost savings. Future studies may need to explore the relationship between depression treatment and healthcare expenditures among Medicare providers who have been designated as PCMH 
providers because PCMH has all the features of a collaborative care model for depression treatment. 


\section{References}

(1) Howell D, Keller-Olaman S, Oliver T, Hack T, Broadfield L, Biggs K, et al. A pan-Canadian practice guideline: screening, assessment and care of psychosocial distress (depression, anxiety) in adults with cancer. Toronto: Canadian Partnership Against Cancer (Cancer Journey Action Group) and the Canadian Association of Psychosocial Oncology 2010. (2) Andersen BL, DeRubeis RJ, Berman BS, Gruman J, Champion VL, Massie MJ, et al. Screening, assessment, and care of anxiety and depressive symptoms in adults with cancer: an American Society of Clinical Oncology guideline adaptation. J Clin Oncol 2014 May 20;32(15):1605-1619.

(3) Centers for Medicare \& Medicaid Services. Bundled Payments for Care Improvement (BPCI) Initiative: General Information. Available at: http://innovation.cms.gov/initiatives/bundledpayments/.

(4) Findley PA, Shen C, Sambamoorthi U. Depression Treatment Patterns among Elderly with Cancer. Depress Res Treat 2012;2012:676784.

(5) Rane PB, Sambamoorthi U, Madhavan S. Depression treatment in individuals with cancer: a comparative analysis with cardio-metabolic conditions. Health Psychology Research 2013;1(1):e2. 


\begin{tabular}{|c|c|c|c|c|}
\hline \multicolumn{5}{|c|}{ Appendix A. Codes Related to Cancer Diagnosis and Treatment } \\
\hline \multicolumn{2}{|c|}{ Cancer Diagnosis and Treatment } & \multirow[b]{2}{*}{$\begin{array}{l}\text { ICD-9-CM } \\
\text { Procedure Codes }\end{array}$} & \multirow[b]{2}{*}{ HCPCS/CPT Codes } & \multirow[b]{2}{*}{$\begin{array}{l}\text { Revenue } \\
\text { Center } \\
\text { Codes }\end{array}$} \\
\hline & $\begin{array}{l}\text { ICD-9-CM Codes } \\
\text { Siter-WHO recodes }\end{array}$ & & & \\
\hline Breast Cancer & 26000 & & & \\
\hline Colorectal Cancer & $\begin{array}{l}21041,21042,21043, \\
21044,21045,21046, \\
21047,21048,21049, \\
21051,21052\end{array}$ & & & \\
\hline Prostate Cancer & 28010 & & & \\
\hline \multicolumn{5}{|c|}{ Cancer Treatment - Surgery } \\
\hline Breast Cancer & & $\begin{array}{l}8520-8529,8533- \\
8536,8540-8548\end{array}$ & $\begin{array}{l}\text { 19120, 19125, 9126, } \\
\text { 19300-19307, }\end{array}$ & \\
\hline Colorectal Cancer & & $\begin{array}{l}4530-4534,4541- \\
4543,4549,4550- \\
4552,4561-4563, \\
4570-4576,4579, \\
4580-4583,4590- \\
4595,4601,4603, \\
4604,4610,4611, \\
4613,4614,4620- \\
4623,4835,4840- \\
4843,4849-4852, \\
4859-4865,4869\end{array}$ & $\begin{array}{l}44140,44141,4143- \\
44147,4150,44160, \\
44204-44208,4150- \\
44153,44155,4158, \\
44210-44212,5160, \\
45170,45171,5110- \\
45114,45116,5119- \\
45121,45123,5126, \\
45395,45397\end{array}$ & \\
\hline Prostate Cancer & & $602-606$ & $\begin{array}{l}55801,55810,5812, \\
55815,5821,55831, \\
55840,55842,5845, \\
55866\end{array}$ & \\
\hline \multicolumn{5}{|c|}{ Cancer Treatment - Chemotherapy } \\
\hline & V581, V662, V672 & 9925,9928 & $\begin{array}{l}\text { 96401- 96549, Q0083- } \\
\text { Q0085, J9000-J9999, } \\
\text { S9329-S9331, J8501- } \\
\text { 8999, J0640 }\end{array}$ & $\begin{array}{l}0331,0332, \\
0335\end{array}$ \\
\hline \multicolumn{5}{|c|}{ Cancer Treatment - Radiation Therapy } \\
\hline & V580, V661, V671 & $9220-9239$ & $\begin{array}{l}\text { 77261-77799, C1715- } \\
\text { C1720, C2634-C2699, } \\
\text { C1728 }\end{array}$ & 0330,0333 \\
\hline
\end{tabular}

